\title{
VIGILÂNCIA EPIDEMIOLÓGICA DE ENDOFTALMITE E SÍNDROME TÓXICA DO SEGMENTO ANTERIOR APÓS CIRURGIAS DE CATARATA: IDENTIFICAÇÃO E SELEÇÃO DE MARCADORES
}

\author{
Dissertação apresentada ao \\ Programa de Pós-Graduação em \\ Enfermagem da Escola de \\ Enfermagem da Universidade de \\ São Paulo para obtenção do título de \\ Mestre em Ciências
}

Área de Concentração: Cuidado em Saúde

Orientadora: Prof. ${ }^{a}$ Dr. ${ }^{a}$ Maria Clara

Padoveze

"Versão corrigida"

A versão original encontra-se na Biblioteca "Wanda de Aguiar Horta"

SÃO PAULO

2013 
AUTORIZO A REPRODUÇÃO E DIVULGAÇÃO TOTAL OU PARCIAL DESTE TRABALHO, POR QUALQUER MEIO CONVENCIONAL OU ELETRÔNICO, PARA FINS DE ESTUDO E PESQUISA, DESDE QUE CITADA A FONTE.

Assinatura:

Data:

Catalogação na Publicação (CIP)

Biblioteca "Wanda de Aguiar Horta"

Escola de Enfermagem da Universidade de São Paulo

Luz, Reginaldo Adalberto

Vigilância epidemiológica de endoftalmite e Síndrome Tóxica do Segmento Anterior após cirurgias de catarata: identificação e seleção de marcadores / Reginaldo Adalberto de Luz. -- São Paulo, 2013.

$105 \mathrm{p}$.

Dissertação (Mestrado) - Escola de Enfermagem da Universidade de São Paulo.

Orientadora: Profa ${ }^{\mathrm{a}}$. Dra. Maria Clara Padoveze

1. Vigilância epidemiológica 2. Catarata 3. Infecção Hospitalar 3. Endoftalmite I. Título 
Título: Vigilância epidemiológica de endoftalmite e Síndrome Tóxica do Segmento Anterior após cirurgias de catarata: identificação e seleção de marcadores.

Dissertação apresentada ao Programa de Pós-Graduação em Enfermagem da Escola de Enfermagem da Universidade de São Paulo para obtenção do título de Mestre em Ciências.

Aprovado em:

\section{BANCA EXAMINADORA}

Prof. Dr. (a) Instituição:

Julgamento: Assinatura:

Prof. Dr. (a) Instituição:

Julgamento: Assinatura:

Prof. Dr. (a) Instituição:

Julgamento: Assinatura: 
À minha linda e amada esposa Laís, que tanto se privou de muitos momentos de lazer para que eu pudesse estudar. Pela sua compreensão, amor e carinho.

À minha Mãe, exemplo de humildade, perseverança e paciência.

Deu-me estes exemplos e muitos outros sábios ensinamentos.

Aos meus irmãos, Israel, Vanice e Vanilsa que sempre vibraram junto comigo a cada conquista e realização. Meus vínculos vitalícios que sempre poderei contar nas horas difíceis.

Ao meu primo Reginaldo, grande e verdadeiro amigo que sempre comemorou comigo cada conquista nesta minha longa jornada.

À minha querida Tia Leontina, que quando eu ainda era um pobre menino do interior, sem perspectiva alguma de um futuro promissor, acreditou em mim e me colocou no caminho rumo à profissão que escolhi.

Ao Dr. Tadeu Cvintal, um profissional extraordinário, um cientista, um grande professor. Formou grandes médicos oftalmologistas e me deu todas as condições necessárias e ensinamentos para me tornar um enfermeiro especializado em oftalmologia. 


\title{
AGRADECIMENTOS
}

À Deus, por ter me feito como sou. Pela graça de ter a família que tenho, por sempre ter colocado pessoas boas em meu caminho, pela saúde e pela vontade inesgotável de ser um vencedor.

À minha querida orientadora Prof. ${ }^{a}$ Dr. ${ }^{\text {a }}$ Maria Clara Padoveze, por ter acreditado em mim desde o começo e me transformado em um pesquisador em tão pouco tempo. Por ter sido um divisor de águas na minha vida acadêmica.

Às professoras Suely Itsuko Ciosak e Renata Ferreira Takahashi por suas ricas contribuições no Exame de Qualificação

\begin{abstract}
À Prof. ${ }^{a}$ Dr. ․ Kazuko Uchikawa Graziano, que provocou o desejo em mim de fazer o mestrado com uma simples pergunta, digna de um educador, "por que não o mestrado?". Talvez não saiba, mas foi onde tudo começou. Acolheu-me em seu grupo de pesquisa e me apresentou à minha atual orientadora.
\end{abstract}

Ao Instituto de Oftalmologia Tadeu Cvintal, especialmente à Sra.

Maria Aparecida B. Cvintal, que me deu todo apoio e incentivo para a conclusão do curso de mestrado. Esta empresa foi essencial para o meu objeto de pesquisa e me possibilitou todo aprendizado que tenho na área de oftalmologia.

Aos colegas do grupo de pesquisa: Débora Melo, Christian Pelaes, Cassimiro Nogueira e Adriana Félix pela grande ajuda companheirismo e colaboração nesta reta final. 
Lança o teu pão sobre as águas, porque depois de muitos dias 0 acharás. (Eclesiastes 11:1) 
Luz RA. Vigilância epidemiológica de endoftalmite e Síndrome Tóxica do Segmento Anterior após cirurgias de catarata: identificação e seleção de marcadores. [dissertação]. São Paulo: Escola de Enfermagem, Universidade de São Paulo; 2013.

\section{RESUMO}

Introdução: Entre os possíveis Eventos Adversos (EA) mais importantes após cirurgias de catarata estão a endoftalmite, termo que define a infecção intraocular e a Síndrome Tóxica do Segmento Anterior (TASS), que consiste na reação inflamatória aguda póscirúrgica. Contudo, um sistema de vigilância epidemiológica (VE) da ocorrência destes EA não é uma realidade no Brasil, o que dificulta o monitoramento da incidência, detecção precoce de surtos e as medidas de prevenção. Devido as especificidades no campo da oftalmologia, nem sempre o enfermeiro está suficientemente instrumentalizado para contribuir na detecção e monitoramento de casos. A identificação de marcadores destes EA factíveis de serem acompanhados por este profissional irá favorecer o desenvolvimento de um sistema de VE. Objetivo: Identificar os marcadores mais adequados para o diagnóstico epidemiológico de EA após cirurgias de catarata visando à instituição de um sistema de VE específico. Métodos: Trata-se de um estudo longitudinal de série de casos de pacientes submetidos a cirurgias de catarata, realizado em duas etapas. Etapa I: abordagem retrospectiva por meio de revisão de prontuários dos pacientes com diagnóstico de EA (21 casos) no período de abril/2010 a fevereiro/2013. Etapa II: abordagem prospectiva por meio de revisão de prontuários dos pacientes submetidos à cirurgia de catarata sem EA (309 controles) nos meses de maio e junho/ 2013. A amostra baseou-se em um teste de proporções entre duas amostras assumindo que a amostra de controles seria 15 vezes maior que a de casos para detectar uma diferença de pelo menos 35 pontos percentuais na incidência da apresentação de características clínicas entre os dois grupos com 
erro tipo I de $5 \%$ e poder do teste de $90 \%$. As variáveis pesquisadas foram os sinais e sintomas característicos do pós-operatório de cirurgias de catarata bem como informações demográficas e clínicas destes pacientes. Foi realizada estatística descritiva por meio de frequências relativas e absolutas. Resultados: Pacientes com EA apresentaram 0 diagnóstico de endoftalmite e TASS, respectivamente, em $19(90,5 \%)$ e dois casos (9,5\%). Dentre os casos, os sinais mais observados foram: córnea nebulosa, reação de câmara anterior (RCA), edema de córnea (>70\%) e hipópio, hiperemia conjuntival, turvação vítrea e dobras na membrana Descemet ( $>40 \%)$. Dor ocular foi o sintoma relatado por $14(66,7 \%)$ dos pacientes. Dentre os controles, no primeiro dia após a cirurgia os sinais mais apresentados ( $>50 \%$ ) foram: RCA, edema de córnea, hiperemia conjuntival e dobras na Descemet. Córnea nebulosa e edema palpebral em mais que $30 \%$ dos pacientes. Os sinais e sintomas que apresentaram diferença maior que $35 \%$ entre os casos e controles foram: presença de hipópio, vítreo turvo, córnea nebulosa. RCA, hiperemia conjuntival, edema de córnea e dor ocular. A incidência de aplicação de antibiótico intra-vítreo e número de retornos foram maiores entre os casos do que nos controles. Uma ferramenta para auxiliar no sistema de VE foi sugerida a partir dos resultados obtidos no presente estudo. Conclusões: Os marcadores clínicos e epidemiológicos considerados mais adequados para compor uma ferramenta para VE foram: dor, edema de córnea, hiperemia conjuntival, hipópio, RCA, vítreo turvo, aplicação de antibiótico intra-vítreo e número de retornos. A ferramenta proposta por este estudo tem potencialidade para subsidiar a atuação do enfermeiro no sistema de VE de EA para cirurgias de catarata.

PALAVRAS-CHAVE: Vigilância Epidemiológica. Infecção Hospitalar. Endoftalmite. Síndrome tóxica do Segmento Anterior. 
Luz RA. Epidemiological surveillance of endophthalmitis and Toxic Anterior Segment Syndrome after cataract surgery: identification and selection of markers. [dissertation]. São Paulo (SP), Brasil: Escola de Enfermagem, Universidade de São Paulo; 2013.

\section{ABSTRACT}

Introduction: Amongst the most important possible Adverse Events (AE) after cataract surgeries, are the endophthalmitis, a term which defines the intraocular infection and the Toxic Anterior Segment Syndrome (TASS), which is the acute inflammatory post-surgical reaction. However, an epidemiological surveillance (ES) system of these $A E$ isn't a reality in Brazil, which makes difficult the incidence monitoring and early detection of outbreaks and preventive measures. Due to specifics in ophthalmology, nurses are not always enable to detect and monitoring the cases. The identification of markers of these $\mathrm{AE}$ achievable to be monitored by nurses will facilitate the development of an epidemiological ES system. Objective: Identifying most suitable markers for epidemiological diagnosis of $A E$ after cataract surgeries aiming at the establishment of a specific ES system. Methods: This is a longitudinal case series study of patients who underwent cataract surgery performed in two phases. Phase I: a retrospective approach through reviews of medical records of patients that were diagnosed with $A E$ (21 cases) from April/2010 to February/2013. Phase II: prospective approach through reviews medical records of patients without AE (309 controls) in the months of May and June of 2013. The sample size was based on a test of proportion between 2 samples assuming that control sample would be 15 times greater than of the cases to detect a difference of at least 35 percentage points in the incidence of clinical characteristics between the two groups, with type I error of $5 \%$ and power of testing of $90 \%$. The variables studied were signs 
and symptoms of the post-operative presentation of cataract surgeries as well as demographic information and clinics of these patients. A descriptive statistics was carried out by using relative and absolute frequencies. Results: Patients with EA were diagnosed with endophthalmitis and TASS, respectively, in $19(90,5 \%)$ and two cases $(9,5 \%)$. Among cases, the signs most frequently observed were: corneal nebulosity, anterior chamber reaction (ACR), corneal edema $(>70 \%)$, and hypopyon, conjunctival hyperemia, vitreous haze e Descemet's membrane folds (DMF) $(>40 \%)$. Ocular pain was reported by $14(66,7 \%)$ of patients. Amongst controls, on the first day after surgery the most frequent signals $(>50 \%)$ were: ACR, corneal edema, conjunctival hyperemia and DMF. Corneal nebulosity and eyelid edema in more than $(30,0 \%)$ patients. The signs that showed a difference greater than $35 \%$ between the cases and controls were: hypopyon, vitreous haze, corneal nebulosity, ACR, conjunctival hyperemia, corneal edema, and eye pain. The incidence of intravitreal antibiotic injection and the number of medical consultation returns were bigger amongst the cases than in the controls. A tool to assist in the ES system was suggested from the results obtained in the present study. Conclusions: The clinical and epidemiological markers considered the most adequate to form a tool for ES is: ocular pain, corneal edema, conjunctival hyperemia, hypopyon, ACR, vitreous haze, intravitreal antibiotic injection and the number of returns. The tool suggested by this study has the potential to support the nurses' roles related to ES system for monitoring EA in cataract surgeries.

KEYWORDS: Epidemiological Surveillance. Nosocomial infection. Endophthalmitis. Toxic Anterior Segment Syndrome 


\section{LISTA DE QUANDROS}

Quadro 1 - Número de casos de endoftalmite segundo agente etiológico e país de publicação. São Paulo, 2013 ......30

Quadro 2 - Incidência de endoftalmite após cirurgia da catarata segundo países onde foram realizados os estudos, ano de publicação, população estudada e número de casos. São Paulo, 2013 32

Quadro 3 - Causas prováveis ou comprovadas dos surtos de endoftalmite de acordo com o país, ano de publicação e número de casos. São Paulo, 2013 34

Quadro 4 - Número de casos relacionados a surtos de endoftalmite, de acordo com agentes etiológicos identificados e os locais onde foram realizados os estudos. São Paulo, 2013 35

Quadro 5 - Incidência de TASS segundo os países, ano de publicação, número de cirurgias realizadas e número de casos. São Paulo, 2013 ......................................36

Quadro 6 - Causas atribuídas a TASS, segundo local, ano do estudo, número de casos e causa atribuída. São Paulo, 2013 41

Quadro 7 - Distribuição dos casos de eventos adversos de acordo com sexo, idade, dias para o diagnóstico, acuidade visual (AV) ao diagnóstico, $1^{\circ}$ Reintervenção, $2^{\circ}$ Reintervenção, no de retornos e acuidade visual final (AVF). São Paulo, 2013 65

Quadro 8 - Distribuição dos casos segundo o EA e sinais e sintomas observados ao exame ou relatados pelo paciente no pós-operatório dos pacientes submetidos à cirurgia de catarata de acordo com o tipo de evento adverso no dia do diagnóstico. São Paulo, 2013 66 


\section{LISTA DE ILUSTRAÇÕES}

Figura 1- llustração da anatomia do globo ocular humano 19

Figura 2 - llustração do processo de retirada da catarata pela técnica de facoemulsificação. 21

Figura 3 - Ilustração da lente intraocular colocada após a remoção da catarata 22

Figura 4- llustração da córnea e suas camadas .23

Figura 5 - Fotografia de um olho após cirurgia de catarata apresentando dobras na membrana Descemet

Figura 6 - Fotografia de um olho após cirurgia de catarata com presença de fibrina na câmara anterior

Figura 7 - Fotografia do olho após cirurgia de catarata com presença de hifema .25

Figura 8 - Fotografia do olho após cirurgia de catarata com presença de hipópio

Figura 9 - Fotografia do olho após cirurgia de catarata com presença de trave vítrea 28

Figura 10 - Fotografia do olho com diagnóstico de endoftalmite apresentado hipópio, fibrina e edema de córnea 29 


\section{LISTA DE SIGLAS}

ASA Associação Americana dos Anestesiologistas

ASCRS American Society of Cataract and Refractive Surgery

AV Acuidade Visual

AVF Acuidade Visual Final

BAV Baixa Acuidade Visual

BSS Balanced Salt Solution

CA Câmara Anterior

$\mathrm{CCIH}$ Comissões de Controle de Infecção Hospitalar

CD Conta Dedos

CDC Centers for Disease Control

COTC Centro de Oftalmologia Tadeu Cvintal

EA Eventos Adversos

EEC Extração Extra-capsular

ESCRS European Society of Cataract \& Refractive Surgeons

EtO Óxido de Etileno

EUA Estados Unidos da América

FDA Food and Drug Administration

HA Humor Aquoso

IRAS Infecções Relacionadas à Assistência à Saúde

ISC Infecção de Sítio Cirúrgico

LIO Lente Intraocular

MDHHS Maine Department of Health and Human Services

PC Precipitados Ceráticos

RCA Reação de Câmara Anterior

SUS Sistema Único de Saúde

SVE Solução Viscoelástica

TASS Toxic Anterior Segment Syndrome

VE Vigilância Epidemiológica 


\section{SUMÁRIO}

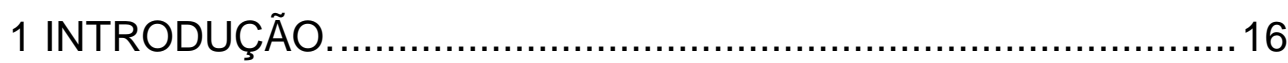

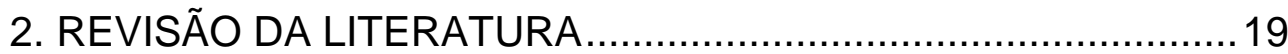

2.1 CATARATA E SEU TRATAMENTO …...................................19

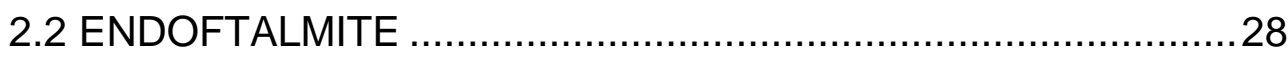

2.3 SÍNDROME TÓXICA DO SEGMENTO ANTERIOR ...................36

3 REFERENCIAL TEÓRICO....................................................... 48

3.1 VIGILÂNCIA EPIDEMIOLÓGICA COMO FERRAMENTA PARA

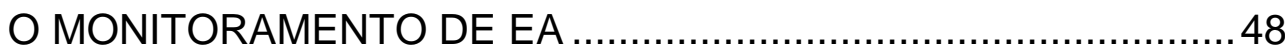

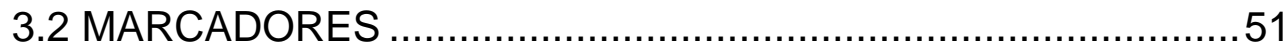

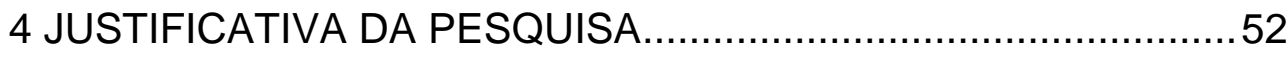

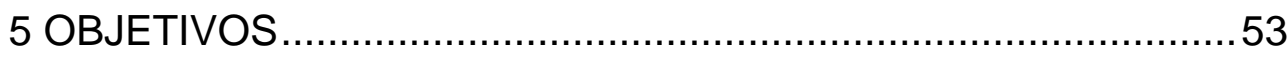

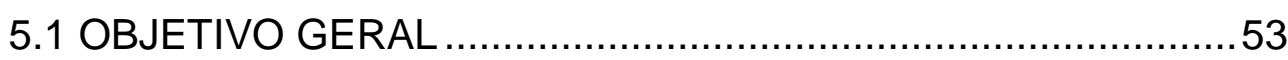

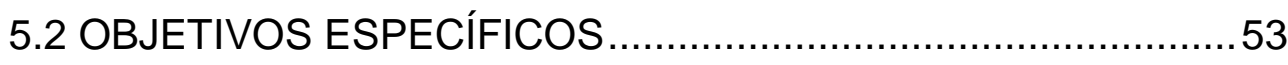

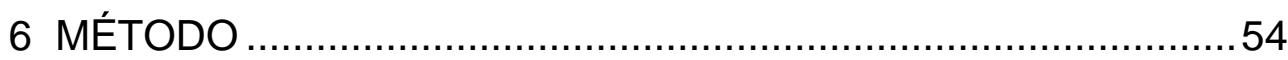

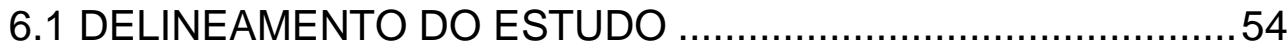

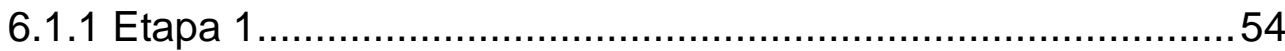

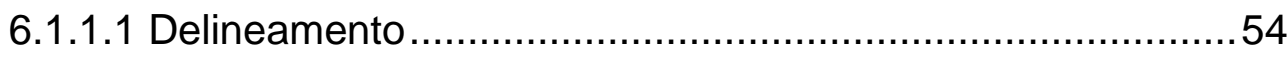

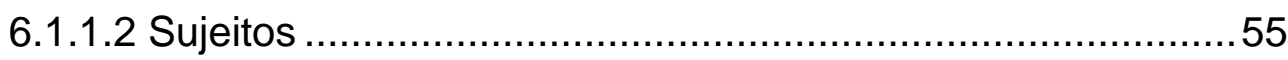

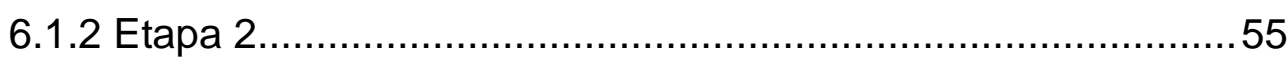

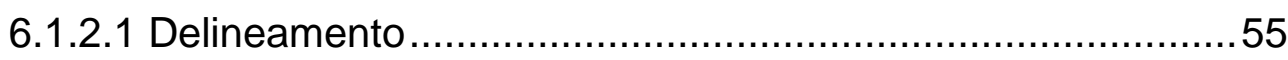

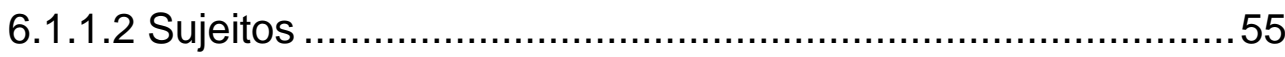

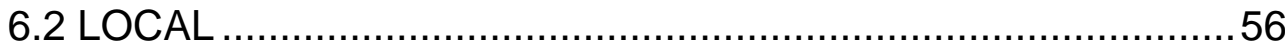

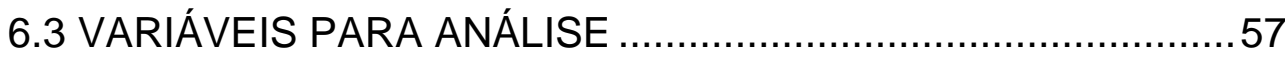

6.3.1 Caracterização geral, clínica e oftalmológica do paciente no

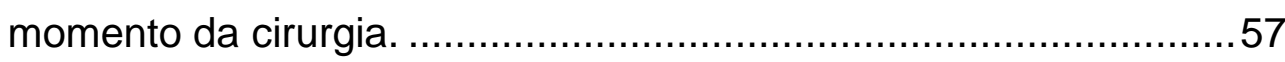

6.3.2 Características clínicas e epidemiológicas pós-operatória......57

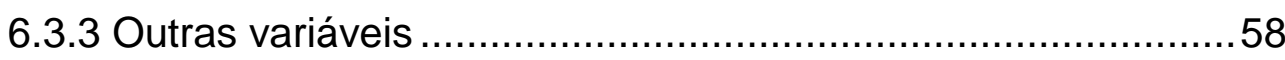

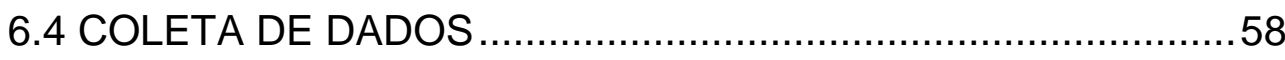

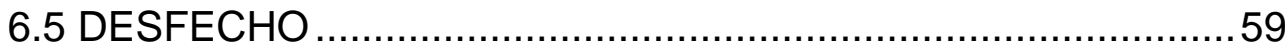


6.6 ASPECTOS ESTATÍSTICOS ............................................ 59

6.7 ASPÉCTOS ÉTICOS ......................................................6 60

7. RESULTADOS ..................................................................... 61

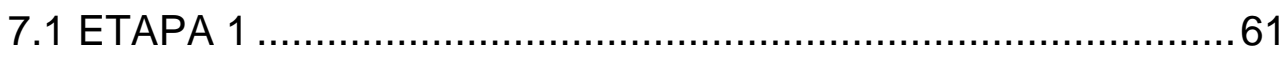

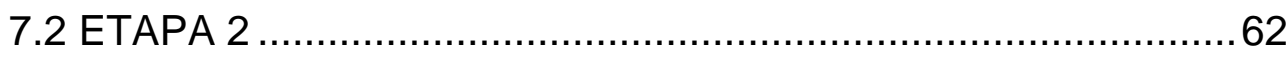

7.3 CONSTRUÇÃO DA FERRAMENTA PARA VE .....................69

7.3.1 Identificação e seleção dos marcadores ...............................69

7.3.2 Critério para inclusão de casos a serem monitorados por meio da ferramenta de VE .......................................................... 70

7.3.3 Processo sugerido para monitoramento de EA pós-cirurgias de

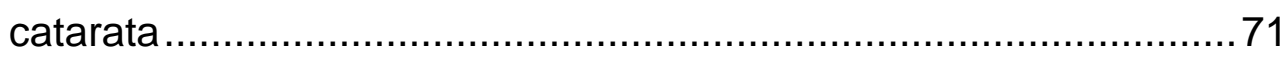

7.3.4 Critério para definição dos casos ....................................72

7.3.4.1 Caso suspeito ............................................................ 72

7.3.4.2 Caso confirmado....................................................... 72

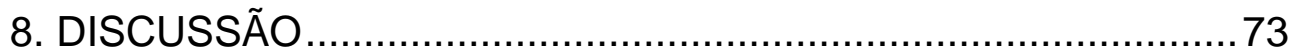

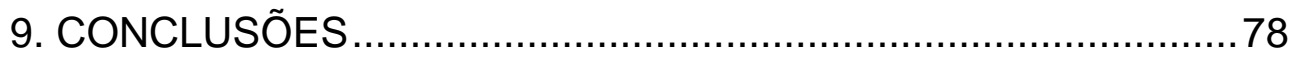

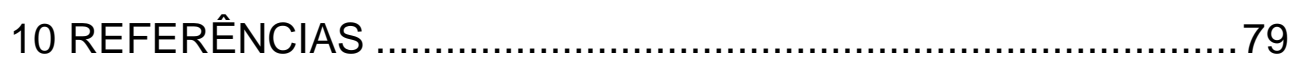

APÊNDICE A - Impresso para anotação médica da consulta pós-

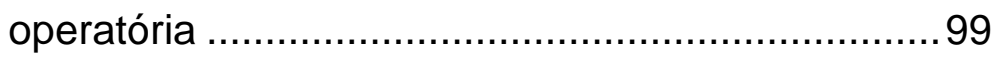

APÊNDICE B - Tabela de conversão da acuidade visual em percentual de acuidade visual central .................100

APÊNDICE C - Formulário de vigilância epidemiológica para TASS e endoftalmite após cirurgias de catarata...............101

APÊNDICE D - Exemplo de um formulário criado no programa Epiinfo para vigilância de eventos adversos após cirurgia de catarata .......................................... 102

ANEXO 1 - Autorização da instituição co-participante ................. 103

ANEXO 2 - Parecer consubstanciado do CEP ............................ 104

ANEXO 3 - Gráfico do IBGE demonstrando a tendência do envelhecimento da população brasileira .............. 105 




\section{INTRODUÇÃO}

Catarata é o termo utilizado para a opacificação do cristalino, nossa lente intraocular (LIO) natural. Dentre as várias causas, a senilidade é a mais comum e o principal sintoma apresentado é a diminuição da acuidade visual (AV). ${ }^{1-3}$ É a principal causa responsável de cegueira no Brasil ${ }^{4-9}$ e considerada um problema de saúde pública. ${ }^{6,7}$

Nas últimas décadas houve uma iniciativa governamental objetivando minimizar a magnitude deste problema com a criação de campanhas para cirurgias da catarata. ${ }^{10}$ Dados dos últimos cinco anos mostram que foram realizados quase dois milhões de procedimentos cirúrgicos para extração da catarata financiados pelo Sistema Único de Saúde (SUS) em todo o país, necessitando um investimento de mais de 794 milhões de reais. ${ }^{11}$

Estudos analisando o perfil dos pacientes submetidos a tal cirurgia demonstram que se trata de uma população idosa com baixo nível de escolaridade e baixo poder aquisitivo.,12,13 Muitas vezes, representam pacientes que possuem plano privado de saúde, porém, não puderam arcar com tal tratamento por falta de recursos financeiros, e recorreram a rede pública de assistência a saúde. ${ }^{13}$

Com o aumento a cada ano no número de cirurgias de catarata já se tem a percepção da importância na avaliação da qualidade dos serviços prestados pelo SUS a estes pacientes, assumindo como premissa que a qualidade não deve ser sacrificada em favor da quantidade. ${ }^{7,14-16}$

Como todo procedimento cirúrgico, a cirurgia de catarata não está isenta de riscos, podendo apresentar complicações intra e pósoperatória ${ }^{17}$ que podemos chamar de eventos adversos (EA) ${ }^{*}{ }^{18,19}$ Estes eventos pode comprometer a qualidade na atenção aos

\footnotetext{
* Evento adverso - [...] lesão ou dano não intencional que resultou em incapacidade ou disfunção, temporária ou permanente, e/ou prolongamento do tempo de permanência ou morte como consequência do cuidado prestado. (Gallotti, 2004; Mendes et al., 2008)
} 
pacientes cirúrgicos de catarata, o que torna a estimativa destes riscos um elemento essencial para direcionar o planejamento em saúde no Brasil.

Dentre as complicações pós-operatórias que comprometem o resultado das cirurgias, a infecção intraocular conhecida como endoftalmite é a que causa maior preocupação nos serviços de oftalmologia em todo o mundo, visto seu prognóstico devastador. ${ }^{20-24}$ Sua incidência pode chegar até $0,31 \%,{ }^{25}$ entretanto, no Brasil é pouco conhecida, porém com tendência a relatos esporádicos de ocorrências de surtos. ${ }^{26-29}$

Outro EA importante é a reação inflamatória exacerbada denominada de Síndrome Tóxica do Segmento Anterior (TASS)", que na maioria das vezes se manifesta nas primeiras 12 horas após a cirurgia ${ }^{30-34}$ e que pode levar à necessidade de outras cirurgias como transplante de córnea ou cirurgia antiglaucomatosa, com um resultado final desfavorável. ${ }^{31,32,35,36} \mathrm{~A}$ maior incidência já reportada foi de $2,13 \%{ }^{37}$ e sua apresentação clínica e evolução são muito semelhantes aos da endoftalmite, o que dificulta seu diagnóstico diferencial e tratamento. ${ }^{38,39}$ Ambos os EA comprometem os resultados cirúrgicos e suas incidências refletem a qualidade dos serviços prestados.

Já existe a preocupação em acompanhar os resultados após a cirurgia de catarata, pelo reconhecimento de que não raramente os resultados após a cirurgia são menos positivos que os esperados e as complicações não são raras. ${ }^{7,15,40,41}$ Neste contexto, justifica-se o uso da epidemiologia no campo da oftalmologia com vistas à coletividade $^{42}$ e sua expressiva contribuição para a produção científica na área da saúde coletiva. ${ }^{43}$

Neste sentido, a vigilância epidemiológica (VE) surge como uma ferramenta essencial neste processo, formando a base de avaliação da qualidade destes serviços de saúde ${ }^{44,45}$ porém não 
tem sido rotineira a utilização de sistemas de VE para cirurgias oftalmológicas, de modo geral, nas instituições brasileiras.

No Brasil poucos estudos têm relatado a incidência destes EA no pós-operatório das cirurgias oftalmológicas, ${ }^{22,46-48}$ o que nos leva a pensar em subnotificação por inexistência ou ineficiência de um sistema de vigilância epidemiológica efetivo. Entre as dificuldades para o estabelecimento de um sistema de VE pode-se inferir as características peculiares dos procedimentos cirúrgicos para a extração da catarata, como a alta rotatividade de pacientes, as dificuldades para participação de outros profissionais de saúde, além do oftalmologista, no diagnóstico epidemiológico e até mesmo a falta de incentivo para esta vigilância no contexto das políticas públicas de saúde.

O enfermeiro pode ter um papel mais ativo e determinante na melhoria deste processo, assim como já acontece nas comissões de controle de infecção hospitalar $(\mathrm{CClH})$, no que tange a outros EA em serviços de saúde. Contudo, para que o profissional enfermeiro de prevenção e controle de infecções relacionadas à assistência à saúde (IRAS) consiga atuar ativamente neste processo, é necessária a criação de uma estrutura e processo de trabalho para esta finalidade e o desenvolvimento de marcadores factíveis de serem acompanhados por este profissional.

Este estudo buscou conhecer as características clínicas e epidemiológicas dos EA selecionados, a saber, endoftalmite e TASS, a partir do estudo da evolução de pacientes submetidos à cirurgia de catarata, a fim de apontar os marcadores mais indicados para a construção de um sistema de vigilância epidemiológica para tais episódios. Este estudo foi norteado pela seguinte questão: Quais são os elementos a serem recomendados para a instituição de um sistema de vigilância epidemiológica para TASS e Endoftalmite? 




\section{REVISÃO DA LITERATURA}

\subsection{CATARATA E SEU TRATAMENTO}

O olho humano é dividido em dois segmentos, anterior e posterior. O segmento posterior é preenchido pelo humor vítreo, composto basicamente por água e eletrólitos. O segmento anterior é dividido pela íris em duas câmaras, a anterior e a posterior. ${ }^{49} \mathrm{Na}$ câmara posterior se localizam a zônula e saco capsular, dentro do qual fica o cristalino..$^{50}$

A câmara anterior (CA) é o local onde são observados os principais sinais de inflamação e infecção após as cirurgias de catarata. É preenchida pelo humor aquoso (HA), uma solução coloidal opticamente vazia à biomicroscopia, em que normalmente não são observadas partículas ou células ao exame. A presença de partículas ou células suspensas nessa solução produz o efeito Tyndall, quando há a difração da luz. ${ }^{51}$ (Figura 1)

Figura 1- llustração da anatomia do globo ocular humano

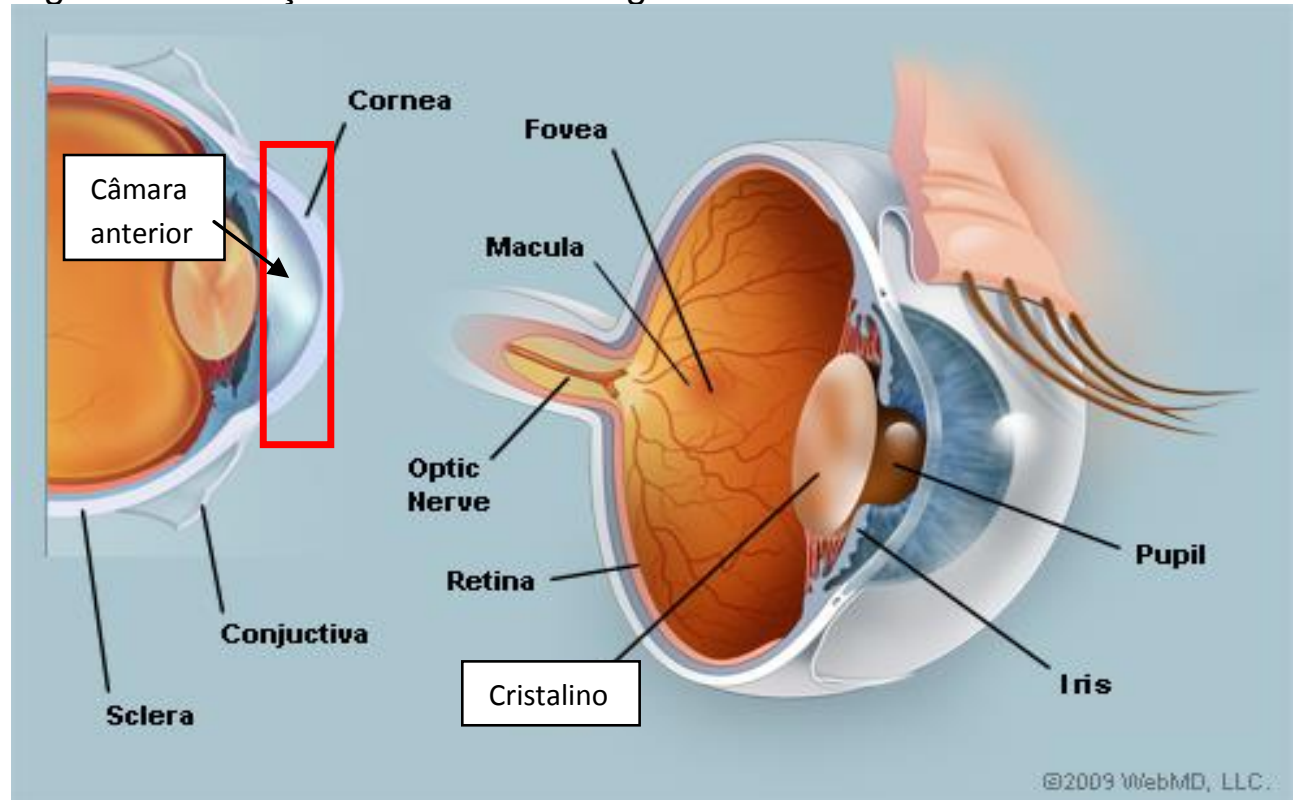

Fonte:http://img.webmd.com/dtmcms/live/webmd/consumer assets/site images/art icles/image article collections/anatomy pages/EYE2.jpg 
O cristalino é uma LIO natural, biconvexa e transparente. É composta de colágeno e proteínas ${ }^{52}$ e tem a função de focalizar a imagem na retina através de seu poder de conversão, capacidade esta que se perde gradativamente com o avançar da idade por se tornar opaco. $O$ resultado deste processo origina o que conhecemos como catarata. ${ }^{1-3}$

A maior causa desta opacificação é a senilidade, mas pode ser causada também por trauma contuso, radiação ultravioleta, queimadura química, choque elétrico, diabetes mellitus e outras doenças oculares como alta miopia e uveíte. Outras causas incluem o uso prolongado de corticosteroides sistêmicos, substâncias tóxicas como: nicotina, cobre e ferro, além da possibilidade de origem congênita. ${ }^{1-3}$

Os sinais e sintomas mais comuns do paciente com catarata além da Baixa Acuidade Visual (BAV) são: fotofobia, que consiste na maior sensibilidade e menor tolerância à luz, alteração na visão de cores, ofuscamento ou borramento da imagem e diplopia, que significa visão dupla. ${ }^{1,2,17}$

A catarata pode ser classificada segundo a localização da opacificação como nuclear, cortical ou subcapsular e conforme o grau de opacidade, podendo receber a denominação de incipiente, madura ou hipermadura. ${ }^{2}$ A catarata nuclear, responsável pela redução da visão de longe, a mais típica em pacientes idosos, é caracterizada pelo aumento da densidade do núcleo do cristalino. ${ }^{17,53}$

O segundo tipo de catarata denominada cortical pode estar associado ao diabetes e não causa prejuízo à visão por estar localizada apenas na córtex do cristalino, mas compromete a visão conforme ela progride atingindo o eixo visual. ${ }^{17} \mathrm{Um}$ terceiro tipo é a catarata subcapsular, que afeta os indivíduos menos idosos entre os 40 e 60 anos de idade e pode estar associada com diabetes, inflamação ocular e uso de esteroides. Localiza-se principalmente 
entre a córtex e a cápsula do cristalino, podendo vir ou não acompanhada de opacificação do núcleo. ${ }^{17,53}$

O tratamento da catarata é sempre um procedimento cirúrgico, ${ }^{2,17}$ que consiste na remoção do cristalino opacificado através de duas técnicas comumente utilizadas atualmente: a extração extracapsular (EEC) e a facoemulsificação, sendo esta última a mais utilizada. Na técnica de EEC a incisão é de $8 \mathrm{~mm}$ a $10 \mathrm{~mm}$ na região limbar ou escleral por onde o núcleo do cristalino é extraído por inteiro e o material cortical é aspirado, mantendo a cápsula posterior intacta. Após a remoção da catarata é implantada a LIO e a incisão é suturada com fio de nylon $10-0 .{ }^{2} \mathrm{Na}$ técnica de facoemulsificação o cristalino é retirado em partes fragmentadas e emulsificadas. São realizadas duas incisões na córnea que podem variar de $1.5 \mathrm{~mm}$ a $3.2 \mathrm{~mm}$ dependendo do tipo de LIO utilizada por onde entrará a ponteira da caneta de facoemulsificação que vibra a uma frequência ultrassônica fazendo a emulsificação e sucção do cristalino. (Figura 2)

Figura 2 - llustração do processo de retirada da catarata pela técnica de facoemulsificação

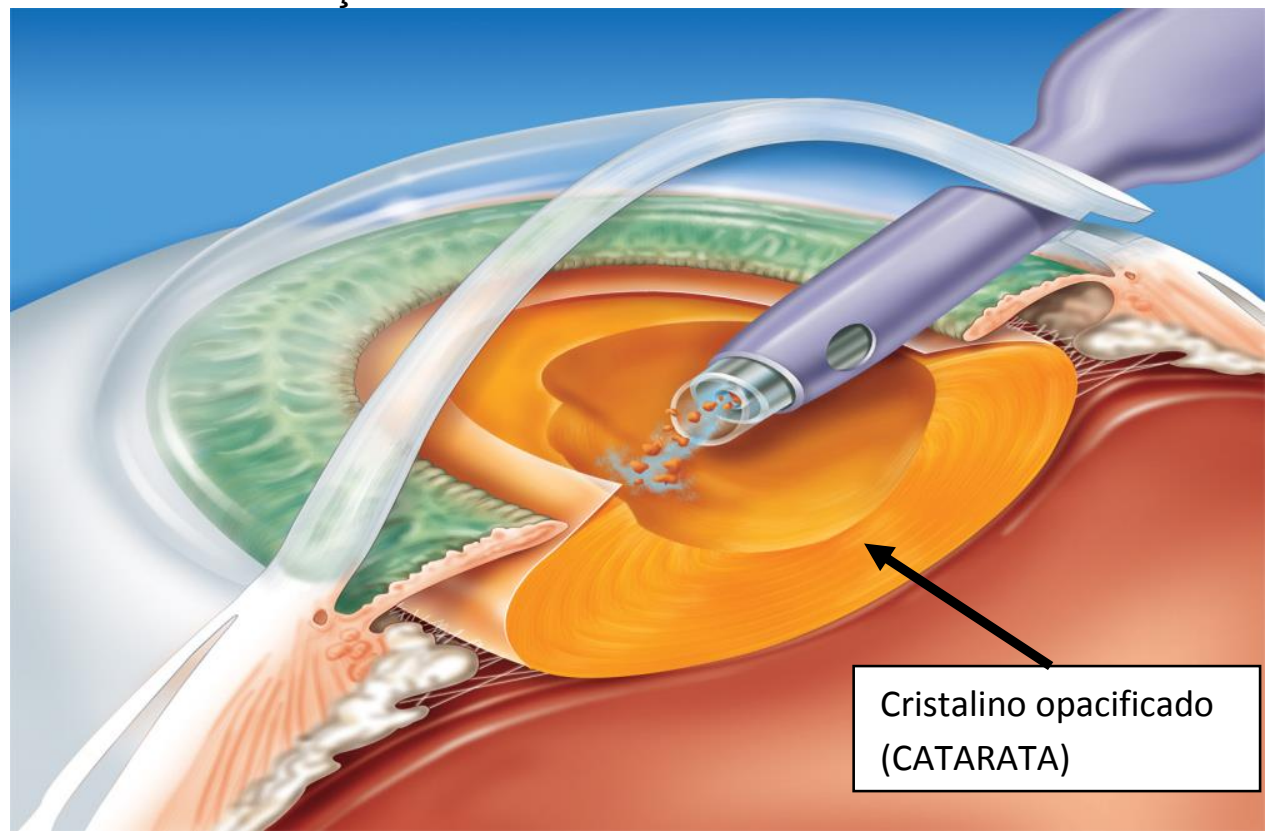

Disponível em:

http://www.fernandomoro.com.br/home/index.php?option=com content\&view=artic le\&id=91\&ltemid $=2$ 
Após a extração deste cristalino doente, os restos de material cortical são aspirados, uma LIO artificial é injetada dobrada dentro olho e posicionada utilizando a própria estrutura ocular para sua fixação após se desdobrar passivamente. ${ }^{17,54}$ (figura 3)

Figura 3 - llustração da lente intraocular colocada após a remoção da catarata

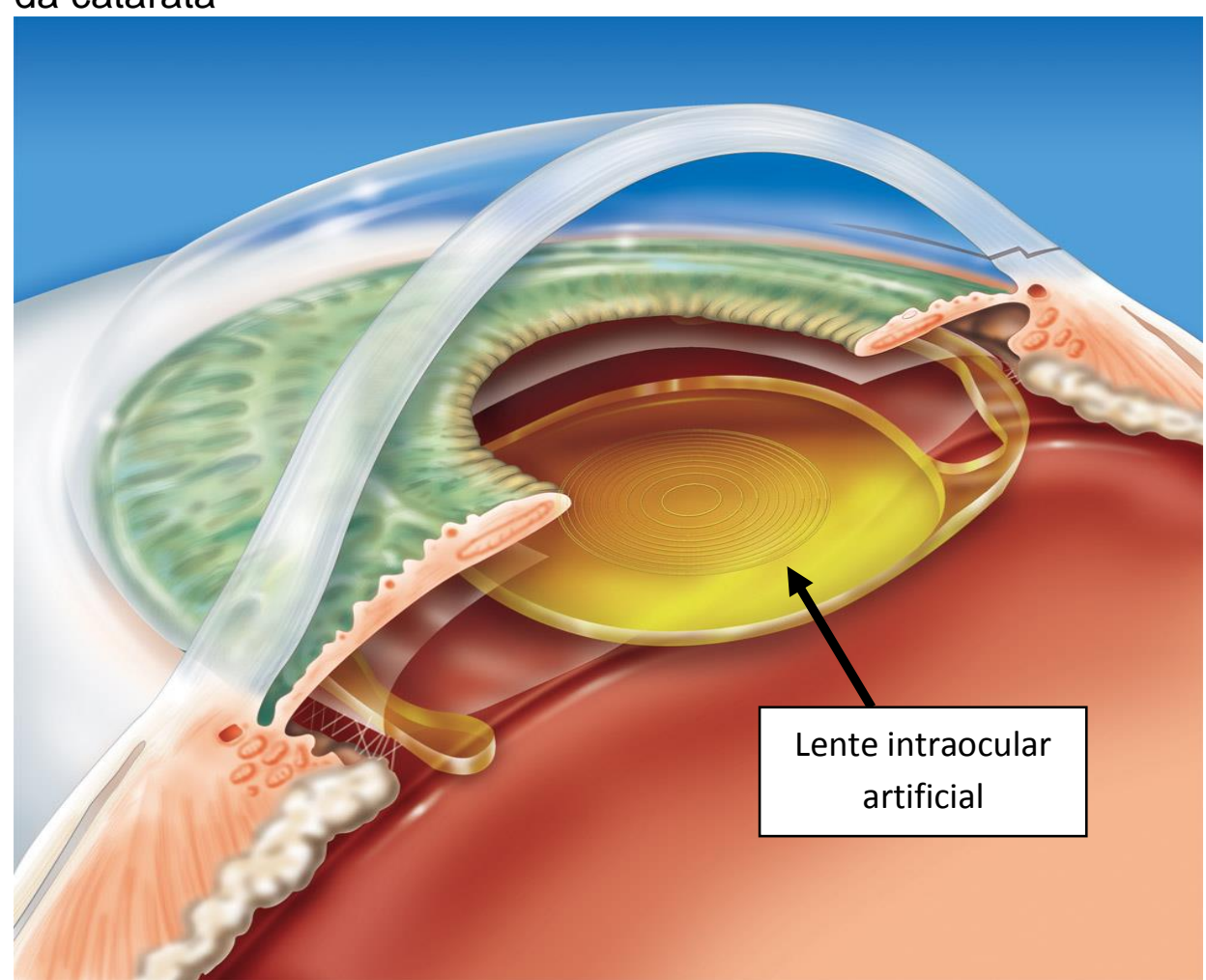

Disponível em:

http://www.fernandomoro.com.br/home/index.php?option=com content\&view=artic le\&id=91\&ltemid $=2$

Durante o acompanhamento do paciente após a cirurgia, alguns sinais são observados ao exame oftalmológico principalmente na córnea e na CA. Estes sinais determinam a quantidade e frequência dos retornos para acompanhamento pósoperatório e servem para o diagnóstico de eventos adversos como TASS e endoftalmite. 
Os principais sinais observados após a cirurgia de catarata são:

\section{- Córnea nebulosa}

A córnea é um tecido avascularizado, o que the confere a sua transparência com principal característica. ${ }^{49} \mathrm{O}$ trauma cirúrgico costuma tornar a córnea menos transparente no pós-operatório e de maneira transitória, porém a persistência de uma córnea mais nebulosa deve levantar a suspeita de endoteliopatias préoperatórias, trauma cirúrgico excessivo ou reação inflamatória, que pode ser ou não de causa infecciosa. ${ }^{55}$ (Figura 4)

Figura 4- llustração da córnea e suas camadas

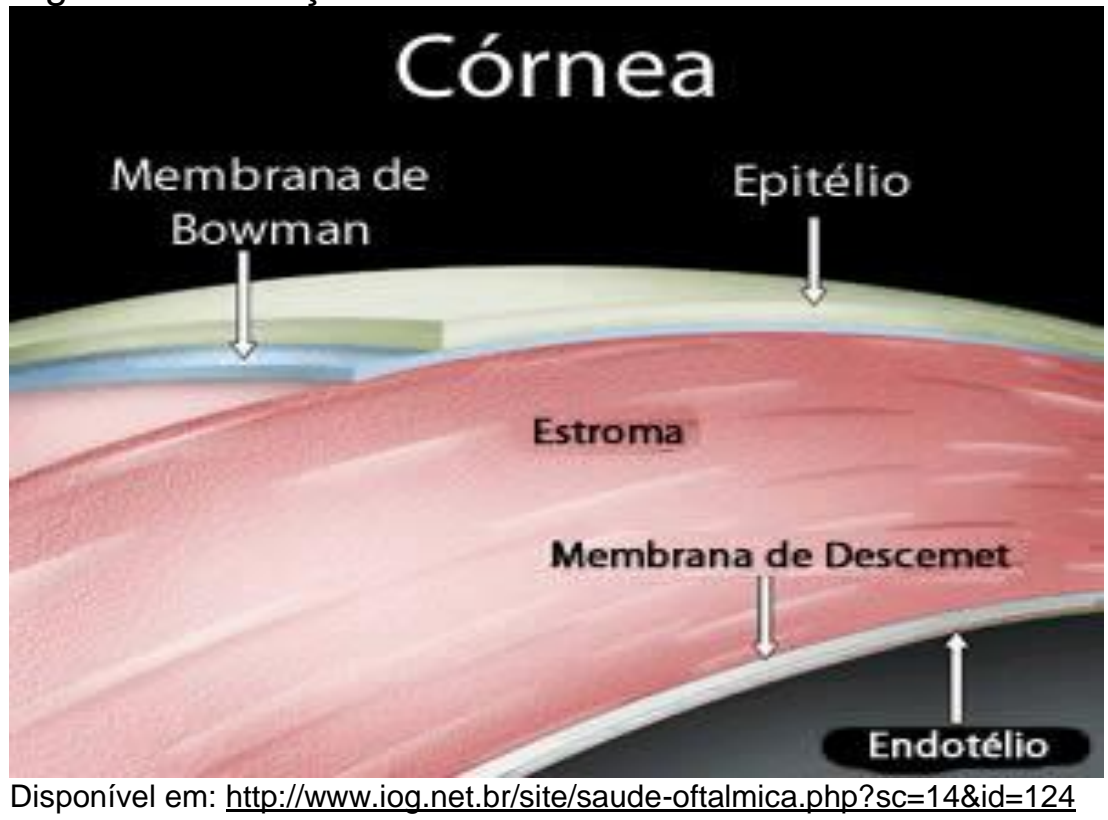

- Dobras na membrana Descemet

A córnea possui cinco camadas, uma delas é a membrana Descemet. Devido à diminuição da pressão intraocular provocada pelo trauma cirúrgico ela pode apresentar dobras. Estas dobras se caracterizam por duas linhas brilhantes, separadas por um espaço escuro. Representam uma diminuição da pressão intraocular, que pode ocorrer em função da cirurgia. ${ }^{56}$ (Figura 5) 
Figura 5 - Fotografia de um olho após cirurgia de catarata apresentando dobras na membrana Descemet

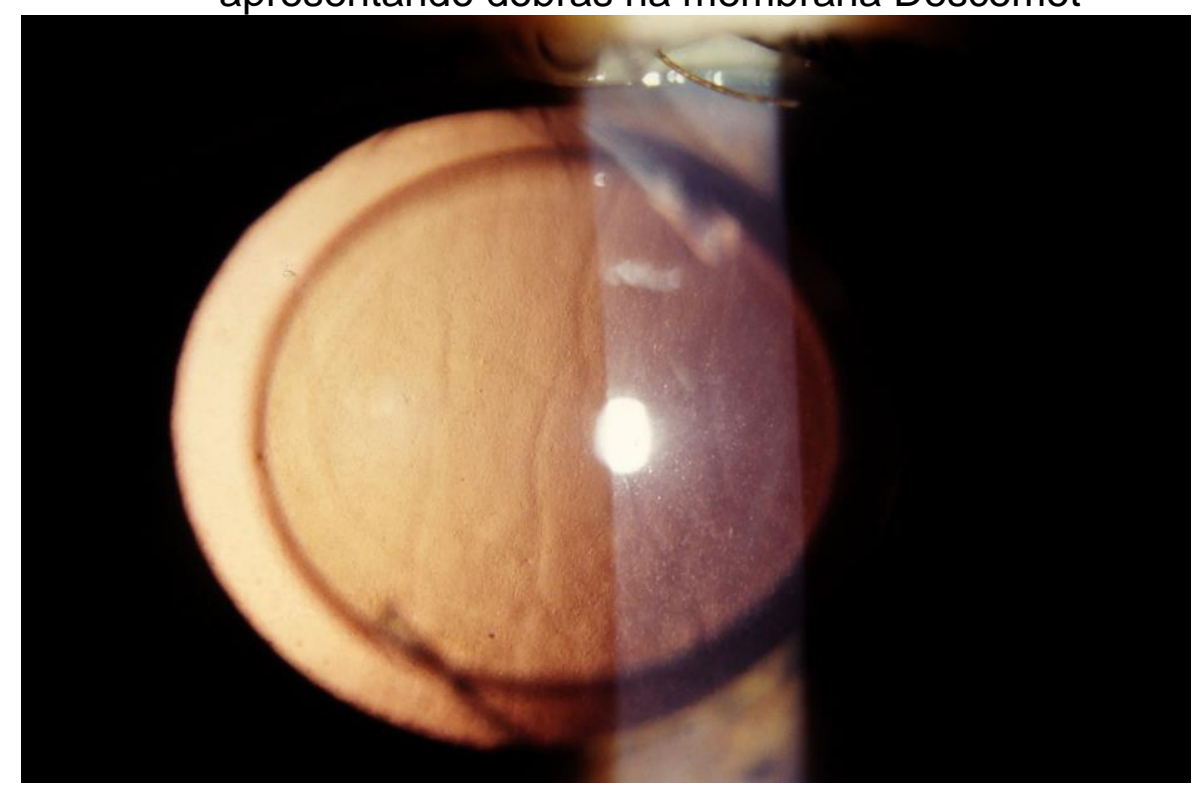

FONTE: Instituto de Oftalmologia Cvintal. Arquivo didático de imagens.

\section{- Fibrina na CA}

Os depósitos de fibrina que podem ocorrer isoladamente ou associados aos precipitados ceráticos (PC), são frequentes nas fases iniciais dos processos inflamatórios uveais. Caracterizam-se por finos depósitos de diferentes formas, geralmente disseminados pelo endotélio ou preferencialmente depositados na metade inferior da córnea. ${ }^{57}$ (Figura 6)

\section{- Flare}

Aparece quando o HA se torna preenchido por transudato ou exsudato proteico causando a interrupção da passagem de luz, efeito esse que se convencionou a chamar de flare. ${ }^{57}$

\section{- Hifema}

É uma coleção de sangue que se acumula na câmara anterior formando um nível. Na cirurgia de catarata geralmente é causado pelo trauma cirúrgico importante ou decorrente de lesão de neovasos de íris em pacientes que portadores de rubeosis. ${ }^{55}$ (Figura 7) 
Figura 6 - Fotografia de um olho após cirurgia de catarata com presença de fibrina na câmara anterior

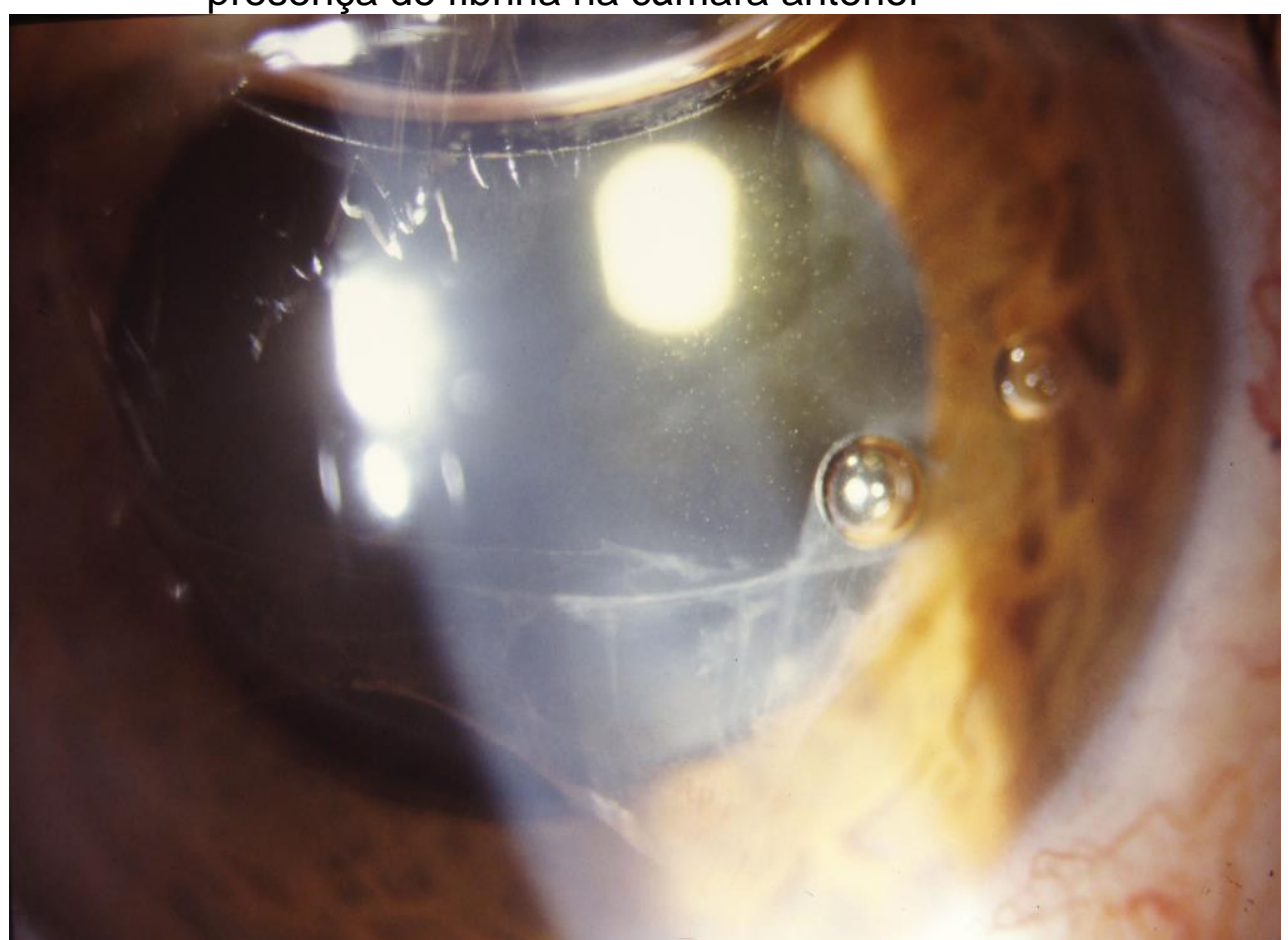

FONTE: Instituto de Oftalmologia Cvintal. Arquivo didático de imagens

Figura 7 - Fotografia do olho após cirurgia de catarata com presença de hifema

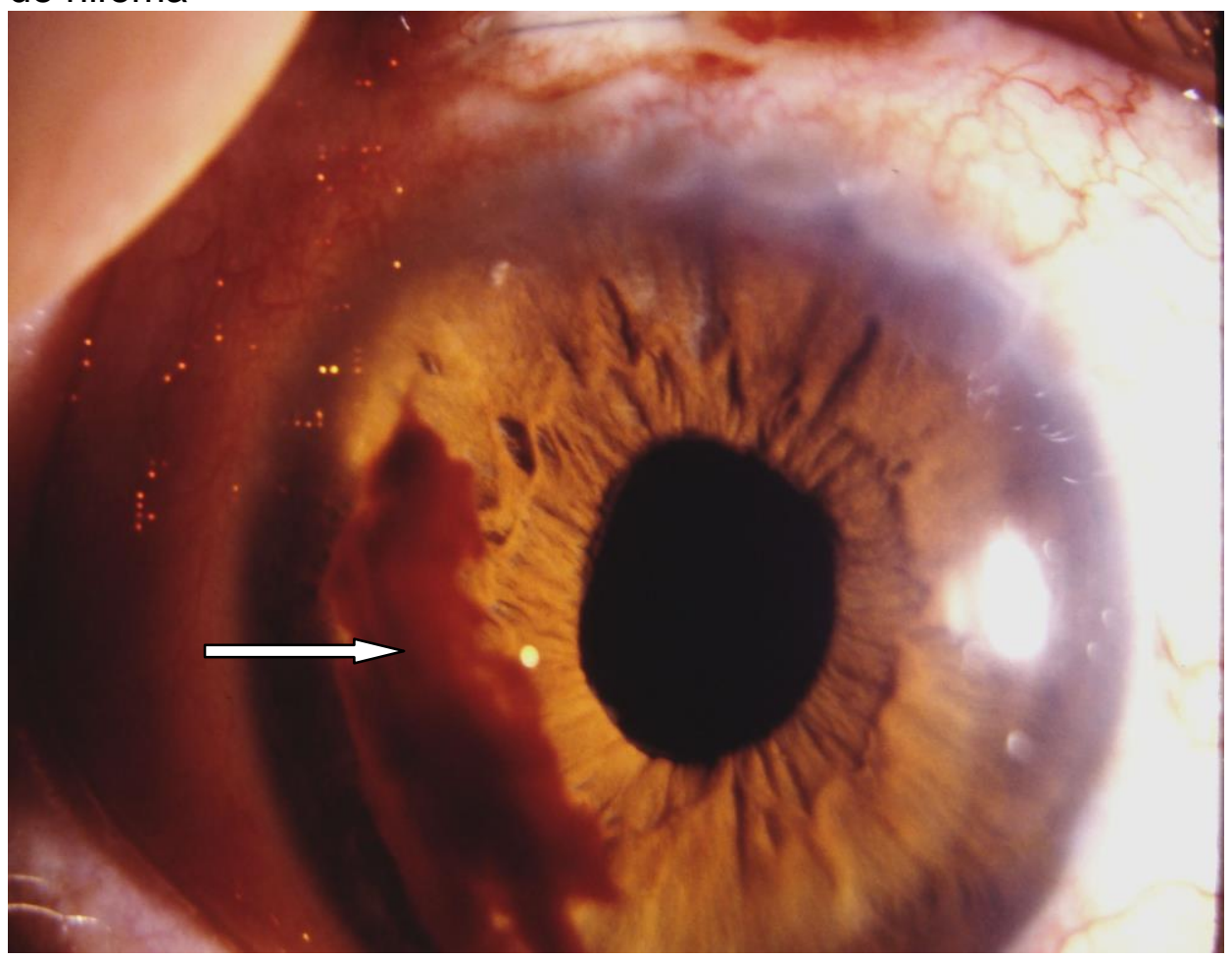

FONTE: Instituto de Oftalmologia Cvintal. Arquivo didático de imagens 


\section{- Hiperemia Conjuntival e Injeção Ciliar}

A hiperemia conjuntival é causada pelo ingurgitamento dos vasos conjuntivais, que dão o aspecto mais avermelhado a essa camada. ${ }^{58} \mathrm{~A}$ injeção ciliar é a hiperemia da região perilímbica de cor violácea ou de uma hiperemia mais difusa da conjuntiva de coloração mais avermelhada. A injeção ciliar pode ser diferenciada da hiperemia conjuntival pelo uso da fenilefrina tópica, que torna a coloração normal na hiperemia conjuntival. ${ }^{57}$

\section{- Hipópio}

O segmento anterior do olho possui uma barreira seletiva chamada de barreira hemato-aquosa, responsável pelo controle do fluxo entre a corrente circulatória e o HA. Quando ocorrem alterações na sua permeabilidade vascular permitindo o influxo proteico e celular, forma-se o hipópio. ${ }^{51}$ Este sinal menos comumente observado no pós-operatório de cirurgias de catarata, é uma coleção esbranquiçada que se acumula inferiormente na câmara anterior formando um nível. ${ }^{59}$ É característico da inflamação intensa ${ }^{58}$ e pode ter origem infecciosa, não infecciosa ou tumoral. ${ }^{57}$ O não infeccioso, onde não são encontrados elementos bacterianos ou fúngicos, é o tipo mais comum. ${ }^{51}$ (Figura 8 )

\section{- Precipitados ceráticos}

São agregados de células inflamatórias que se depositam no endotélio corneano a partir do $H A^{51}$. Estas células podem ser os linfócitos, plasmócitos, eosinófilos, células epitelióides ou macrófagos mononucleares. ${ }^{58}$

\section{- Reação de câmara anterior (RCA)}

Pode ser verificada por meio do exame clínico na lâmpada de fenda quando se observa células em quantidade anormal em seu interior ${ }^{51}$ e geralmente indica a presença de atividade inflamatória. ${ }^{57}$ 
O número de células observado ao exame pode indicar a gravidade da atividade inflamatória instalada, ${ }^{58}$ embora possa ser encontrada até uma célula por campo em indivíduos normais. ${ }^{60}$

Figura 8 - Fotografia do olho após cirurgia de catarata com presença de hipópio

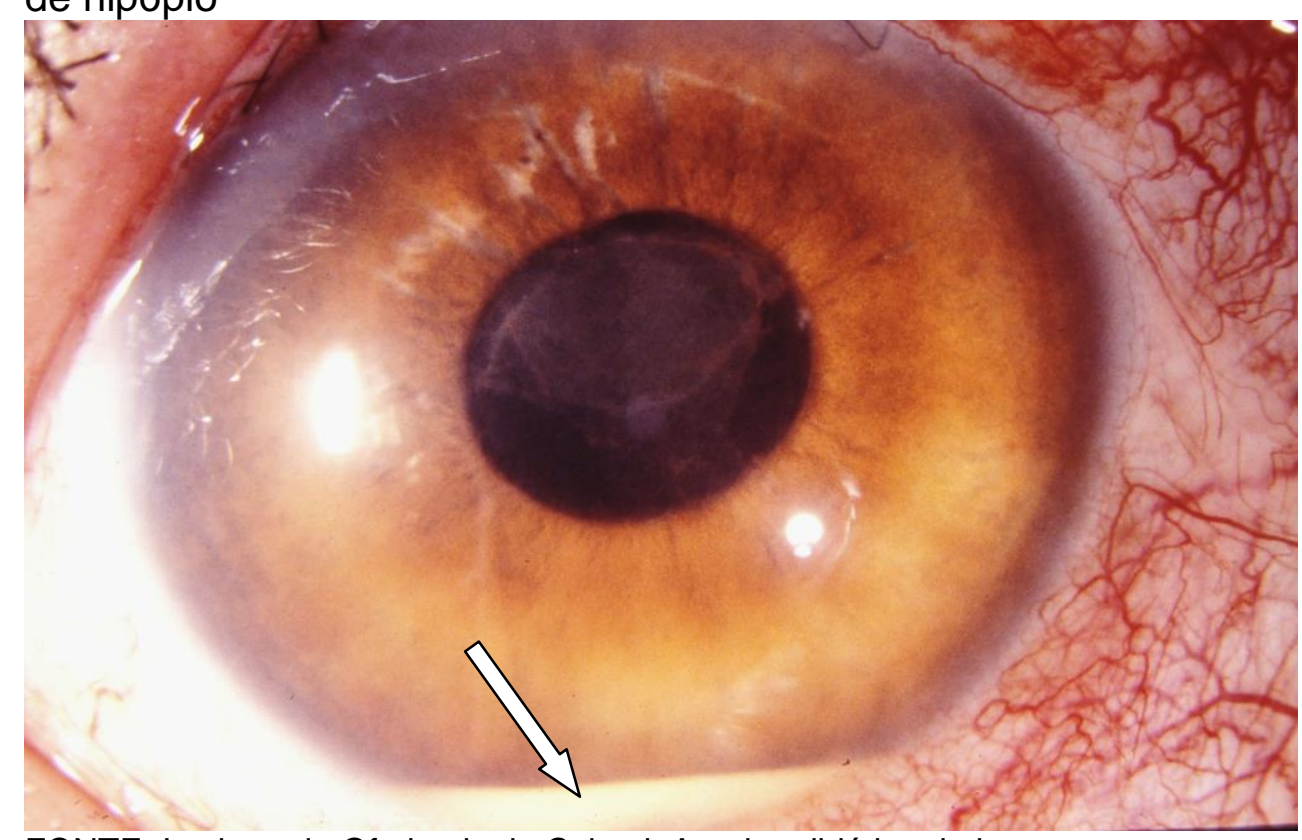

FONTE: Instituto de Oftalmologia Cvintal. Arquivo didático de imagens

\section{- Seidel}

Consiste no vazamento do humor aquoso decorrente do fechamento incompleto da ferida operatória. ${ }^{55}$ Por formar uma solução de continuidade entre o meio externo e a câmara anterior, o risco para a ocorrência de endoftalmite é potencialmente maior ${ }^{61}$

\section{- Trave Vítrea}

O Humor vítreo é um hidrogel que preenche a cavidade posterior do olho, inclusive atrás da cápsula posterior do cristalino. ${ }^{49}$ A ruptura da capsula posterior cria um pertuito, por onde o gel vítreo pode passar, de forma a depositar-se na câmara anterior. As traves vítreas observadas após cirurgias de catarata complicadas são filetes ou cogumelos de material transparente, porém de consistência diferente do humor aquoso. ${ }^{55}$ (Figura 9) 
Figura 9 - Fotografia do olho após cirurgia de catarata com presença de trave vítrea

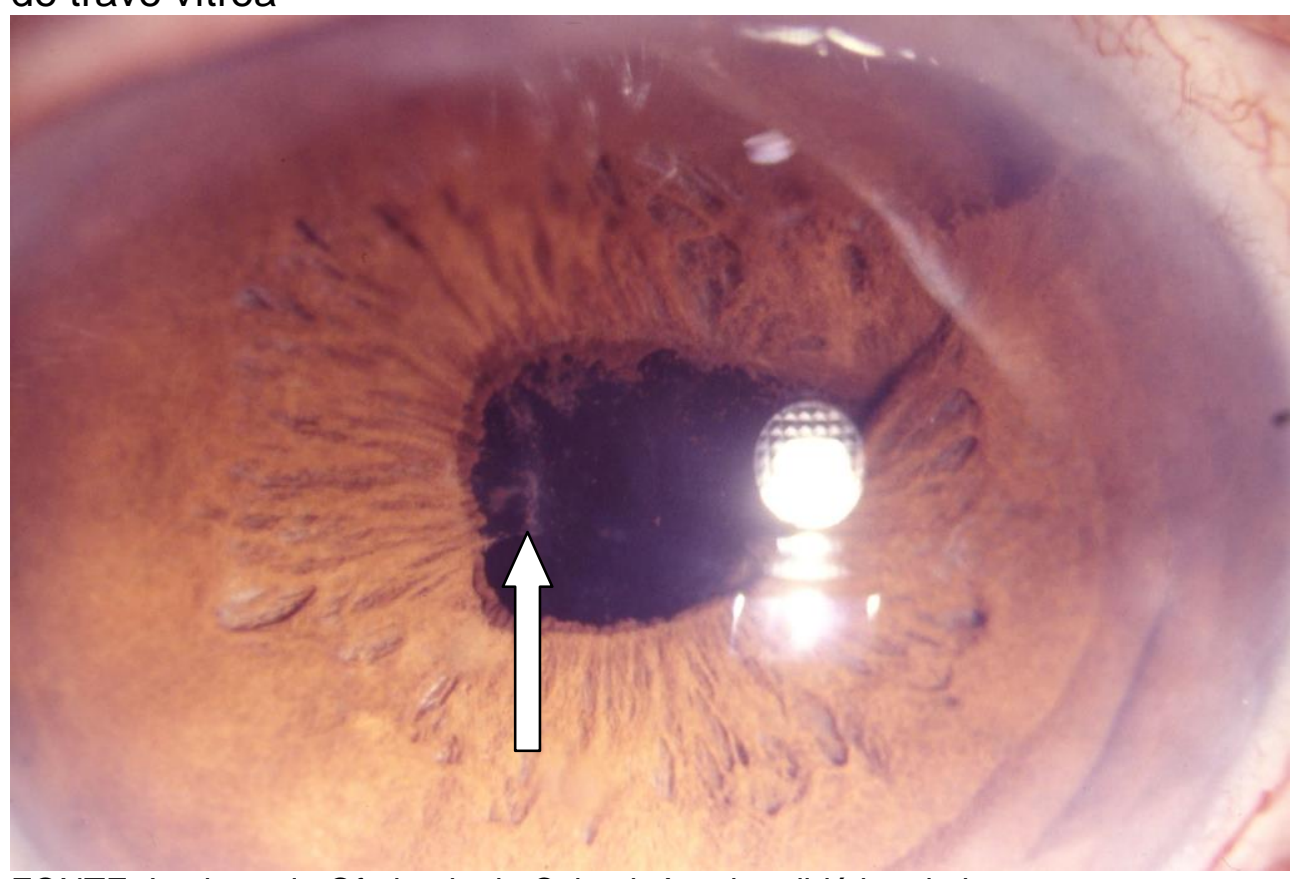

FONTE: Instituto de Oftalmologia Cvintal. Arquivo didático de imagens

- Vítreo turvo

Representa a infiltração do vítreo por células e proteínas, causando uma turvação dos meios ópticos e dificuldade de visualização da retina e coróide. ${ }^{57}$ Células ou depósitos vítreos são sempre patológicos(6) e pode refletir o grau e o caráter da inflamação. ${ }^{51}$

\subsection{ENDOFTALMITE}

É o termo utilizado para a infecção confinada no interior do globo ocular, uma das mais temidas complicações após cirurgias de catarata. É geralmente de prognóstico ruim, evoluindo muitas vezes para a necessidade da retirada do globo ocular ou de seu conteúdo interno. ${ }^{21-23,62}$

A apresentação clínica deste tipo de infecção ocorre na maioria das vezes nos primeiros quatro dias após a cirurgia ${ }^{27,38,63-69}$ e com menor frequência entre o quarto e o $30^{\circ} \mathrm{dia} .^{23,70-73}$ Muitos 
casos podem ocorrer após um mês, ${ }^{62,65,72}$ porém são classificadas como endoftalmite pós-operatória aguda se forem diagnosticados em até seis semanas. ${ }^{69,74-79}$

Os sinais mais frequentemente observados são: edema de córnea e hipópio, ${ }^{23,39,64,66,71,80}$ hiperemia conjuntival, ${ }^{26,39,80,81}$ flare, ${ }^{66,80,81} \mathrm{RCA}^{23,26,39,66,71}$ fibrina na $\mathrm{CA},{ }^{23,39,64,71}$ turvação vítrea, $^{64,66,80,81}$ edema de pálpebras, ${ }^{39,80}$ hifema $^{39,71}$ e secreção conjuntival. ${ }^{80}$ (Figura 10)

Em muitos casos o pacientes se queixam de dor $26,66,80$ e/ou BAV que ao exame se mostra igual ou pior que conta dedos (CD). ${ }^{23,39,64,66,71,80}$

Figura 10 - Fotografia do olho com diagnóstico de endoftalmite apresentado hipópio, fibrina e edema de córnea

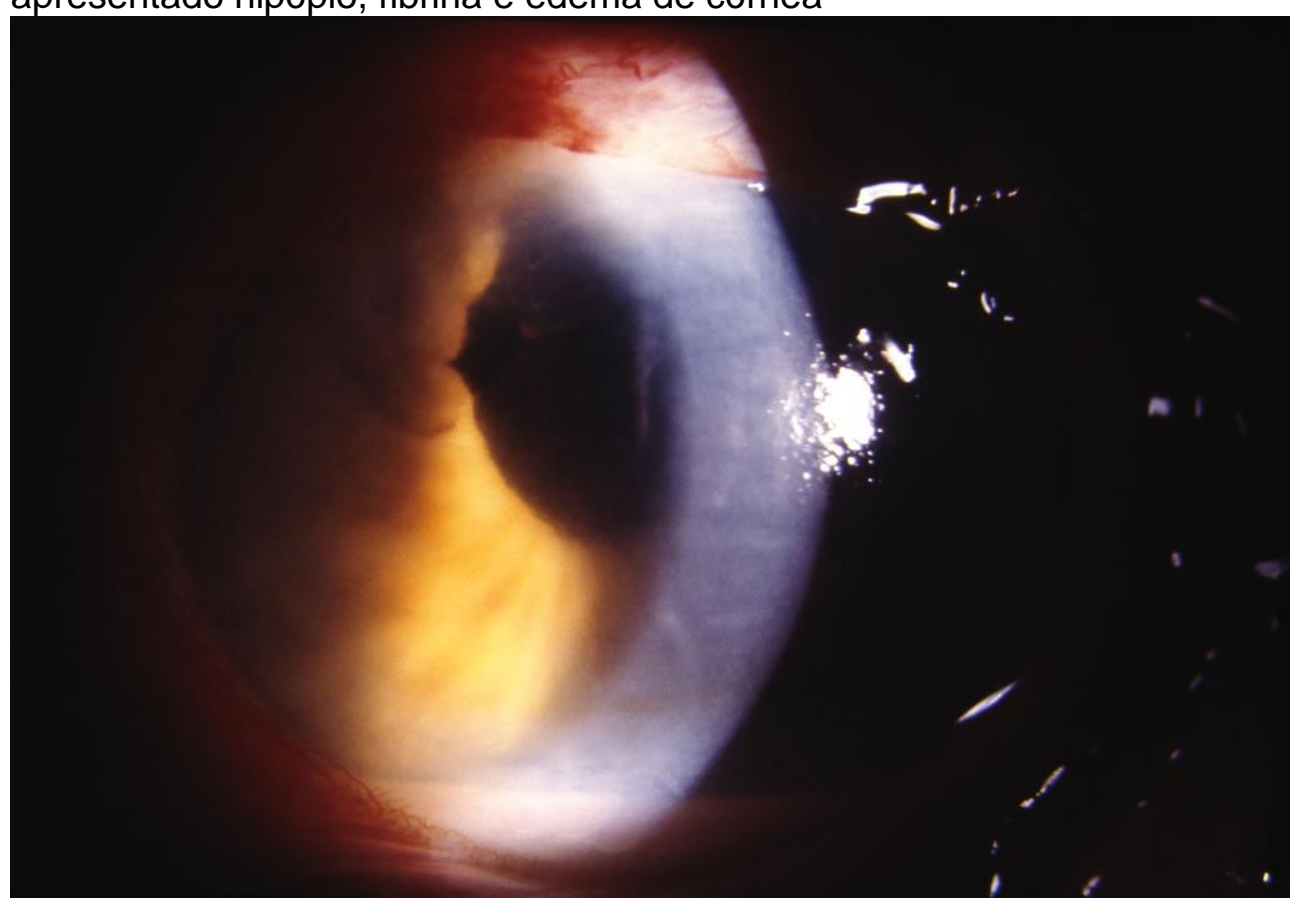

FONTE: Instituto de Oftalmologia Cvintal. Arquivo didático de imagens

Os agentes etiológicos mais comuns são os gram-positivos, sobretudo os Staphylococcus coagulase negativa ${ }^{25,47,69,80,82,83}$ e menos comumente os fungos ${ }^{76,83,84}$ e gram-negativos, sendo este último de evolução mais rápida e de pior prognóstico. ${ }^{20,22,85,86}$ (Quadro1) 
Quadro 1 - Número de casos de endoftalmite segundo agente etiológico e país de publicação. São Paulo, 2013

\begin{tabular}{|c|c|c|c|c|c|c|c|c|c|c|c|c|c|c|c|c|c|c|}
\hline 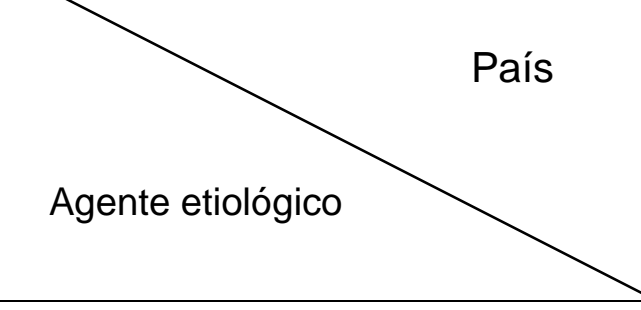 & 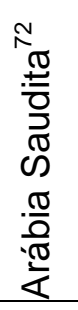 & 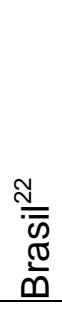 & $\begin{array}{l}\frac{\hat{f}}{\overline{\mathscr{D}}} \\
\frac{\mathbb{\varpi}}{\tilde{m}}\end{array}$ & 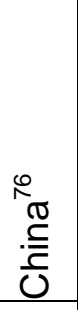 & 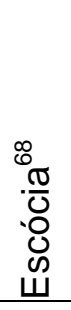 & 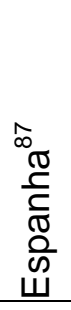 & 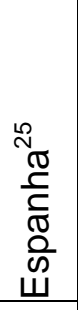 & $\begin{array}{l}\stackrel{ \pm}{\mathbb{S}} \\
\stackrel{\vec{J}}{\Psi}\end{array}$ & $\stackrel{+}{\stackrel{+}{\leftrightarrows}}$ & 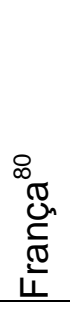 & 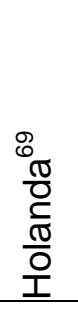 & 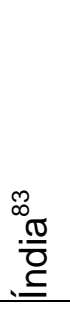 & 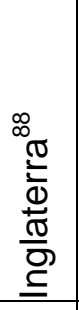 & $\begin{array}{l}\stackrel{ \pm}{\infty} \\
\stackrel{\sqrt{0}}{=} \\
\stackrel{5}{=}\end{array}$ & 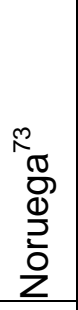 & 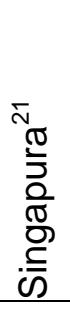 & 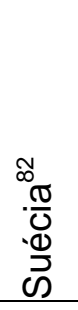 & $\begin{array}{l}\bar{\pi} \\
\stackrel{0}{0}\end{array}$ \\
\hline Sem crescimento & 2 & 7 & 28 & 23 & 13 & 2 & 15 & 11 & 25 & & 84 & & 11 & 37 & 1 & 9 & 17 & 285 \\
\hline Staphylococcus coagulase-negativo & & 1 & 26 & 3 & 7 & & 17 & 4 & 1 & 26 & 89 & & 1 & & & 3 & 35 & 213 \\
\hline Staphylococcus aureus & 2 & & 2 & & & & 4 & & 8 & 6 & 20 & 8 & & 12 & 1 & 1 & & 64 \\
\hline Enterococcus spp. & & & 1 & 1 & & & 1 & 1 & 4 & & 3 & 1 & 1 & & 2 & 3 & 42 & 60 \\
\hline Streptococcus spp. & 3 & 1 & 1 & & 4 & & & 2 & & 7 & 10 & 2 & 1 & 3 & 2 & 1 & 9 & 46 \\
\hline Pseudomonas aeruginosa & 1 & 8 & 2 & 4 & & 1 & & & 13 & & 2 & 4 & & 4 & & 2 & & 41 \\
\hline Staphylococcus epidermidis & 6 & & & 4 & & & & & & & & 14 & 1 & 4 & 2 & & & 31 \\
\hline Streptococcus viridans & 3 & & 7 & 1 & & & 2 & & & & 11 & & & & & & & 24 \\
\hline Streptococcus pneumoniae & 3 & 1 & 1 & & & & 2 & & 1 & & 12 & & & & & 1 & & 21 \\
\hline Pseudomonas spp. & & & & & & & & & & 1 & & 7 & 1 & & & & 10 & 19 \\
\hline Proteus spp. & & & 2 & 1 & & 2 & & & 2 & 1 & 3 & & & 1 & & & & 12 \\
\hline Acinetobacter spp. & & & 1 & & & & & & & & 1 & 5 & & 1 & & & & 8 \\
\hline Alcaligenes faecalis & & & & & & & & & & & & 7 & & & & & & 7 \\
\hline
\end{tabular}


(continuação)

\begin{tabular}{|c|c|c|c|c|c|c|c|c|c|c|c|c|c|c|c|c|c|c|}
\hline 4 & 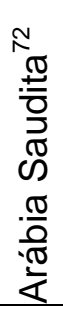 & $\begin{array}{l}\frac{\text { N }}{\overline{\mathcal{T}}} \\
\frac{\mathrm{U}}{\mathrm{m}}\end{array}$ & $\begin{array}{l}\frac{\pi}{\bar{c}} \\
\frac{\pi}{2} \\
\end{array}$ & 范 & 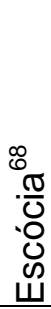 & 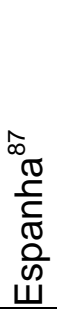 & 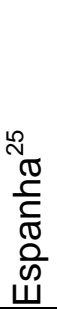 & 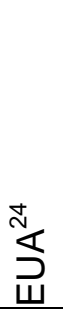 & 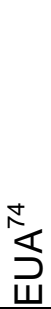 & 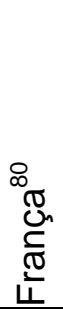 & $\begin{array}{l}\frac{8}{8} \\
\frac{\pi}{0} \\
\frac{0}{0} \\
\frac{0}{0} \\
\text { 오․ }\end{array}$ & $\begin{array}{l}{ }^{\infty} \\
\frac{\widetilde{\sigma}}{0} \\
. \underline{\underline{C}}\end{array}$ & 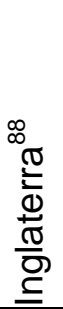 & 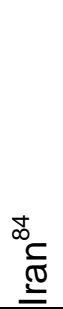 & 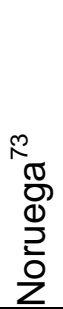 & 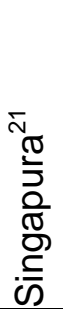 & 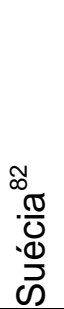 & $\begin{array}{l}\overline{\widetilde{\sigma}} \\
\stackrel{0}{0}\end{array}$ \\
\hline Haemophilus spp. & & & 1 & 1 & & & 1 & & & & 3 & & & 1 & & & & 7 \\
\hline Outros & 2 & & 2 & & & & & & 1 & & & 2 & & & & & & 7 \\
\hline Enterobacter spp. & & & & & & & & & & & & 2 & & 4 & & & & 6 \\
\hline Klebsiella spp. & & & & 1 & & 1 & & & & & & 2 & & & & 1 & & 5 \\
\hline Aspergillus spp. & & & & 1 & & & & & & & & 3 & & & & & & 4 \\
\hline Corynebacterium spp. & & & & 1 & & 1 & & & & & & 2 & & & & & & 4 \\
\hline Bacillus spp. & & & & & & & & & & & & 3 & & & & & & 3 \\
\hline Citrobacter spp. & & & & & & & & & & & & 3 & & & & & & 3 \\
\hline Candida albicans & & & & & & & & & & & & 1 & & 1 & & & & 2 \\
\hline Escherichia coli & & & & & & & & & & & & & & 2 & & & & 2 \\
\hline Moraxella catarrhalis & & & & & & & & & 2 & & & & & & & & & 2 \\
\hline Nocardia spp & & & & & & & & & & & & 2 & & & & & & 2 \\
\hline Stenotrophomonas maltophilia & & & & & & & & & 2 & & & & & & & & & 2 \\
\hline Phialemonium spp. & & & & & & & & & & & & 1 & & & & & & 1 \\
\hline Serratia marcescens & & 1 & & & & & & & & & & & & & & & & 1 \\
\hline
\end{tabular}

$\mathrm{EUA}=$ Estados Unidos da América

(conclusão) 
A evolução dos casos de endoftalmite não é muito favorável e na maioria dos casos a Acuidade visual final (AVF) destes pacientes é de CD ou cegueira total. ${ }^{20,22,23,26,39,62,67,72,73}$

Não é rara a necessidade da retirada de todo o conteúdo intraocular ou até mesmo a retirada do globo ocular através dos procedimentos de evisceração $0^{20-22,29,72}$ ou enucleação ${ }^{23,24,62}$ respectivamente. Em condições favoráveis quando o diagnóstico é precoce, o agente etiológico é de virulência menor e o tratamento é adequado, a AVF dos pacientes afetados pode ser mais favorável com visão igual ou melhor que 20/70. ${ }^{24,38,64,66}$

A incidência de endoftalmite após cirurgias para extração da catarata é em média $0,11 \%$ variando de taxas menores que $0,06 \%{ }^{21,65,82,83,87}$ até taxas mais altas de $0,31 \%{ }^{25}$ (Quadro2)

Quadro 2 - Incidência de endoftalmite após cirurgia da catarata segundo países onde foram realizados os estudos, ano de publicação, população estudada e número de casos. São Paulo, 2013

\begin{tabular}{|c|c|c|c|c|}
\hline Local & $\begin{array}{c}\text { Ano de } \\
\text { Publicação }\end{array}$ & $\begin{array}{c}\text { População } \\
\text { estudada }\end{array}$ & $\begin{array}{c}\text { Número } \\
\text { de Casos }\end{array}$ & $\begin{array}{c}\text { Incidência } \\
\text { (\%) }\end{array}$ \\
\hline Suécia $^{82}$ & 2013 & 464996 & 135 & 0,03 \\
\hline Canadá65 $^{65}$ & 2009 & 13.931 & 6 & 0,04 \\
\hline Singapura $^{21}$ & 2012 & 50.177 & 21 & 0,04 \\
\hline Espanha $^{87}$ & 2012 & 13305 & 7 & 0,05 \\
\hline India $^{83}$ & 2010 & 131.904 & 70 & 0,05 \\
\hline Noruega $^{73}$ & 2011 & 15.254 & 9 & 0,06 \\
\hline $\begin{array}{c}\text { Arábia } \\
\text { Saudita }^{72}\end{array}$ & 2009 & 29.509 & 20 & 0,07 \\
\hline Grécia $^{62}$ & 2009 & 8.393 & 7 & 0,08 \\
\hline India $^{89}$ & 2009 & 42426 & 38 & 0,09 \\
\hline Iran $^{84}$ & 2012 & 7.737 & 8 & 0,10 \\
\hline EUA $^{24}$ & 2013 & 16.264 & 19 & 0,12 \\
\hline EUA $^{77}$ & 2012 & 3.280 .966 & 4006 & 0,12 \\
\hline Canadá $^{90}$ & 2010 & 490690 & 754 & 0,15 \\
\hline Escócia $^{68}$ & 2009 & 9664 & 19 & 0,20 \\
\hline Brasiil $^{47}$ & 2010 & 24.590 & 71 & 0,29 \\
\hline Espanha $^{25}$ & 2010 & 13652 & 42 & 0,31 \\
\hline
\end{tabular}

EUA: Estados Unidos da América 
Embora a incidência deste tipo de infecção seja baixa, o cenário em casos de surtos é devastador devido à quantidade de pacientes afetados, visto que em um único dia geralmente são realizadas muitas cirurgias de catarata e os pacientes podem estar expostos a um mesmo fator de risco. ${ }^{20,26,63,86,91-93}$

Relatos de surtos têm sido reportados em vários países e dentre as causas mais comuns estão os medicamentos e insumos já contaminados de fábrica ou durante a manipulação, como a solução salina balanceada (BSS) ${ }^{* 64,71,91}$ e o corante azul de tripan. ${ }^{85,94}$ Contudo, muitas vezes as causas não são possíveis de serem identificadas. ${ }^{20,26,63,70,92,95-97}$ (Quadro 3)

No Brasil, além de dois relatos mais recentes, ${ }^{26,27}$ outros surtos de endoftalmite foram reportados pela Secretaria de Vigilância em Saúde por meio de seu Boletim Eletrônico Epidemiológico. No primeiro, 31 casos foram identificados e a causa foi a solução viscoelástica (SVE) previamente contaminada de fábrica que foi utilizada durante os procedimentos ${ }^{28}$. No segundo, ocorreram seis casos em um único centro oftalmológico onde a principal causa apontada foi a falta de condições sanitárias para procedimentos cirúrgicos. $^{29}$

Os microrganismos que mais comumente causam surtos de endoftalmite são os gram-negativos, sobretudo as Pseudomonas aeruginosa $^{20,26,66,85,86,92-94,98}$ seguido pelos gram-positivos ${ }^{70,95,99}$ e menos frequentemente os fungos. ${ }^{23,71}$ (Quadro 4)

Além da busca pelas causas das endoftalmites, estudos objetivaram identificar os fatores de risco relacionados a esse tipo de infecção, apesar da dificuldade metodológica frente à baixa incidência dos casos. Apisarnthanarak et al. (2008) ${ }^{95}$ identificaram como fatores de risco para endoftalmite a condição clínica do paciente com ASA>III de acordo com a classificação da Associação

${ }^{*}$ BSS - Balanced Salt Solution 
Quadro 3 - Causas prováveis ou comprovadas dos surtos de endoftalmite de acordo com o país, ano de publicação e número de casos. São Paulo, 2013

\begin{tabular}{|c|c|c|c|c|}
\hline Local & $\begin{array}{c}\text { Ano de } \\
\text { Publicação }\end{array}$ & $\begin{array}{l}\text { № de } \\
\text { casos }\end{array}$ & Causas prováveis & Causas comprovadas \\
\hline Brasil $^{28}$ & 2004 & 31 & * & Solução viscoelástica contaminado \\
\hline Alemanha $^{91}$ & 2009 & 26 & * & BSS contaminado \\
\hline Índia ${ }^{86}$ & 2009 & 20 & * & Ar condicionado \\
\hline Índia ${ }^{93}$ & 2010 & 19 & Ar condicionado & * \\
\hline Índia ${ }^{66}$ & 2012 & 11 & * & Lente intraocular contaminada \\
\hline Turquia $^{23}$ & 2011 & 9 & $\begin{array}{l}\text { Solução de antibiótico diluída e } \\
\text { utilizada para todos os pacientes no }\end{array}$ & * \\
\hline Índia ${ }^{98}$ & 2005 & 9 & * & $\begin{array}{l}\text { Caneta de facoemulsificação e tubulação interna } \\
\text { do aparelho de faco }\end{array}$ \\
\hline Turquia $^{71}$ & 2009 & 8 & BSS contaminado após manipulação & * \\
\hline Suiça ${ }^{99}$ & 2006 & 8 & $\begin{array}{l}\text { Oclusão ineficiente da incisão na } \\
\text { córnea provocada pelo bisturi de }\end{array}$ & * \\
\hline Brasil $^{27}$ & 2013 & 7 & $\begin{array}{l}\text { Vias de irrigação e aspiração } \\
\text { utilizadas sem esterilização entre os }\end{array}$ & \\
\hline$E^{\prime} \cup A^{94}$ & 2009 & 6 & * & Corante Azul de tripan contaminado \\
\hline Turquia $^{64}$ & 2011 & 5 & BSS contaminado & * \\
\hline Espanha $^{85}$ & 2006 & 4 & * & Corante Azul de tripan contaminado \\
\hline
\end{tabular}

BSS= Balanced Salt Solution; EUA= Estados Unidos da América; I/A= Irrigação e aspiração 
Quadro 4 - Número de casos relacionados a surtos de endoftalmite, de acordo com agentes etiológicos identificados e os locais onde foram realizados os estudos. São Paulo, 2013

\begin{tabular}{|c|c|c|c|c|c|c|c|c|c|c|c|c|c|c|c|c|c|c|c|c|c|c|c|}
\hline Agente etiológico País & $\begin{array}{l}\bar{\sigma}_{\widetilde{\sigma}} \\
\frac{\sigma}{\sigma} \\
\frac{\sigma}{\sigma} \\
\frac{E}{\Phi} \\
\frac{1}{\sigma}\end{array}$ & 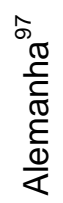 & $\begin{array}{l}\frac{\hat{v}}{\bar{D}} \\
\frac{\tilde{D}}{\bar{\omega}}\end{array}$ & 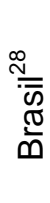 & $\begin{array}{l}\stackrel{\mathscr{N}}{\bar{m}} \\
\frac{\pi}{\infty} \\
\frac{\pi}{n}\end{array}$ & 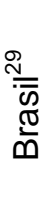 & 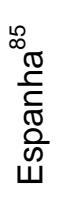 & 离 & 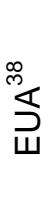 & $\frac{\stackrel{N}{\sigma}}{\frac{\sigma}{0}}$ & 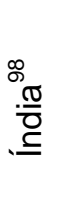 & 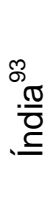 & 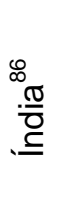 & 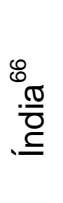 & $\begin{array}{l}\tilde{\sigma}^{\sigma} \\
. \underline{\underline{\sigma}} \\
. \underline{\subseteq}\end{array}$ & 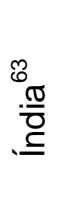 & 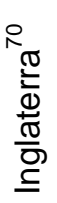 & 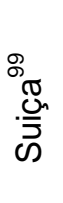 & 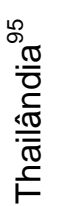 & 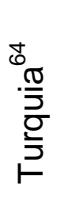 & 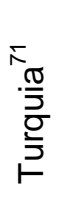 & $\frac{\substack{\frac{\pi}{5} \\
\frac{0}{5}}}{\frac{1}{5}}$ & \\
\hline Pseudomonas & & & & & 2 & 6 & 4 & 4 & & 1 & 9 & 2 & 2 & 1 & 2 & & & & & & & & 11 \\
\hline Enterobacter spp. & & & & 8 & & & & & & & & & & & & 1 & & & & & & & 27 \\
\hline Stenotrophomonas & 2 & & & & & & & & & & & & & & & & & & & 1 & & & 27 \\
\hline Fusarium spp. & & & & & & & & & & & & & & & & & & & & & 8 & 9 & 17 \\
\hline Empedobacter brevis & & 1 & & & & & & & & & & & & & & & & & & & & & 12 \\
\hline Staphylococcus & & & & & & & & & 2 & & & 5 & & & & & & 1 & & & & & 8 \\
\hline Ochrobactrum anthropi & & & 7 & & & & & & & & & & & & & & & & & & & & 7 \\
\hline Pseudomonas spp. & & & & 6 & & & & & & & & & & & & & & & 1 & & & & 7 \\
\hline Streptococcus spp. & & & & & & & & & & & & & & & & & 3 & 1 & 2 & & & & 6 \\
\hline Staphylococcus aureus & & & & & & & & & & & & 4 & & & & & 1 & & & & & & 5 \\
\hline SCN & & & & & & & & & & & & & & & & & & & 4 & & & & 4 \\
\hline Cellulosimicrobium & & & & & & & & & & & & & & & & & & & & 3 & & & 3 \\
\hline Bukholderia cepacia & & & & & & & & 2 & & & & & & & & & & & & & & & 2 \\
\hline Klebsiella spp. & & & & 1 & & & & & & & & & & & & & & & & & & & 1 \\
\hline
\end{tabular}

$S C N=$ Staphylococcus coagulase-negativo; EUA= Estados Unidos da América 
Americana dos Anestesiologistas (ASA) ${ }^{*}$, um determinado cirurgião, glicose pré-operatória $>200 \mathrm{mg} / \mathrm{dl}$ e diabetes. Outros fatores de risco como o tipo de incisão, complicação intraoperatória e LIO de silicone foram reportados em um estudo multicêntrico realizado pela Sociedade Europeia de Cirurgiões de Catarata e Refrativa (ESCRS) ${ }^{\dagger},{ }^{100}$

O não uso de cefuroxime após a cirurgia, ${ }^{77,101}$ pacientes com idade superior a 84 anos, ${ }^{77,101}$ tempo de facoemulsificação ${ }^{102}$ e pacientes do sexo masculino ${ }^{21,77}$ também foram apontados como fator de risco.

\subsection{SÍNDROME TÓXICA DO SEGMENTO ANTERIOR}

A TASS caracterizada como uma reação inflamatória aguda causada por substâncias exógenas não infecciosas ${ }^{30-32}$ apresenta uma incidência média de $0,98 \%$, variando de $0,07 \%$ a $2,13 \%$ (Quadro5).

Quadro 5 - Incidência de TASS segundo os países, ano de publicação, número de cirurgias realizadas e número de casos. São Paulo, 2013

\begin{tabular}{|c|c|c|c|c|}
\hline Local & $\begin{array}{c}\text { Ano de } \\
\text { Publicação }\end{array}$ & $\begin{array}{c}\text { Cirurgias } \\
\text { Realizadas }\end{array}$ & $\begin{array}{c}\text { Quantidade } \\
\text { de Casos }\end{array}$ & $\begin{array}{c}\text { Incidência } \\
\text { (\%) }\end{array}$ \\
\hline EUA $^{103}$ & 2006 & 2713 & 2 & 0.07 \\
\hline India $^{104}$ & 2011 & 26408 & 60 & 0,23 \\
\hline Turquia $^{105}$ & 2010 & 1742 & 14 & 0.80 \\
\hline Paquistão $^{34}$ & 2013 & 18140 & 15 & 0,80 \\
\hline Korea $^{30}$ & 2008 & 801 & 15 & 1,87 \\
\hline Turquia $^{37}$ & 2012 & 893 & 19 & 2,13 \\
\hline
\end{tabular}

$\mathrm{EUA}=$ Estados Unidos da América

Contudo, a incidência deste evento certamente está subestimada, visto que poucos estudos foram publicados com esta informação devido à dificuldade no diagnóstico e à subnotificação.

Quanto à caracterização da TASS, vários estudos descreveram detalhadamente os sinais clínicos, contribuindo para o

\footnotetext{
* ASA - American Society of Anesthesiologists

${ }^{++}$ESCRS - European Society of Cataract \& Refractive Surgeons
} 
melhor entendimento e diagnóstico diferencial. Entretanto, há uma grande variação entre os casos reportados a partir do primeiro e clássico relato por Monson, Mamalis e Olson (1992) ${ }^{106}$ Dentre os sinais observados, os mais comuns são: edema de córnea, deposição de células e fibrina na $C A,{ }^{30,33-35,107}$ seguidos por flare, ${ }^{33,34,107,108} \mathrm{BAV}^{30,34,106,107}$ e midríase..$^{30,31,34,106}$ Outros sinais menos frequentes, porém não menos importantes são: a pupila irregular e/ou não reagente ${ }^{30,31,106}$, pressão intraocular alta $^{32,33,37,106,109}$ e hipópio. ${ }^{35,107,109,110}$ O tempo para a detecção destes sinais é de 12 a 36 horas, sendo que na maioria das vezes são detectados nas primeiras 12 horas com pelo menos quatro das manifestações descritas. ${ }^{30-34}$

Quanto às características morfológicas, Avisar e Weinberger $(2010)^{108}$ compararam córneas sadias com córneas afetadas pela TASS e concluíram que as córneas afetadas eram caracterizadas pelo baixo nível de densidade das células endoteliais, alto coeficiente de variação das áreas celulares e baixa porcentagem média de células hexagonais. Os pacientes afetados não apresentam uma sintomatologia característica, sendo que em alguns casos podem apresentar baixa acuidade visual $\left.\right|^{30,106,110,111}$ e raramente dor. ${ }^{31,33,109}$

A evolução dos casos de TASS é geralmente benigna e de prognóstico favorável $\left.\right|^{33,37,109,110,112}$, porém nos casos mais graves mais da metade em média evoluem para a descompensação da córnea com necessidade da sua substituição através da cirurgia de transplante de córnea. ${ }^{30-32,35,36,113}$ Outra complicação decorrente desta síndrome é a elevação da pressão intraocular impossível de ser controlada por meio de terapia medicamentosa sendo necessária a cirurgia antiglaucomatosa. ${ }^{30-32}$

O tratamento geralmente é medicamentoso à base do uso concomitante de colírios esteroides, antibióticos e $\mathrm{NaCl}$ $5 \% .^{30,37,114,115} \mathrm{Em}$ alguns casos há a necessidade de procedimentos 
cirúrgicos adicionais como: lavagem da CA, substituição da LIO e vitrectomia anterior ou posterior. . $^{32,109,110}$

Os fatores que podem ser associados como as causas de TASS são vários e de difícil comprovação, na maioria das vezes. Pesquisadores conduziram investigações para elucidar a etiologia deste evento, mas poucos conseguiram apontar as prováveis causas suportadas por uma evidência forte ou comprovação laboratorial. ${ }^{31}$ $33,115,116$

Em outubro de 2006 foi notificada ao MDHHS ${ }^{*}$ nos Estados Unidos da América (EUA) a ocorrência de oito casos de TASS e juntamente com o Centro de Controle e Prevenção de Doenças $(C D C)^{\dagger}$ investigaram e implementaram medidas para evitar novos casos. A despeito de várias adequações nos procedimentos de limpeza e esterilização do instrumental cirúrgico como: substituição de insumos e medicamentos e revisão de equipamentos dentre outras medidas, outros quatro pacientes operados apresentaram quadro de TASS, o que levou à suspensão imediata das cirurgias de catarata. Devido às inúmeras variáveis levantadas hipoteticamente como causa, não foi possível identificar o que causou TASS nos 12 pacientes. Antes de retomar a realização das cirurgias para correção de catarata, medidas adicionais foram tomadas como: uso único das cânulas de irrigação e aspiração, troca do BSS, enxágue dos instrumentais com água estéril e interrupção do uso de detergente enzimático para lavagem dos instrumentais. A partir destas intervenções, nenhum dos 222 pacientes operados em seguida evoluiu com TASS. ${ }^{117}$

Em uma tentativa de educar os cirurgiões sobre as causas, sintomas e tratamento de TASS, membros da indústria e da Sociedade Americana de Cirurgia de Catarata e Refrativa (ASCRS) ${ }^{\ddagger}$ desenvolveram uma força tarefa cooperativa. Por meio de um

\footnotetext{
* MDHHS - Maine Department of Health and Human Services

${ }^{+} \mathrm{CDC}$ - Centers for Disease Control

${ }^{\ddagger}$ ASCRS - American Society of Cataract and Refractive Surgery
} 
questionário postado no site da ASCRS foram analisadas as respostas que incluíram as informações sobre o processo de limpeza e esterilização dos instrumentais cirúrgicos e tipo de materiais e medicamentos utilizados nas cirurgias para correção da catarata. Foram incluídos neste estudo os questionários respondidos por centros de vários países incluindo os dos EUA, Itália, Espanha, Romênia, México, Argentina e Brasil. O resultado da análise desses questionários foi complementado pelos dados obtidos por entrevista e por observação direta em visitas realizadas aos centros oftalmológicos dos EUA que apresentaram casos de TASS no período de 2005 e 2009. Dos 68 questionários inclusos na pesquisa, foram identificados 909 casos em 50.114 cirurgias realizadas e 367 casos reportados durante a visitação dos centros cirúrgicos após a realização de 143.919 cirurgias. As não conformidades mais observadas nestas visitas foram: o enxágue inadequado das canetas de facoemulsificação, vias de irrigação e aspiração e a reutilização de materiais de uso único como as cânulas e luvas de infusão "Sleeves". ${ }^{46} \mathrm{Em}$ continuidade a esse trabalho, Bodnar, Clouser e Mamalis (2012) ${ }^{118}$ fizeram uma análise retrospectiva desse mesmo banco de dados referente ao período de junho de 2009 a março de 2012 e compararam com os dados do primeiro levantamento. Neste período foram reportados pelos centros participantes a realização de aproximadamente 69.000 cirurgias com a detecção de 1454 casos de TASS sendo o processo de lavagem e esterilização e reutilização de materiais de uso único as inconformidades mais observadas.

Rose $(2012)^{119}$ relatou a ocorrência de seis casos de TASS em que não foi possível determinar a etiologia, porém, com a aquisição de um equipamento específico para lavagem de materiais canulados não surgiram novos casos ao longo de dois anos, o que sugere um nexo causal entre falha da limpeza (dos instrumentais e vias de irrigação e aspiração) e a ocorrência do TASS nas cirurgias de catarata. 
Determinar a causa de TASS não tem sido uma tarefa fácil, sendo o cenário de surto o que mais propiciou sucesso nas investigações em apontá-las ${ }^{31,33,34,103,116}$ (Quadro 6)

O uso indevido da solução de ortoftaldeído no processamento dos instrumentais cirúrgicos foi a causa apontada por Jun e Chung $(2010)^{115}$ no relato de um caso de TASS após cirurgia de catarata em que esta solução fora utilizada para deixar os instrumentais de molho antes de serem submetidos à esterilização por gás óxido de etileno (EtO) ${ }^{*}$. É importante destacar que se trata de um desinfetante e não um produto indicado para limpeza. Este produto é um desinfetante de alto nível que foi associado no passado a reações inflamatórias agudas em situações particulares em casos em que o enxágue do material submetido a desinfecção pelo produto não foi completo. Por este motivo, atualmente o fabricante do ortoftaldeído contra indica a desinfecção de cistoscópios para pacientes que se submeteram a tratamento oncológico prévio, justificado pela constatação de reação anafilática observada em estudos anteriores. Este fato sugere o potencial tóxico de eventuais resíduos do ortoftaldeído.

Outro relato do uso indevido de produto aponta para a solução de glutaraldeído como a causa de um surto de seis casos de TASS com resultados devastadores que evoluíram para a necessidade de transplante de córnea em cinco deles. Esta solução foi utilizada no processamento dos instrumentais como tratamento prévio à autoclavação sem a realização do enxágue. ${ }^{31}$ Semelhante a este relato, Huang et al. (2010) $)^{112}$ apontaram o uso de um instrumental cirúrgico esterilizado em solução de glutaraldeído como a provável causa de TASS em uma criança de oito anos após cirurgia de catarata o que levou à revisão do protocolo de esterilização dos instrumentais e insumos utilizados neste tipo de cirurgia.

${ }^{*}$ EtO - Ethylene oxide 
Quadro 6 - Causas atribuídas a TASS, segundo local, ano do estudo, número de casos e causa atribuída. São Paulo, 2013

\begin{tabular}{|c|c|c|c|c|}
\hline Local & Ano do estudo & Surto & Quant. casos & Causa atribuída \\
\hline EUA $^{116}$ & 2008 & Sim & 112 & Endotoxinas no BSS \\
\hline Índia $^{104}$ & 2011 & Não & 60 & BSS com pH 6.0 \\
\hline Turquia $^{37}$ & 2012 & Não & 19 & Esterilização em Óxido de Etileno \\
\hline EUA $^{120}$ & 2004 & Não & 16 & Detergente enzimático \\
\hline Korea $^{30}$ & 2008 & Não & 15 & Esterilização em Óxido de Etileno \\
\hline Paquistão $^{34}$ & 2013 & sim & 15 & Ringer Lactato com pH alto \\
\hline EUA $^{109}$ & 2000 & não & 10 & Pomada \\
\hline EUA $^{32}$ & 2006 & não & 8 & Sulfato \\
\hline EUA $^{103}$ & 2006 & sim & 8 & Cefuroxime intraocular \\
\hline França $^{33}$ & 2011 & sim & 6 & Glutaraldeído \\
\hline Turquia $^{31}$ & 2006 & sim & 6 & Solução Viscoelástica \\
\hline Holanda $^{111}$ & 2011 & não & 3 & Azul de Tripan \\
\hline EUA $^{35}$ & 2010 & não & 2 & Solução Viscoelástica \\
\hline Israel $^{110}$ & 2010 & não & 2 & Glutaraldeído \\
\hline China $^{112}$ & 2010 & não & 1 & Hipersensibilidade do paciente \\
\hline Korea do SUL $^{121}$ & 2007 & não & 1 & LIO \\
\hline EUA $^{114}$ & 2006 & não & 1 & Ortoftaldeído \\
\hline Korea do SUL & 2010 & não & 1 & \\
\hline
\end{tabular}

EUA: Estados Unidos da América; BSS: Balanced Salt Solution; LIO: Lente intraocular. 
Em 2004 após ter sido identificado três casos de TASS, até então conhecido pela equipe como um tipo de endoftalmite estéril, Clouser (2004), ${ }^{120}$ revisou a literatura para verificar outros casos parecidos e investigou as possíveis causas das inflamações exacerbadas característica destes casos. Ao consultar outros cirurgiões, foi levantada a possibilidade de serem casos típicos de TASS, o que foi confirmado por outro cirurgião mais experiente neste assunto.

Sem sucesso nas investigações, foi solicitada a ajuda de um consultor especialista após a ocorrência de dois casos em cinco meses e outros dois casos após quatro meses. Foram levantadas várias hipóteses, dentre elas, o fato de a solução enzimática não ter sido trocada com frequência adequada, mas sim, somente quando estivesse visivelmente suja.

Outra hipótese foi a possibilidade de evaporação da água do banho de detergente enzimático nas cubas da lavadora ultrassônica e consequente aumento na sua concentração, fato que, sem o enxágue apropriado antes da esterilização poderia ser a causa de TASS por possível introdução de resquícios de detergente enzimático dentro do olho carreados pelos instrumentais cirúrgicos. Todavia, o estudo experimental de Leder et al. (2012), ${ }^{122}$ que simulou um enxágue inadequado dos instrumentais, não dá suporte a esta hipótese ao concluir que mesmo uma quantidade elevada de resquícios de detergente não poderia ser a principal causa de TASS, assim como demonstrado no estudo de Parikh et al (2002). ${ }^{123}$ Contudo, outro especialista neste assunto questiona estas afirmações, dada as diferenças das reações em olhos de ratos comparados com os olhos humanos. ${ }^{124}$

Ari et al (2012) ${ }^{37}$ descreveram a evolução clínica de 19 casos de TASS após a realização de 893 cirurgias de catarata em crianças no período de 2006 a 2011. Os medicamentos e fluidos não fizeram parte das investigações, e a revisão e a análise dos dados das cirurgias, conduziram os autores a suspeitaram que a esterilização 
em gás EtO dos Kits para vitrectomia anterior tenha sido a causa, pois apenas os casos que utilizaram este material evoluíram com TASS e foram os primeiros casos do dia. Após a mudança no processo de esterilização com a interrupção do uso de EtO como agente esterilizante nenhum caso novo foi registrado.

Também relacionado ao EtO, Choi e Shyn $(2008)^{30}$, após a detecção de 15 casos de TASS em um período de 9 meses iniciaram uma revisão de prontuários para caracterizar os casos e procuraram as causas reavaliando os materiais e medicamentos utilizados, bem como o processo de esterilização dos instrumentais.

Embora os autores admitam a limitação do estudo em provar a etiologia dos casos de TASS, a esterilização por EtO foi apontada como a causa mais provável, visto que após adotarem a autoclavação dos materiais ao invés do EtO não houve mais casos semelhantes ao longo de dois anos subsequentes. Contudo, esta hipótese não se mostrou confiável de acordo com o estudo de Calogero et al. (2012) ${ }^{125}$ que avaliou a reação intraocular causada pelo EtO em um estudo com ratos e constatou que este não está associado ao TASS.

Hellinger et al.(2006) ${ }^{103}$, investigaram as causas de um surto de 8 casos de TASS após a realização de 21 cirurgias de catarata. Depois de descartados vários fatores que pudessem ser associados aos casos, foi dada atenção à qualidade da água utilizada no processo de limpeza e esterilização bem como a manutenção dos equipamentos utilizados e chegaram à conclusão de que apesar do surto possivelmente ter sido multifatorial em sua etiologia, o sulfato foi uma das impurezas encontradas na água do reservatório da autoclave podendo ser apontado como o principal fator associado aos casos de TASS.

Kutty et al. (2008) $)^{116}$ apresentaram o resultado de uma investigação nacional desencadeada a partir de quatro casos de TASS reportados ao CDC nos EUA que envolveu sete centros 
oftalmológicos em seis estados diferentes. Foram realizados testes para detecção e quantificação de toxinas e contaminantes microbianos nas soluções utilizadas no hospital quais sejam: lubrificantes, anestésicos, BSS, polivinilpirrolidona-iodo (PVP-I) e anti-inflamatórios, dentre outros. O CDC reportou que dentre os produtos testados, o BSS estava com alto nível de Endotoxinas de $0.908 \mathrm{EU} / \mathrm{mL}$ em média, variando de 0.515 à $2.234 \mathrm{EU} / \mathrm{mL}$, portanto muito maior que o limite permitido para soluções parenterais que é de $0.5 \mathrm{EU} / \mathrm{mL}$. Os produtos da marca testada foram retirados do mercado, o que resultou na interrupção dos surtos que até então já havia chegado a 112 casos.

Em parceria com o Food and Drug Administration (FDA), Buchen et al. $(2012)^{126}$ conduziram um experimento em um modelo animal para avaliar o teor máximo permitido de endotoxinas nas soluções para uso intraocular. Os autores concluíram que o limite estabelecido para soluções endovenosas de $0,5 \mathrm{EU} / \mathrm{ml}$ podem ser associados à inflamação ocular após as cirurgias oftalmológicas. $\mathrm{O}$ estudo demonstrou que uma concentração de Endotoxinas na ordem de $0,25 \mathrm{EU} / \mathrm{mL}$ e $0,75 \mathrm{EU} / \mathrm{mL}$ pode ter capacidade para causar depósitos de células na superfície de LIO, flare e RCA, porém sem causar edema de córnea. Os autores expressam a preocupação quanto a potencialidade de reação inflamatória com o atual nível de Endotoxinas aceito para soluções de irrigação intraocular e SVE similares a soluções parenterais.

Reforçando estes achados, outro estudo experimental investigou a concentração mínima de endotoxinas capazes de causar TASS em olhos de ratos e concluiu que uma concentração de $0,23 \mathrm{EU} / \mathrm{mL}$ é capaz de causar reação inflamatória no segmento anterior do olho. ${ }^{127}$

Relacionado ao BSS, Sengupta et al. (2011) ${ }^{104}$ reportaram 60 casos de TASS. Em 31 deles a etiologia permaneceu desconhecida, porém houve dois aglomerados de casos em que foram apontadas como causas, respectivamente o pH de 6.0 do BSS 
(aglomerado de 12 casos) e um determinado lote de SVE (aglomerado de 17 casos).

Outros relatos também sugeriram a SVE como provável causa de TASS em pacientes com alta miopia que ainda não tinham catarata, mas que foram submetidos à implantação de um tipo de LIO sem a remoção do cristalino. Kremer, Levinger e Levinger $(2010)^{110}$ levantaram a suspeita da SVE como a causa de TASS por ter sido usada nos dois pacientes acometidos por TASS que haviam sido submetidos a esta modalidade de cirurgia e não nos demais. Embora não tenha sido realizada uma investigação que dê suporte a esta hipótese, esta foi reforçada pelo fato da SVE ficar em contato por mais tempo com os tecidos da CA do olho, principalmente a íris e o endotélio corneano, quando comparado à cirurgia de catarata convencional pela técnica de facoemulsificação.

Van Philips (2011) ${ }^{111}$ em um relato similar manteve a hipótese de que a SVE tenha sido o agente causador da TASS, embora tenha considerado outras possíveis causas. Diferentemente destes estudos, Mathys, Cohen e Bagnell $(2008)^{128}$ observaram em aproximadamente 20 pacientes uma pequena quantidade de material opaco desconhecido entre a cápsula posterior e a LIO. Após ampla análise laboratorial, concluíram que o material era resquícios de SVE utilizado durante a cirurgia e que em um período de dois meses não causaram reação inflamatória.

Corantes e antibióticos intraoculares durante a cirurgia e pomadas utilizadas no curativo ao final também são apontados como potenciais causadores de TASS. Buzard et al. (2010) ${ }^{35}$ reportaram dois casos de TASS relacionados ao uso do corante azul de tripan de marca genérica que após análises laboratoriais se mostraram quase três vezes mais tóxicos que o original. Os autores puderam apontar este corante como causa, por ter sido o único medicamento diferente utilizado nos dois casos que desenvolveram TASS dentre 10 cirurgias realizadas no mesmo dia e pelo mesmo cirurgião. Em 
outro surto de TASS de pacientes operados no mesmo dia pelo mesmo cirurgião, constatou-se que a causa foi a administração em elevada concentração de antibiótico intraocular. Um cirurgião, que usou pela primeira vez cefuroxime na CA do olho após a cirurgia, diluiu a medicação na enfermaria deixando de fazer a rediluição, injetando de 40 a $50 \mathrm{mg}$ ao invés de $1 \mathrm{mg}{ }^{33}$

Werner et al. $(2006)^{32}$ relataram detalhadamente as características clínicas de oito casos de TASS após cirurgias de catarata realizadas pelo mesmo cirurgião em um centro oftalmológico. Todos os casos tinham em comum, resquícios de óleo proveniente da pomada oftálmica utilizada sob o curativo após a cirurgia e encontrada na superfície das LIO explantadas. A pomada oftálmica foi apontada como a etiologia dos casos, que evoluíram em sua maioria para a substituição da LIO e quatro dos oito casos tiveram a necessidade de transplante de córnea.

Embora a pomada tenha sido fortemente associada como a causa, outros estudos mostraram uma reação inerte deste mesmo produto. Chen et al. (2005) ${ }^{129}$ relataram o caso de um paciente que teve resquícios de pomada depositada na superfície da LIO por mais de um ano sem causar reação inflamatória, semelhante aos estudos de Wong e Bank (2006) ${ }^{130}$ e Humayun, Gottlieb e Rafuse (2006) ${ }^{131}$ em que resquícios da pomada na $\mathrm{CA}$ do olho não foram suficientes para causar reação inflamatória.

Jehan et al. (2000) ${ }^{109}$ relataram a ocorrência de 10 casos após cirurgias de catarata realizadas por dois oftalmologistas em dois centros oftalmológicos nos EUA. Foi enviado aos cirurgiões envolvidos um questionário contendo questões que incluíram o histórico dos pacientes envolvidos, evolução clínica da inflamação e dados peri-operatórios como: equipamentos e medicamentos utilizados e o pessoal envolvido.

A análise destes questionários permitiu a caracterização dos casos e a evolução clínica, além de possibilitar a investigação da causa. Os autores postularam ser a LIO a provável causa, visto que 
todos os casos utilizaram o mesmo tipo e marca, além do fato de esta LIO ter sido retirada do mercado pela própria empresa fabricante após outros relatos de eventos adversos. ${ }^{109}$

Também relacionado ao tipo de lente, Moshirfar et al. $(2006)^{114}$ apesar de terem considerado outras prováveis causas, alertam para a possibilidade de um tipo específico de LIO ter sido a causa. 




\title{
3 REFERENCIAL TEÓRICO
}

\subsection{VIGILÂNCIA EPIDEMIOLÓGICA COMO FERRAMENTA PARA O MONITORAMENTO DE EA}

\begin{abstract}
A Lei $8080 / 90^{132}$ define vigilância epidemiológica como:
[...] um conjunto de ações que proporcionam o conhecimento, a detecção ou prevenção de qualquer mudança nos fatores determinantes e condicionantes de saúde individual ou coletiva, com a finalidade de recomendar e adotar as medidas de prevenção e controle das doenças ou agravos.
\end{abstract}

O seu propósito é fornecer aos profissionais de saúde orientação técnica e informações de forma permanente e contínua que por sua vez irá evitar ou diminuir a subnotificação e subsidiar as ações para prevenção e controle dos agravos à saúde. ${ }^{44,133-135}$

Um sistema de VE permite estimar a magnitude da morbidade e mortalidade de um agravo, documentar a disseminação de doenças e auxiliar na a identificação de fatores de risco. Além disto, favorece a identificação de problemas emergentes em saúde, direciona as recomendações para medidas de prevenção e controle e permite a avaliação do impacto destas medidas. A VE também contribui para o acompanhamento de tendências e a detecção de epidemias. Todo o processo envolvido em um sistema de VE auxilia na revisão de práticas e definição de prioridades em saúde. No entanto, entre as limitações de um sistema de VE estão a subnotificação, a baixa representatividade, o baixo grau de oportunidade e a inconsistência na definição de caso. ${ }^{136}$

No caso da VE para infecções do sítio cirúrgico (ISC), a subnotificação é apontada como uma das dificuldades da operacionalização da $\mathrm{VE}^{134}$ o que leva as $\mathrm{CCIH}$ utilizarem algumas estratégias para evitá-la como: a instituição de ambulatórios específicos para avaliação de presença de infecção nos 
pacientes ${ }^{45,137}$ e busca ativa através de contatos telefônico com os pacientes operados que já tiveram alta hospitalar. ${ }^{133,138}$ Dentre estas, a melhor opção para uma vigilância com qualidade é o ambulatório de egressos cirúrgicos; contudo, quando a única opção é a vigilância por meio de contato telefônico deve-se levar em consideração algumas fragilidades deste método como a superestimação da incidência de ISC. ${ }^{45}$

Esta estratégia tem sido cada vez mais utilizada pelas instituições, visto que mais de $50 \%$ das instituições que participaram como notificantes ao sistema de vigilância epidemiológicas das infecções hospitalares do estado de São Paulo em 2005 informaram que fizeram vigilância pós-alta. ${ }^{139}$ Estudos que buscaram avaliar a eficácia da vigilância pós-alta, constatou que as taxas são maiores quando se faz este tipo de VE, o que confirma a subnotificação na falta desta. ${ }^{45,133,137,138,140}$

Não obstante, o amplo espaço quanto à VE de IRAS que conta inclusive com iniciativa e programa governamental de monitoramento, ${ }^{141}$ as cirurgias de catarata não estão contempladas em nenhuma iniciativa governamental com vistas ao seu monitoramento, a despeito de seu volume e importância quanto a gravidade dos EA a que estas estão potencialmente sujeitas.

A infecção intraocular após cirurgia de catarata com implante de LIO se enquadra nos critérios nacionais de IRAS em que é considerado como infecção hospitalar quando ocorre nos primeiros 30 dias após a cirurgia ou até um ano, por ter sido implantado uma prótese. ${ }^{142}$ Contudo, algumas características particulares das cirurgias de catarata como o pequeno tempo de permanência na instituição (em geral, não mais que 12 horas) e o grande número de cirurgias realizadas dificultam o estabelecimento de um sistema de VE. Diante disso é necessário viabilizar ferramentas para VE de modo que a busca pelos casos possa ser realizado pelo enfermeiro a partir de definições e critérios previamente estabelecidos apenas 
utilizando a revisão dos prontuários ou outras estratégias complementares. É evidente que um sistema completo de VE não prescinde da participação do profissional médico, no entanto, instrumentalizar os enfermeiros para a participação no processo é uma forma de aumentar a captação de casos e reduzir a subnotificação.

Para isso a simplicidade deve ser utilizada como um princípio orientador dos sistemas de vigilância, tendo em vista facilitar a operacionalização e reduzir os custos. ${ }^{135,143}$ Neste contexto podemos lançar mão de recursos como a criação de impressos próprios para as anotações médicas voltadas para a facilidade de compilação dos dados por outros profissionais e o uso da informática em que se pode construir um banco de dados passível de ser utilizado por enfermeiros como já salientado por Nichiata et al $(2003)^{144}$ sobre os benefícios de seu uso.

Isto pode responder até certo ponto ao questionamento de Freixas, Salles e Garcia $(2009)^{145}$ sobre que recursos são necessários para o trabalho do enfermeiro visto os desafios do enfermeiro de controle de infecção e a sobrecarga de trabalho e competências deste profissional na atualidade.

Como um dos papéis da enfermagem na prevenção e controle de IRAS, ${ }^{146}$ o enfermeiro tem plenas condições de implantar e conduzir um sistema de VE em centros oftalmológicos, utilizando de sua formação e conhecimento de epidemiologia e estatística, a exemplo de Florence Nightingale, que com medidas simples e viáveis diminuiu a mortalidade associadas à infecções. ${ }^{147}$ Podemos considerar seu trabalho como a origem da pesquisa em enfermagem ${ }^{148}$ e que influenciou as áreas de controle de infecção e epidemiologia hospitalar. ${ }^{149}$

Como mencionado por Freixas, Salles e Garcia $(2009)^{145} \mathrm{O}$ enfermeiro de controle de infecção tem a missão de prevenir os EA e frente a cada atividade realizada deve-se ter certeza de que está resolvendo os problemas e promovendo uma melhoria para o 
paciente. No momento em que o paciente tem a percepção do esforço da instituição em acompanhar os índices de infecção, isto pode ter influência positiva na credibilidade dos serviços prestados. ${ }^{45}$

$\mathrm{Na}$ perspectiva de um cenário em que no futuro possa ser possível um sistema de vigilância em nível nacional deste tipo de agravo com a finalidade de avaliação dos serviços prestados ao SUS e detecção de surtos nestas instituições prestadoras, é necessário primordialmente instituir no âmbito dos serviços de saúde um sistema de VE que seja capaz de identificar e rastrear todos os seus casos de EA.

\subsection{MARCADORES}

De acordo com o vocabulário dos Descritores em Ciências da Saúde (DeCS), os marcadores são definidos como:

\footnotetext{
Parâmetros biológicos mensuráveis e quantificáveis ( $p$. ex., concentração específica de enzima, concentração específica de hormônio, distribuição fenotípica de um gene específico em uma população, presença de substâncias biológicas) que servem como índices para avaliações relacionadas com a saúde e com a fisiologia, como risco para desenvolver uma doença, distúrbios psiquiátricos, exposição ambiental e seus efeitos, diagnóstico de doenças, processos metabólicos, abuso na utilização de substâncias, gravidez, desenvolvimento de linhagem celular, estudos epidemiológicos, etc.
}

Neste estudo, o termo marcador será atribuído às características da apresentação clínica e epidemiológica que se mostrarem adequadas para a identificação dos casos suspeitos de acordo com as diferenças apresentadas entre os pacientes acometidos e não acometidos pelos eventos adversos estudados. 


\section{JUSTIFICATIVA DA PESQUISA}

O elevado volume cirúrgico oftalmológico é uma realidade no Brasil, particularmente as cirurgias de extração de catarata na rede do SUS, o que aponta para a exposição de um grande contingente de indivíduos a potenciais $E A$ em decorrência destes procedimentos.

A falta de conhecimento do enfermeiro frente aos EA estudados bem como a falta de um processo de trabalho organizado com vistas à VE sistematizada e permanente destes eventos limitam ações preventivas, detecção de casos e investigação de surtos. Por isso faz-se necessário caracterizar epidemiologicamente os EA de forma que o enfermeiro seja capaz de identificar os casos independentemente da notificação pelo profissional médico e criar uma estrutura e processo de trabalho para vigilância epidemiológica.

O presente estudo poderá oferecer subsídios para o estabelecimento de um sistema de VE para estes EA associados à cirurgia de catarata com potencial aplicabilidade em larga escala com vistas à tomada de decisões e planejamento em saúde. 




\section{OBJETIVOS}

\subsection{OBJETIVO GERAL}

Identificar os marcadores relevantes para o diagnóstico epidemiológico de eventos adversos de TASS e Endoftalmite visando à instituição de um sistema de vigilância epidemiológica específico.

\subsection{OBJETIVOS ESPECÍFICOS}

I Conhecer as características clínicas e epidemiológicas do pósoperatório dos pacientes com diagnóstico de eventos adversos após cirurgias de catarata

II. Conhecer as características clínicas e epidemiológicas do pósoperatório de pacientes sem diagnóstico de eventos adversos após cirurgias de catarata.

III Identificar as diferenças na apresentação clínica no pós-operatório entre os pacientes com e sem eventos adversos após cirurgia de catarata.

IV Propor uma ferramenta para a coleta e armazenamento de dados para o sistema de vigilância epidemiológica visando a atuação do enfermeiro. 




\section{MÉTODO}

\subsection{DELINEAMENTO DO ESTUDO}

Trata-se de um estudo longitudinal de série de casos realizado em duas etapas, com abordagens prospectiva e retrospectiva. A opção por duas abordagens na linha do tempo se deu em função da característica epidemiológica dos eventos observados.

Visando a melhor qualidade possível das informações contidas nos prontuários, optou-se pela abordagem prospectiva dos casos de indivíduos sem EA. Entretanto, em função das restrições de tempo para a realização do estudo, foi necessário adotar a abordagem retrospectiva para a avaliação de casos de ocorrência de EA, pela necessidade de aglutinar um maior número de casos.

\subsubsection{Etapa 1}

\subsubsection{Delineamento}

Estudo longitudinal retrospectivo de série de casos por meio de revisão de prontuários dos pacientes com diagnóstico de EA (endoftalmite e TASS) no período de abril/2010 a fevereiro/2013. (35 meses) 


\subsubsection{Sujeitos}

Pacientes submetidos à cirurgia para extração da catarata com diagnóstico de TASS ou Endoftalmite, realizado pelo médico assistente no processo da rotina assistencial, no período do estudo. Foram excluídos os pacientes que não fizeram um acompanhamento de no mínimo 3 meses pelo COTC ou que não compareceram em todos os retornos programados. Todos os prontuários foram avaliados até o último retorno do paciente antes da alta do ambulatório.

\subsubsection{Etapa 2}

\subsubsection{Delineamento}

Estudo longitudinal prospectivo de série de casos por meio de revisão de prontuários dos pacientes submetidos à cirurgia de catarata nos meses de maio e junho de 2013.

\subsubsection{Sujeitos}

Todos os pacientes submetidos à cirurgia de catarata no período do estudo, que não tenham evoluído para diagnóstico de endoftalmite ou TASS. Foram excluídos os pacientes que não fizeram um acompanhamento de no mínimo três meses pelo COTC ou que não compareceram em todos os retornos programados. Todos os prontuários foram avaliados até o último retorno do paciente antes da alta do ambulatório. 


\subsection{LOCAL}

A pesquisa foi realizada no Centro de Oftalmologia Tadeu Cvintal (СОTC), uma instituição filantrópica que atende exclusivamente pacientes do SUS, localizada no município de São Paulo e credenciada pelo Ministério da Educação e Cultura como instituição de ensino para residência médica em oftalmologia. São realizados aproximadamente 17.000 atendimentos ambulatoriais e 4.500 cirurgias oftalmológicas por ano, sendo que mais de $90 \%$ são cirurgias para extração da catarata.

No período do estudo esta instituição executou os procedimentos cirúrgicos em um centro cirúrgico alocado em uma instituição hospitalar no município de São Paulo, a saber, Hospital Silvio Romero, o qual é caracterizado como hospital-dia. Entretanto, o atendimento pré e pós-operatório ocorreu exclusivamente nas dependências da instituição do estudo.

Como parte da rotina, os pacientes foram avaliados no primeiro dia após a cirurgia e, nas situações em que não houve nenhuma intercorrência, os demais retornos rotineiros foram em torno do $8^{\circ}$ e $40^{\circ}$ dia. Esta avaliação foi realizada no ambulatório do COTC pelos médicos da instituição como parte integrante do processo da linha de cuidado do paciente cirúrgico e todas as informações foram registradas no mesmo prontuário do paciente em que foram feitos os registros da cirurgia.

Para uma melhor qualidade das informações, foi desenvolvido e utilizado um impresso específico para as anotações médicas no pós-operatório dos pacientes, o qual foi incorporado como impresso de rotina a partir de maio/2012. (APÊNDICE A) 


\subsection{VARIÁVEIS PARA ANÁLISE}

\subsubsection{Caracterização geral, clínica e oftalmológica do paciente} no momento da cirurgia.

- Idade

- Sexo

- Presença de diabetes (conforme registrado pelo médico no prontuário no momento da anamnese na primeira consulta).

- Presença de hipertensão arterial sistêmica (conforme registrado pelo médico no prontuário no momento da anamnese na primeira consulta).

- Acuidade visual pré-operatória (APÊNDICE B)

\subsubsection{Características clínicas e epidemiológicas pós-operatória}

As variáveis coletadas foram escolhidas por serem frequentemente citadas na literatura como sinais e sintomas dos eventos adversos.

- Córnea nebulosa (sim/não)

- Desepitelização da córnea (sim/não)

- Dobras na Descemet (sim/não)

- Edema de córnea (sim/não)

- Edema palpebral (sim/não)

- Flare na câmara anterior do olho (sim/não)

- Hifema (sim/não)

- Hiperemia conjuntival (sim/não)

- Hipópio (sim/não)

- Injeção ciliar (sim/não)

- Membrana inflamatória sobre a LIO (sim/não)

- Midríase (sim/não) 
- Precipitados ceráticos (PC) (sim/não)

- Presença de fibrina na câmara anterior do olho (sim/não)

- Pupila irregular (sim/não)

- Reação de câmara anterior (sim/não)

- Relato de dor ocular (sim/não)

- Seidel (sim/não)

- Trave Vítrea (sim/não)

- Vitreíte (sim/não)

- Vítreo turvo (sim/não)

\subsubsection{Outras variáveis}

Estas variáveis foram escolhidas pela hipótese de potencial diferença entre as duas amostras, podendo vir a ser incorporados como marcadores para o sistema de vigilância.

- Acuidade visual pós-operatória

- Dias para o diagnóstico (número de dias entre a data da cirurgia e a data da hipótese diagnóstico documentada pelo médico em prontuário)

- Número de retornos (número de consultas de retorno no acompanhamento pós-operatório)

- Reintervenções cirúrgicas (tipo de cirurgias realizadas como intervenções terapêuticas subsequentes e relacionadas ao olho operado para extração de catarata)

\subsection{COLETA DE DADOS}

Os dados foram coletados apenas pelo pesquisador a partir da avaliação dos prontuários do COTC. As informações médicas presentes foram consideradas como sim ou não e as ausentes foram registradas como não informadas. Os dados foram armazenados 
diretamente em um banco de dados elaborado pelo próprio pesquisador para esta finalidade, utilizando-se o programa Epi Info versão 7.1.2.0 (Centers for Disease Control and Prevention, Atlanta, GA)

\subsection{DESFECHO}

Foram considerados como EA os casos em que no pósoperatório das cirurgias de catarata evoluíram com um dos eventos que se seguem, tendo como critério de referência o diagnóstico confirmado por um médico oftalmologista da instituição em até seis semanas após a realização da cirurgia.

Endoftalmite pós-operatória, definida como uma infecção confinada ao interior do globo ocular é caracterizada pela presença no pós-operatório de queda acentuada da acuidade visual, dor, hipópio, reação de câmara anterior, turvação vítrea, presença de fibrina, hiperemia conjuntival e edema palpebral, sendo que nem todos os casos apresentam todos os sinais acima mencionados, porém pelo menos três deles.

TASS, definido como uma reação inflamatória intraocular aguda caracterizada pela presença no pós-operatório de queda acentuada da acuidade visual, edema de córnea, reação de câmara anterior, presença de fibrina e pressão intraocular elevada, sendo que nem todos os casos apresentam todos os sinais acima mencionados, porém pelo menos três deles.

\subsection{ASPECTOS ESTATÍSTICOS}

O cálculo amostral foi baseado em um teste de proporções entre duas amostras. Assumindo que a amostra de controles 
(indivíduos sem a apresentação dos EA em estudo) seria 15 vezes maior que a de casos (indivíduos com a apresentação de pelo menos um dos EA em estudo), para detectar uma diferença na de pelo menos 35 pontos percentuais na de apresentação de características clínicas entre os dois grupos com erro tipo I de 5\% e poder do teste de $90 \%$, foram necessários 21 casos e 308 controles. A opção pela diferença de 35 pontos percentuais foi arbitrada pelo pesquisador levando-se em consideração a necessidade de não elencar número excessivo de marcadores, mas sim selecionar aqueles cuja diferença na apresentação entre os casos com e sem os EA apresentasse maior relevância.

Foi utilizado o programa Epi Info versão 7.1.2.0 (Centers for Disease Control and Prevention, Atlanta, GA) para a análise de dados. Realizou-se estatística descritiva por meio de frequências relativas e absolutas.

\subsection{ASPÉCTOS ÉTICOS}

Por se tratar de um estudo observacional por meio de revisão de prontuários, não foi necessário o Termo Livre e Esclarecido de consentimento para os pacientes. Foi obtida a autorização formal para a utilização dos prontuários e publicação dos resultados pela instituição onde se deu o estudo, garantindo a preservação do sigilo das informações e seu uso apenas para fins científicos. (ANEXO 1)

O projeto de pesquisa foi submetido e aprovado pelo Comitê de Ética em Pesquisa da Escola de Enfermagem da Universidade de São Paulo (CEP-EEUSP) CAAE: 01039912.3.0000.5392, no dia 18 de março de 2013. (ANEXO 2) 




\section{RESULTADOS}

\subsection{ETAPA 1}

A amostra dos pacientes com EA foi composta por oito $(38,1 \%)$ mulheres e $13(61,9 \%)$ homens, totalizando 21 casos. A média de idade foi de 68,3 anos (variação 47 a 83 anos; DP 9) sendo que $9(42,9 \%)$ dos pacientes tinham idade superior a 70 anos.

Dentre todos os pacientes, sete $(33,3 \%)$ informaram ser portadores de diabetes e nove $(42,9 \%)$ informaram ser portadores de hipertensão arterial sistêmica (HAS).

Endoftalmite foi o diagnóstico de 19 (90,5\%) casos e dois casos $(9,5 \%)$ foram diagnosticados como TASS. Dentre os 14 $(66,7 \%)$ casos em que foram enviadas amostras para cultura, não houve crescimento microbiano em oito $(57,1 \%)$ delas. Dentre os sete casos com crescimento microbiano, três $(1,4 \%)$ casos foram identificados Stpahylococcus coagulase negativo, seguido por dois $(14,3 \%)$ Streptococcus spp. e um $(7,1 \%) S$. aureus.

O tempo para o diagnóstico dos casos após a realização da cirurgia foi em média 7,2 dias (variando de 1 a $30 \mathrm{DP}=8,5$ ). A maioria deles, $11(52,4 \%)$, foi diagnosticada após o terceiro dia pósoperatório. (Quadro 7)

Os sinais observados com maior frequência no dia do diagnóstico, presentes em mais que $70 \%$ dos pacientes foram: córnea nebulosa, RCA e edema de córnea. (Quadro 8)

Estavam presentes em mais que $40 \%$ dos casos os sinais: hipópio, hiperemia conjuntival, turvação vítrea e dobras na membrana Descemet. Em menos que 30\% dos casos, foi observada a presença de fibrina na CA, membrana inflamatória sobre a LIO, edema palpebral, precipitados ceráticos, trave vítrea, injeção ciliar e 
flare. Foi observada a presença de seidel, desepitelização da córnea, hifema e vitreíte em menos que $10 \%$ dos casos. Midríase ou pupila irregular não foram observadas em caso algum. (Tabela 1)

Dentre as reintervenções necessárias para o tratamento do EA após o diagnóstico, a aplicação de antibiótico intravítreo foi realizada em todos os casos em ambiente cirúrgico. Em 13 (61,9\%) casos houve a necessidade de duas reintervenções cirúrgicas e em três casos foram necessárias mais que duas reintervenções.

O número de retornos dos pacientes acometidos pelo EA foi em média 14,3 (variação 8 a 25; DP 4,5). (Quadro 7)

Quanto à $A V$ destes pacientes antes da cirurgia de catarata, quatro (19\%) tinham visão melhor que $20 / 60$ e em nove $(42,9 \%)$ casos o grau de AV variou entre $20 / 60$ e 20/200. Oito (38,1\%) pacientes já tinham visão igual ou pior que $C D$ no momento da indicação da cirurgia. A AVF, avaliada pelo menos após dois meses de acompanhamento, foi pior que 20/50 na maioria dos casos $17(54,6 \%)$ sendo que sete $(33,3 \%)$ dentre todos os casos evoluíram para visão igual ou pior que CD. (Tabela 2 )

\subsection{ETAPA 2}

A amostra dos pacientes sem EA foi composta por 192 $(62,1 \%)$ mulheres e 117 (37,9\%) homens, totalizando 309 casos. A média de idade foi de 68,3 anos (variação 41 a 95; anos, DP 9,6) sendo que $140(45,3 \%)$ dos pacientes tinham idade superior a 70 anos.(Tabela 3)

Informaram serem portadores de diabetes 85 (28\%) pacientes e $167(54,9 \%)$ relataram ter hipertensão arterial sistêmica como uma de suas comorbidades. 
Tabela 1 - Sinais e sintomas observados ao exame ou relatados pelo paciente no pós-operatório dos pacientes submetidos à cirurgia de catarata de acordo com a presença ou ausência de evento adverso (Endoftalmite e TASS). São Paulo. 2013

\begin{tabular}{|c|c|c|c|c|c|c|c|c|c|c|c|}
\hline \multirow{3}{*}{ Sinal } & \multicolumn{3}{|c|}{ Com eventos adversos $^{\dagger} \mathrm{n}=21$} & \multicolumn{3}{|c|}{$\begin{array}{c}\text { Sem eventos adversos }^{\ddagger} \mathrm{n}=309 \\
\text { (primeiro pós-operatório) }\end{array}$} & \multirow{3}{*}{$\begin{array}{l}\text { Diferença } \\
\text { Percentual }\end{array}$} & \multicolumn{3}{|c|}{$\begin{array}{l}\text { Sem eventos adversos* } n=309 \\
\text { (segundo retorno pós-operatório) }\end{array}$} & \multirow{3}{*}{$\begin{array}{l}\text { Diferença } \\
\text { Percentual }\end{array}$} \\
\hline & Sim & Não & $\mathrm{NI}$ & Sim & Não & $\mathrm{NI}$ & & Sim & Não & $\mathrm{NI}$ & \\
\hline & n (\%) & n (\%) & n (\%) & n (\%) & n (\%) & n (\%) & & n (\%) & n (\%) & n (\%) & \\
\hline Córnea nebulosa & $18(85,7)$ & $3(14,3)$ & 0 & $138(44,7)$ & $156(50,5)$ & $15(4,9)$ & 41,1 & $105(34)$ & $191(61,8)$ & $13(4,2)$ & 51,7 \\
\hline Desepitelização & $1(4,8)$ & $16(76,2)$ & $4(19)$ & $22(7,1)$ & $270(87,4)$ & $17(5,5)$ & $-2,4$ & $2(0,6)$ & $57(18,4)$ & $250(80,9)$ & 4,1 \\
\hline Dobras na Descemet & $9(42,9)$ & $10(47,6)$ & $2(9,5)$ & $159(51,5)$ & $148(47,9)$ & $2(0,6)$ & $-8,6$ & $108(35)$ & $145(46,9)$ & $56(18,1)$ & 7,9 \\
\hline Dor ocular & $14(66,7)$ & $7(33,3)$ & 0 & $82(26,5)$ & $221(71,5)$ & $6(1,9)$ & 40,1 & $1(0,3)$ & $273(88,3)$ & $35(11,3)$ & 66,3 \\
\hline Edema de córnea & $15(71,4)$ & $5(23,8)$ & $1(4,8)$ & $209(67,6)$ & $98(31,7)$ & $2(0,6)$ & 3,8 & $62(20,1)$ & $217(70,2)$ & $30(9,7)$ & 51,4 \\
\hline Edema Palpebral & $4(19)$ & $12(57,1)$ & $5(23,8)$ & $98(31,7)$ & $200(64,7)$ & $11(3,6)$ & $-12,7$ & $1(0,3)$ & $31(10)$ & $277(89,6)$ & 18,7 \\
\hline Fibrina & $6(28,6)$ & $10(47,6)$ & $5(23,8)$ & $10(3,2)$ & $296(95,8)$ & $3(1)$ & 25,3 & $1(0,3)$ & $88(28,5)$ & $220(71,2)$ & 28,2 \\
\hline Flare & $2(9,5)$ & $12(57,1)$ & $7(33,3)$ & $75(24,3)$ & $223(72,2)$ & $11(3,6)$ & $-14,7$ & $5(1,6)$ & $88(28,5)$ & $216(69,9)$ & 7,9 \\
\hline Hifema & $1(4,8)$ & $17(81)$ & $3(14,3)$ & $4(1,3)$ & $302(97,7)$ & $3(1)$ & 3,5 & 0 & $83(26,9)$ & $226(73,1)$ & 4,8 \\
\hline Hiperemia Conjuntival & $12(57,1)$ & $6(28,6)$ & $3(14,3)$ & $184(59,5)$ & $119(38,5)$ & $6(1,9)$ & $-2,4$ & $7(2,3)$ & $29(9,4)$ & $273(88,3)$ & 54,9 \\
\hline Hipópio & $13(61,9)$ & $8(38,1)$ & 0 & $5(1,6)$ & $303(98,1)$ & $1(0,3)$ & 60,3 & 0 & $217(70,2)$ & $92(29,8)$ & 61,9 \\
\hline Injeção Ciliar & $3(14,3)$ & $12(57,1)$ & $6(28,6)$ & $47(15,2)$ & $228(73,8)$ & $34(11)$ & $-0,9$ & $1(0,3)$ & $33(10,7)$ & $275(89)$ & 14,0 \\
\hline MI sobre a LIO & $6(28,6)$ & $12(57,1)$ & $3(14,3)$ & $6(1,9)$ & $297(96,1)$ & $6(1,9)$ & 26,6 & $4(1,3)$ & $92(29,8)$ & $213(68,9)$ & 27,3 \\
\hline Midríase & 0 & $17(81)$ & $4(19)$ & $24(7,8)$ & $282(91,3)$ & $3(1)$ & $-7,8$ & $3(1)$ & $293(94,8)$ & $13(4,2)$ & 1,0 \\
\hline Precipitados ceráticos & $5(23,8)$ & $12(57,1)$ & $4(19)$ & $5(1,6)$ & $298(96,4)$ & $6(1,9)$ & 22,2 & $1(0,3)$ & $90(29,1)$ & $218(70,6)$ & $\begin{array}{r}23,5 \\
\text { (continua) }\end{array}$ \\
\hline
\end{tabular}


(continuação)

\begin{tabular}{|c|c|c|c|c|c|c|c|c|c|c|c|}
\hline & \multicolumn{3}{|c|}{ Com eventos adversos $^{\dagger} \mathrm{n}=21$} & \multicolumn{3}{|c|}{$\begin{array}{l}\text { Sem eventos adversos }{ }^{\ddagger} n=309 \\
\text { (primeiro pós-operatório) }\end{array}$} & \multirow{3}{*}{$\begin{array}{l}\text {-Diferença } \\
\text { Percentual }\end{array}$} & \multicolumn{3}{|c|}{$\begin{array}{l}\text { Sem eventos adversos }{ }^{*} \mathrm{n}=309 \\
\text { (segundo retorno pós-operatório) }\end{array}$} & \multirow{3}{*}{$\begin{array}{l}\text {-Diferença } \\
\text { Percentual }\end{array}$} \\
\hline & Sim & Não & $\mathrm{NI}$ & Sim & Não & $\mathrm{NI}$ & & Sim & Não & $\mathrm{NI}$ & \\
\hline & n (\%) & n (\%) & n (\%) & n (\%) & $\mathrm{n}(\%)$ & n (\%) & & n (\%) & n (\%) & n (\%) & \\
\hline Pupila Irregular & 0 & $17(81)$ & $4(19)$ & $11(3,6)$ & $297(96,1)$ & $1(0,3)$ & $-3,6$ & 0 & $296(95,8)$ & $13(4,2)$ & 0 \\
\hline Reação de CA & $18(85,7)$ & $1(4,8)$ & $2(9,5)$ & $251(81,2)$ & $48(15,5)$ & $10(3,2)$ & 4,5 & $57(18,4)$ & $236(76,4)$ & $16(5,2)$ & 67,3 \\
\hline Seidel & $1(4,8)$ & $20(95,2)$ & 0 & $15(4,9)$ & $281(90,9)$ & $13(4,2)$ & $-0,1$ & 0 & $263(85,1)$ & $46(14,9)$ & 4,8 \\
\hline Trave Vítrea & $5(23,8)$ & $16(76,2)$ & 0 & $1(0,3)$ & $303(98,1)$ & $5(1,6)$ & 23,5 & $3(1)$ & $131(42,4)$ & $175(56,6)$ & 22,8 \\
\hline Vitreíte & $1(4,8)$ & $19(90,5)$ & $1(4,8)$ & 0 & $304(98,4)$ & $5(1,6)$ & 4,8 & $1(0,3)$ & $134(43,4)$ & $174(56,3)$ & 4,4 \\
\hline Vítreo Turvo & $10(47,6)$ & $11(52,4)$ & 0 & 0 & $303(98,1)$ & $6(1,9)$ & 47,6 & $1(0,3)$ & $274(88,7)$ & $34(11)$ & 47,3 \\
\hline $\begin{array}{l}\text { †Dados referer } \\
\text { (conclusão) } \\
\text { †Referente ao } 1^{\circ} \\
{ }^{*} \text { Média de } 9,1 \text { dia } \\
\mathrm{NI}=\text { Não informad } \\
\text { Diferença percent } \\
\text { Nota: Os valores }\end{array}$ & $\begin{array}{l}\text { s ao } \\
\text { após a ci } \\
\text { variando } c \\
\text { l= }[\% \text { de } p \\
\text { egativos } s\end{array}$ & $\begin{array}{l}\text { ia do } \\
\text { rgia } \\
5 \text { a } 17 \text { DF } \\
\text { sença no }\end{array}$ & $\begin{array}{l}\text { diagnós } \\
=2 \text { ). } \\
\text { casos c }\end{array}$ & eventos & sos] - [\% c & dias & (variando & $\mathrm{de}$ & a 30 & $8,5)$ & \\
\hline
\end{tabular}


Quadro 7 - Distribuição dos casos de eventos adversos de acordo com sexo, idade, dias para o diagnóstico, acuidade visual (AV) ao diagnóstico, 1ำ Reintervenção, 2ํㅜㄹ Reintervenção, ํำ de retornos e acuidade visual final (AVF). São

Paulo, 2013

\begin{tabular}{|c|c|c|c|c|c|c|c|c|}
\hline Caso & SEXO & IDADE & $\begin{array}{l}\text { Dias para o } \\
\text { diagnóstico }\end{array}$ & $\begin{array}{c}\mathrm{AV} \text { ao } \\
\text { diagnóstico }\end{array}$ & 1ㅇ Reintervenção & 2 Reintervenção & $\begin{array}{c}\text { N DE } \\
\text { RETORNOS }^{\ddagger}\end{array}$ & AVF \\
\hline 1 & $\mathrm{M}$ & 68 & 27 & $\mathrm{CD}$ & Injeção de ATB intravítreo & & 14 & $20 / 200$ \\
\hline 2 & $\mathrm{M}$ & 71 & 2 & MM & Vitrectomia posterior + Injeção de ATB intravítreo & Vitrectomia anterior* & 11 & NPL \\
\hline 3 & $\mathrm{M}$ & 72 & 8 & $\mathrm{NI}$ & Injeção de ATB intravítreo & Vitrectomia posterior & 17 & $20 / 30$ \\
\hline 4 & $\mathrm{M}$ & 66 & 14 & MM & Injeção de ATB intravítreo & & 16 & $20 / 40$ \\
\hline 5 & $\mathrm{M}$ & 75 & 8 & PL & Vitrectomia posterior + Injeção de ATB intravítreo & Vitrectomia posterior & 12 & $20 / 20$ \\
\hline 6 & $\mathrm{~F}$ & 58 & 8 & MM & Lavagem da câmara anterior + Injeção de ATB intravítreo & Vitrectomia posterior & 19 & $20 / 70$ \\
\hline 7 & $\mathrm{M}$ & 69 & 30 & MM & Vitrectomia posterior + Injeção de ATB intravítreo & Injeção de ATB intravítreo & 22 & NPL \\
\hline 8 & $\mathrm{M}$ & 63 & 20 & MM & Injeção de ATB intravítreo & Vitrectomia posterior & 20 & $20 / 70$ \\
\hline 9 & $\mathrm{M}$ & 54 & 1 & $\mathrm{NI}$ & Vitrectomia posterior + Injeção de ATB intravítreo & Retinopexia & 17 & $20 / 70$ \\
\hline 10 & $\mathrm{~F}$ & 72 & 2 & MM & Injeção de ATB intravítreo & Vitrectomia posterior* $^{*}$ & 25 & $\mathrm{PL}$ \\
\hline 11 & $\mathrm{~F}$ & 64 & 2 & MM & Lavagem da câmara anterior + Injeção de ATB intravítreo & & 8 & PL \\
\hline 12 & $\mathrm{~F}$ & 67 & 4 & MM & Vitrectomia posterior + Injeção de ATB intravítreo & & 18 & $20 / 70$ \\
\hline 13 & $\mathrm{~F}$ & 61 & 1 & $\mathrm{CD}$ & Injeção de ATB intravítreo & & 12 & $20 / 70$ \\
\hline 14 & $\mathrm{~F}$ & 83 & 5 & MM & Vitrectomia posterior + Injeção de ATB intravítreo & Injeção de ATB intravítreo* & 9 & NPL \\
\hline 15 & $\mathrm{~F}$ & 47 & 1 & $20 / 200$ & $\begin{array}{l}\text { Lavagem da câmara anterior + Injeção de ATB intravítreo + } \\
\text { explante da LIO }\end{array}$ & & 11 & NPL \\
\hline 16 & $\mathrm{M}$ & 80 & 1 & $\mathrm{NI}$ & Vitrectomia posterior + Injeção de ATB intravítreo & Vitrectomia posterior & 11 & $20 / 200$ \\
\hline 17 & $\mathrm{M}$ & 68 & 2 & MM & Vitrectomia posterior + Injeção de ATB intravítreo & Injeção de ATB intravítreo & 13 & $20 / 70$ \\
\hline 18 & M & 75 & 6 & PL & Vitrectomia posterior + Injeção de ATB intravítreo & & 12 & CD \\
\hline 19 & $\mathrm{M}$ & 60 & 2 & $\mathrm{CD}$ & Lavagem da câmara anterior + Injeção de ATB intravítreo & Injeção de ATB intravítreo & 12 & $20 / 100$ \\
\hline 20 & $\mathrm{M}$ & 80 & 2 & MM & Vitrectomia anterior & & 11 & $20 / 50$ \\
\hline 21 & $\mathrm{~F}$ & 77 & 5 & MM & Lavagem da câmara anterior + Injeção de ATB intravítreo & Injeção de ATB intravítreo & 10 & $20 / 200$ \\
\hline
\end{tabular}

$\mathrm{CD}=$ Conta dedos; $\mathrm{NI}=$ Não informado; $\mathrm{MM}=$ Movimento de mãos; $\mathrm{PL}=$ Percepção de luz; $\mathrm{ATB}=\mathrm{Antibiótico;} \mathrm{LIO}=\mathrm{Lente}$ intraocular; NPL= Não

percebe a luz.

${ }^{*}$ Pacientes que necessitaram que mais de duas reintervenção cirúrgicas após o diagnóstico de evento adverso. $\ddagger$ Até 60 dias após a cirurgia de catarata. 
Quadro 8 - Distribuição dos casos segundo o EA e sinais e sintomas observados ao exame ou relatados pelo paciente no pós-operatório dos pacientes submetidos à cirurgia de catarata de acordo com o tipo de evento adverso no dia do diagnóstico. São Paulo, 2013

\begin{tabular}{|c|c|c|c|c|c|c|c|c|c|c|c|c|c|c|c|}
\hline Caso & Evento adverso & BAV & Dor & $\begin{array}{c}\text { Edema } \\
\text { palpebral }\end{array}$ & $\begin{array}{l}\text { Hiperemia } \\
\text { conjuntival }\end{array}$ & $\begin{array}{c}\text { Edema } \\
\text { de } \\
\text { córnea }\end{array}$ & $\begin{array}{l}\text { Córnea } \\
\text { nebulosa }\end{array}$ & \begin{tabular}{|c} 
Dobras \\
na \\
Descemet
\end{tabular} & RCA & $\begin{array}{c}\text { Fibrina } \\
\text { na CA }\end{array}$ & Flare & $\begin{array}{l}\text { Precipitados } \\
\text { ceráticos }\end{array}$ & Hipópio & \begin{tabular}{|c|} 
MI \\
sobre \\
a LIO \\
\end{tabular} & $\begin{array}{c}\text { MI } \\
\text { pupilar }\end{array}$ \\
\hline 1 & ENDOFTALMITE & + & + & - & + & + & + & + & + & - & - & - & + & - & - \\
\hline 2 & ENDOFTALMITE & + & - & - & + & + & + & + & - & - & - & - & - & - & - \\
\hline 3 & ENDOFTALMITE & * & + & * & + & + & + & - & * & * & * & * & - & - & - \\
\hline 4 & TASS & + & + & - & + & + & + & + & + & * & * & * & + & * & + \\
\hline 5 & ENDOFTALMITE & + & + & - & + & - & - & - & + & - & - & - & - & + & + \\
\hline 6 & ENDOFTALMITE & + & + & - & + & + & + & - & + & + & * & + & - & + & - \\
\hline 7 & ENDOFTALMITE & + & - & - & + & * & + & * & + & * & * & + & + & * & * \\
\hline 8 & ENDOFTALMITE & + & + & * & * & + & + & - & + & * & * & + & - & - & - \\
\hline 9 & ENDOFTALMITE & * & - & - & - & + & - & - & + & - & - & - & - & - & - \\
\hline 10 & ENDOFTALMITE & + & + & + & + & + & + & + & + & + & - & - & + & * & * \\
\hline 11 & ENDOFTALMITE & + & + & - & - & + & + & + & + & - & - & - & + & + & - \\
\hline 12 & ENDOFTALMITE & + & - & * & * & + & + & - & + & - & + & + & - & - & - \\
\hline 13 & ENDOFTALMITE & + & + & - & - & - & - & - & + & - & + & - & + & - & - \\
\hline 14 & ENDOFTALMITE & + & + & + & + & + & + & + & * & - & - & - & + & - & - \\
\hline 15 & ENDOFTALMITE & + & - & + & + & - & + & - & + & + & - & - & + & + & - \\
\hline 16 & ENDOFTALMITE & * & + & - & - & + & + & + & + & - & - & - & + & - & - \\
\hline 17 & ENDOFTALMITE & + & + & + & + & + & + & + & + & + & - & - & + & - & + \\
\hline 18 & ENDOFTALMITE & + & + & * & + & - & + & - & + & - & * & * & - & - & + \\
\hline 19 & ENDOFTALMITE & + & - & - & - & - & + & * & + & * & * & * & + & + & - \\
\hline 20 & TASS & + & - & * & * & + & + & + & + & + & - & - & + & + & - \\
\hline 21 & ENDOFTALMITE & + & + & - & - & + & + & - & + & + & - & + & + & - & - \\
\hline
\end{tabular}

$(+)=$ Presente; $(-)=$ Ausente; $\left({ }^{*}\right)=$ Não informado. 
Tabela 2 - Acuidade pré e pós-operatória dos pacientes submetidos à cirurgia de catarata de acordo com a presença ou ausência de evento adverso. São Paulo. 2013

\begin{tabular}{|c|c|c|c|c|}
\hline \multirow{3}{*}{$\begin{array}{l}\text { ACUIDADE } \\
\text { VISUAL }\end{array}$} & \multicolumn{2}{|c|}{ Pré-operatória } & \multicolumn{2}{|c|}{ Pós-operatória* } \\
\hline & $\begin{array}{c}\text { Com } \\
\text { eventos } \\
\text { adversos } \\
\mathrm{N}=21\end{array}$ & $\begin{array}{c}\text { Sem } \\
\text { eventos } \\
\text { adversos } \\
\mathrm{N}=309\end{array}$ & $\begin{array}{c}\text { Com } \\
\text { eventos } \\
\text { adversos } \\
\mathrm{N}=21\end{array}$ & $\begin{array}{c}\text { Sem } \\
\text { eventos } \\
\text { adversos } \\
N=309\end{array}$ \\
\hline & n (\%) & n (\%) & n (\%) & n (\%) \\
\hline $20 / 20$ a $20 / 25$ & 0 & 0 & $17(5,5)$ & $1(4,8)$ \\
\hline $20 / 30$ a $20 / 50$ & $4(19)$ & $63(20,4)$ & $204(66)$ & $3(14,3)$ \\
\hline $20 / 60$ a $20 / 200$ & $9(42,9)$ & $152(49,2)$ & $76(24,6)$ & $10(47,6)$ \\
\hline CD ou PIOR & $8(38,1)$ & $94(30,4)$ & $12(3,9)$ & $7(33,3)$ \\
\hline
\end{tabular}

$\mathrm{CD}=$ Conta dedos; *Após 60 dias da realização da cirurgia

Ao exame ambulatorial no primeiro dia após a cirurgia, mais da metade apresentaram RCA, edema de córnea, hiperemia conjuntival e dobras na Descemet. Nebulosidade na córnea foi observada em 138 (44,7\%) pacientes e edema palpebral em 98 $(31,7 \%)$. Outros sinais menos frequentes foram a injeção ciliar e flare. Em menos de $2 \%$ dos casos foi detectada a presença de hipópio e nenhum caso apresentou turvação vítrea. Dor ocular foi relatado por $82(26,5 \%)$ pacientes. (Tabela 1$)$

Tabela 3 - Faixa etária dos pacientes submetidos à cirurgia de catarata de acordo com a presença ou ausência de evento adverso. São Paulo. 2013

\begin{tabular}{cccc}
\hline Faixa etária & Com eventos & & Sem eventos \\
\cline { 2 - 2 } (em anos) & $\mathbf{n}(\%)$ & $\mathbf{n}(\%)$ \\
\hline$<51$ & $1(4,8)$ & $13(4,2)$ \\
$51-60$ & $3(14,3)$ & $53(17,2)$ \\
$61-70$ & $8(38,1)$ & $103(33,3)$ \\
$71-80$ & $8(38,1)$ & $112(36,2)$ \\
$>80$ & $1(4,8)$ & $28(9,1)$ \\
\hline
\end{tabular}

O segundo retorno do paciente para acompanhamento pósoperatório aconteceu em média no nono dia (variação 5 a 17; DP= 2) e com uma característica clínica dos sinais e sintomas diferente que as observadas no primeiro dia após a cirurgia. Todos os sinais ou sintomas foram observados em menos que $36 \%$ dos casos. 
Os dois sinais mais observados foram dobras na Descemet em 108 (35\%) pacientes e nebulosidade da córnea em 105 (34\%). Edema de córnea foi detectado em 62 (20,1\%) pacientes e em 57 $(18,4 \%)$ casos foi observada a presença de RCA. Os demais sinais e sintomas estavam presentes em menos que 2,5\% dos casos. (Tabela 1)

Quanto à necessidade de outro procedimento cirúrgico decorrente da evolução pós-operatória, três pacientes foram submetidos aos procedimentos para reposicionamento de LIO, sutura de córnea ou vitrectomia anterior, procedimentos estes que não têm relação com os eventos adversos estudados, mas sim em função de deslocamento da LIO, presença de seidel ou restos de material cortical na câmara anterior, respectivamente.

O número de retornos dos pacientes que não foram acometidos por um dos EA pesquisados foi em média 3,2 (variação 3 a 7; DP 0,6) sendo que 297 (96,1\%) dos pacientes necessitaram de no máximo quatro retornos no período de dois meses.

No momento da indicação da cirurgia, a $\mathrm{AV}$ destes pacientes era pior que 20/50 em 246 (79,6\%) dos casos e dentre estes, 94 $(38,2 \%)$ apresentavam AV igual ou pior que CD. Ao final do acompanhamento ambulatorial a AVF dos pacientes sem eventos adversos estava melhor ou igual a 20/50 em 221 (71,5\%). Em 88 (28,5\%) pacientes foi confirmada uma AVF igual ou pior que 20/60. Dentre todos os casos, $12(3,9 \%)$ tiveram AVF ou pior que CD. (Tabela 2)

Os sinais apresentados no primeiro dia após a cirurgia que tiveram uma diferença maior que $35 \%$ quando comparados com os pacientes com e sem evento adverso foram: presença de hipópio, vítreo turvo, córnea nebulosa e dor ocular. Além destes, no segundo retorno, em média no nono dia após a cirurgia, apresentaram uma diferença maior que $35 \%$ os sinais: RCA, hiperemia conjuntival e edema de córnea. (Tabela 1) 


\subsection{CONSTRUÇÃO DA FERRAMENTA PARA VE}

A partir dos resultados obtidos nos estudos de série de casos, elaborou-se uma ferramenta para contribuir na implantação de um sistema de VE para EA após cirurgia de catarata.

A ferramenta para a instituição da VE para os EA estudados é um formulário para coleta sistemática dos dados para posterior análise quanto a suspeita e confirmação de diagnóstico de TASS ou endoftalmite. (APÊNDICE C)

Como complemento, será necessária a utilização de um banco de dados eletrônico para o armazenamento e tabulação dos dados coletados.

\subsubsection{Identificação e seleção dos marcadores}

Para a escolha dos sinais e sintomas que serão utilizados como marcadores para compor a ferramenta para VE foram levados em consideração os seguintes aspectos:

- Todos os sinais e sintomas que apresentaram uma diferença maior que 35 pontos percentuais entre os pacientes com e sem EA foram considerados elegíveis, a saber: córnea nebulosa, dor ocular, edema de córnea, hiperemia conjuntival, hipópio, reação de $\mathrm{CA}$, vítreo turvo.

- Cinco dos principais sinais inerentes aos pacientes com EA também são comuns em mais da metade dos pacientes sem o EA no primeiro dia pós-operatório, a saber: RCA, edema de córnea, hiperemia conjuntival e dobras na Descemet.

- O quadro clínico no segundo retorno dos pacientes sem EA também apresenta alguns sinais de reação inflamatória, 
porém com menor frequência em relação ao primeiro retorno, a saber, edema de córnea e RCA.

- A nebulosidade da córnea foi observada em 105 (34\%) dos pacientes sem EA mesmo no segundo retorno, o que contra indica seu uso como um marcador, mesmo tendo sido considerado como elegível na análise preliminar.

Posto isto, os sinais e sintomas que tem potencialidade para servir como marcadores e utilizados em um sistema de VE são: dor, edema de córnea, hiperemia conjuntival, hipópio, RCA e vítreo turvo.

Outros componentes selecionados para incorporação na ferramenta de VE foram: número de retornos pós-operatório no período de dois meses e injeção intravítreo de antibiótico no pósoperatório.

Estes marcadores foram escolhidos por terem apresentado uma diferença marcante entre os pacientes com e sem EA.

\subsubsection{Critério para inclusão de casos a serem monitorados por meio da ferramenta de VE}

Os casos que deverão ter as informações registradas na ficha de VE são dos pacientes que tiveram um número de retornos maior do que quatro no período de dois meses. Em outras palavras, para os pacientes com este número de retorno deve-se possuir um alto grau de suspeita de ocorrência de um dos EA em questão.

A escolha deste número de retornos se deu pelo fato de 297 $(96,1 \%)$ pacientes sem EA terem tido no máximo quatro retornos em dois meses de acompanhamento pós-operatório. Levando-se em conta este achado e os dados da literatura, isto significa que será necessário este processo de trabalho em menos de 10\% dos pacientes operados. 


\subsubsection{Processo sugerido para monitoramento de EA pós- cirurgias de catarata}

- Os dados deverão ser verificados rotineiramente no registro de pacientes depois de decorridos dois meses da data da cirurgia de catarata. Entretanto, pacientes com suspeita de qualquer EA indicada pelo médico, poderão, a qualquer momento, ser incorporados ao monitoramento.

- O momento ideal para a coleta dos dados é na consulta anterior ao da primeira reintervenção no período pósoperatório (quando indicada), a saber: Injeção de antibiótico intravítreo, vitrectomia posterior, vitrectomia anterior e lavagem de câmara anterior. Esta recomendação se deve ao fato de que, em geral, as informações referentes aos marcadores selecionados estarão possivelmente disponíveis neste momento.

- Os casos não elegíveis para o monitoramento de suspeita de EA deverão ser registrados no banco de dados eletrônico como "não suspeitos". Apenas serão necessárias as informações: nome, prontuário, cirurgia realizada e data da cirurgia. Estas informações irão compor o denominador para o cálculo de indicadores de incidência no sistema de VE.

- Como sugestão de banco de dados, o programa Epi Info versão 7.1.2.0 (Centers for Disease Control and Prevention, Atlanta, GA) é uma opção por servir também para análises estatísticas, a partir dos dados armazenados. Trata-se de um software de domínio público criado pelo CDC, voltado para a área da saúde no campo da epidemiologia, que possui instruções de fácil manejo para instalação e operação. (APÊNDICE D) 


\subsubsection{Critério para definição dos casos}

\subsubsection{Caso suspeito}

Todos os pacientes que tiveram um número de retornos maior do que quatro no período de dois meses e apresentarem resposta positiva para quaisquer dois dos seguintes itens:

- Dor

- Edema de córnea

- Hiperemia conjuntival

- Reação de CA

\subsubsection{Caso confirmado}

Serão considerados como confirmados os casos que atenderem a um dos critérios abaixo descritos:

- Apresentar ao mesmo tempo dois dos três itens com resposta positiva: hipópio, vítreo turvo ou resultado de cultura positivo.

- Cirurgia de vitrectomia posterior combinada com aplicação de antibiótico intravítreo.

- Diagnóstico clínico de um médico retinólogo

\section{Observações:}

Quando houver crescimento microbiano na cultura de humor vítreo, o diagnóstico será sempre de endoftalmite.

A definição do tipo de EA (endoftalmite ou TASS) deverá ser feita exclusivamente pelo médico retinólogo quando não houver resultado de crescimento microbiano na cultura de humor vítreo. 


\section{DISCUSSÃO}

Considerando que 1.807 .650 cirurgias de catarata foram realizadas pelo SUS de 2008 a 2012 e a média da incidência de endoftalmite e TASS juntas que foram reportadas na literatura é de aproximadamente $1,0 \%$, podemos presumir que quase $20 \mathrm{mil}$ pessoas foram acometidas por um destes eventos nos últimos cinco anos no Brasil.

O aumento da população idosa em uma curva ascendente é esperada para as próximas décadas no Brasil como projetado pela Organização Mundial da Saúde ${ }^{150}$ e pelo Instituto Brasileiro de Geografia e Estatística (IBGE) em 2008.(ANEXO 3) Consequentemente, este aumento tende a ser acompanhado por problemas de saúde relacionados à senilidade como a catarata ${ }^{6,150} \mathrm{e}$ para as adequadas intervenções na recuperação ou prevenção da perda da visão será necessária a atuação de diferentes profissionais de saúde ${ }^{151}$ tendo em vista o perfil destes pacientes.

Estudos que buscaram conhecer o perfil destes pacientes demonstraram que se trata de pacientes idosos com baixa escolaridade e baixo poder aquisitivo ${ }^{8,12,13}$ que estão predispostos a uma condição de vulnerabilidade capaz de limitar sua capacidade de enfrentamento diante de situações de agravo da sua saúde. Situação esta que se torna ainda mais complexa quando não há uma devida orientação dos profissionais de saúde quanto ao seu acompanhamento pós-operatório e também o apoio da família. ${ }^{152}$

A família é geralmente a melhor ou às vezes a única opção para o idoso lidar com suas debilidades relacionadas aos problemas de saúde, principalmente aqueles que o limitam nas tarefas básicas e de autocuidado, ${ }^{152,153}$ portanto são as pessoas que devem ser devidamente orientadas pelo enfermeiro quanto ao déficit de visão do paciente durante sua recuperação após a cirurgia. 
O déficit de visão em decorrência da catarata em um idoso pode acarretar a diminuição na capacidade de autocuidado e dificultar o cumprimento de tarefas básicas do seu cotidiano como cozinhar, locomover, ler e assistir TV. ${ }^{154,155}$ Assim, a correção cirúrgica da catarata proporciona a estes pacientes uma melhor qualidade de vida, ${ }^{154}$ que segundo Rodrigues, Watanabe e Derntl $(2006)^{156}$ passa a ser para estes pacientes a ideia de estar saudável. Entretanto, a ocorrência de EA pode frustrar a expectativa dos pacientes quanto aos benefícios deste procedimento.

Além dos efeitos físicos do bom resultado desta cirurgia, há um ganho para os pacientes no que ser refere ao aspecto psicossocial advindo da melhora na interação destes pacientes. ${ }^{157}$ O estudo de Ribeiro et al. (2004) ${ }^{158}$ investigou a associação entre a presença de sintomas depressivos e a deficiência visual causada por catarata e concluiu que há associação entre aspectos depressivos em idosos com baixa acuidade visual e que há uma melhora nas alterações emocionais ligadas à depressão com a recuperação da visão após cirurgia de catarata.

As alterações em sua rotina provocadas pelo comprometimento de sua saúde pode privá-lo da realização das atividades prazerosas e extra familiares. ${ }^{153} \mathrm{Um}$ destes comprometimentos é a evolução não satisfatória da cirurgia da catarata ou, mesmo que transitório, o processo de reestabelecimento da visão durante uma recuperação pós-operatória prolongada. $\mathrm{O}$ quadro clínico experimentado por estes pacientes pode variar bastante, tanto na intensidade, quanto ao tempo decorrido.

Diferente de estudos anteriores, a presente pesquisa mostrou não apenas as características clínicas e epidemiológicas pósoperatória dos pacientes com os EA, mas também o quadro clínico de um curso normal da evolução pós-operatória dos pacientes sem o acometimento dos EA. 
Quanto aos sinais observados nos pacientes com EA neste estudo, são semelhantes aos reportados por outros que também relataram a presença de RCA e edema de córnea em mais de $70 \%$ dos $\operatorname{casos}^{26,30,34,39,66,107}$ seguido de outros estudos que também apontaram hipópio, ${ }^{23,26,35,39,66,110}$ hiperemia conjuntival, ${ }^{26,39,80,81}$ vítreo turvo ${ }^{64,66,80,81}$ e dobras na Descemet ${ }^{30,31,111}$ como os sinais mais frequentes.

Alguns sinais que em outros estudos se mostraram frequentes entre os casos com $E A,,^{31,33,34,108,111}$ foram observados em uma frequência bem menor em nosso estudo, a saber, fibrina na CA e flare.

Assim como observado em nosso estudo, é normal e comum a reação inflamatória leve e transitória na câmara anterior do olho após as cirurgias de catarata ${ }^{159,160}$ o que dificulta a suspeita de EA na sua forma mais branda e de apresentação precoce.

Embora seja bem conhecido o quadro de endoftalmite, o seu diagnóstico diferencial frente a casos de TASS é difícil ${ }^{37,161}$ como chama a atenção o estudo de Chaudhry et al (2005), ${ }^{38}$ ao remeter às comparações da literatura em que se faz uma distinção entre eles. Informação semelhante foi reportada por Rishi et al. $(2013)^{39} \mathrm{em}$ casos de endoftalmite, mas com quadro característico de TASS. Esta dificuldade é mais um fator que propicia a subnotificação dos casos. $^{104,114}$

Houve uma diferença quanto à necessidade de reintervenções após a cirurgia de catarata. Os pacientes sem EA apenas necessitaram de reintervenções inerentes a eventos esporádicos e pontuais que não tiveram ligação com os EA estudados, enquanto aqueles que apresentaram EA tiveram no mínimo uma e em alguns casos até três reintervenções, como consequência direta dos EA ocorridos, assim como reportado pelos estudos que descreveram o tratamento dos $\operatorname{casos}^{30-32,36,67,69,76,80,81}$. 
Outras diferenças bastante evidentes foram o número de retornos necessários dos pacientes com EA, consideravelmente maior que os demais pacientes e a AVF bem melhor entre os pacientes sem o EA em relação aos demais. Na revisão da literatura realizada no presente estudo não foram encontradas informações deste tipo, provavelmente pelo fato de que nenhum dos trabalhos identificados se propôs a tecer comparações entre os casos com e sem EA, do ponto de vista da evolução clínica e do processo assistencial.

Considerando a necessidade de se propor uma ferramenta que seja útil, simples e factível de ser aplicada a ferramenta aqui proposta está baseada em um formulário específico para uso do enfermeiro na coleta de dados dos pacientes operados e a utilização de um banco de dados eletrônico para armazenamento e tabulação de destes dados.

Concomitante à VE, outras medidas devem fazer parte da rotina de trabalho do enfermeiro com vistas à cooperação multiprofissional. Neste sentido, Conner (2006) ${ }^{162}$ chama a atenção para que se mantenha uma educação continuada para os profissionais que atuam na área de processamento de artigos a propósito da potencialidade de ocorrência de TASS por falhas no processo de lavagem e esterilização dos instrumentais cirúrgicos.

No mesmo sentido da multidisciplinaridade, Kutty et al. $(2008)^{116}$ salienta da importância dos profissionais epidemiologistas em conhecer as causas de TASS. Da mesma forma, Eydelman et al. $(2012)^{159}$ explica a importância do conhecimento prévio da incidência de TASS para que quando houver um aumento nesta incidência, seja constatado em tempo oportuno, a fim de interromper a ocorrência de surtos. Johnston (2006), ${ }^{163}$ dentre várias recomendações enfatiza a necessidade de orientação aos pacientes a retornarem para consulta no ambulatório a qualquer sinal de TASS 
e para que a equipe fique atenta à ocorrência incomum de reação inflamatória no pós-operatório das cirurgias oftalmológicas.

Finalmente, no âmbito das políticas públicas se faz necessária a avaliação da qualidade dos serviços prestados pelo $\mathrm{SUS}^{7,15} \mathrm{em}$ que se leve em consideração não apenas a taxa de sucesso das cirurgias de catarata, mas também a incidência de EA.

Como limitação deste estudo, ressaltamos a impossibilidade de se fazer um estudo de caso-controle retrospectivo pela falta de informação nos prontuários antes da implantação de impresso específico para acompanhamento no pós-operatório. Outra limitação é a baixa incidência destes eventos, a qual exige um tamanho amostral muito amplo, inviabilizando estudos em tempo compatível com o proposto pela presente pesquisa.

Os resultados obtidos no presente estudo apontam para a necessidade de uma etapa seguinte, na qual deverá ser realizada a validação da ferramenta proposta, no contexto de sua utilização em um sistema de VE, aplicando-se métodos pertinentes de validação, e com o apoio de outros especialistas. 




\section{CONCLUSÕES}

Os principais sinais clínicos apresentados pelos pacientes acometidos por TASS ou endoftalmite após cirurgias de catarata foram: dobras na membrana Descemet, edema de córnea, hiperemia conjuntival, hipópio, RCA e vítreo turvo.

Os pacientes sem o diagnóstico dos eventos adversos estudado apresentaram com mais frequência os sinais de: Córnea nebulosa, edema de córnea, dobras na Descemet, hiperemia conjuntival e edema palpebral.

As diferenças na apresentação clínica no pós-operatório entre os pacientes com e sem EA foram a presença de edema de córnea, hiperemia conjuntival, hipópio, RCA e vítreo turvo, além do relato de dor pelos pacientes. Outras diferenças encontradas foram o número de retornos e necessidade de intervenções cirúrgicas e terapêuticas no período pós-operatório.

Os marcadores clínicos e epidemiológicos considerados mais adequados para compor uma ferramenta para vigilância epidemiológica foram: dor, edema de córnea, hiperemia conjuntival, hipópio, RCA, vítreo turvo, aplicação de antibiótico intravítreo e número de retornos. Estes marcadores deverão ser investigados pelo menos dois meses após a realização da cirurgia de catarata.

A ferramenta proposta por este estudo para a coleta de dados para o sistema de vigilância epidemiológica tem potencialidade para subsidiar a atuação do enfermeiro na captação e análise de dados referentes a estes EA. 




\section{REFERÊNCIAS}

1. Kara-José Jr N, Avakian A. Doenças do cristalino. In: Martins MA, Carrilho FJ, Alves VAF, Castilho EA. Clínica médica: doenças dos olhos, doenças dos ouvidos, nariz e garganta, neurologia, transtornos mentais. Barueri: Manole; 2009. p. 58 61. v.6.

2. Coelho RP. Catarata e outras doenças do cristalino. In: Bicas HEA, Jorge AAH. Oftalmologia: fundamentos e aplicações.São Paulo: Tecmedd; p. 293 - 299.2007.

3. Harper RA, Shock JP. Cristalino. In: Vaughan D, Asbury T, Riordan-Evan P. Oftalmologia Geral. $15^{\circ}$ ed. São Paulo: Atheneu; 2003. p. $158-66$

4. Brasil. Ministério da Saúde. Secretaria de Atenção à Saúde. Departamento de Atenção Especializada. Relatório de gestão: atenção especializada média e alta complexidade 2000-2005. Brasília: Ministério da Saúde; 2008. 392 p. (Série C. Projetos, Programas e Relatórios).

5. Resnikoff S, Pascolini D, Etya'ale D, Kocur I, Pararajasegaram R, Pokharel GP, et al. Global data on visual impairment in the year 2002. Bull World Health Organ. 2004;82(11):844-51.

6. Medina $\mathrm{NH}$, Muñoz $\mathrm{EH}$. Atenção à saúde ocular da pessoa idosa. Bepa. 2011;8(85):23 - 8.

7. Salomao SR, Soares FS, Berezovsky A, Araujo-Filho A, Mitsuhiro MR, Watanabe SE, et al. Prevalence and outcomes of cataract surgery in Brazil: the Sao Paulo eye study. Am J Ophthalmol. 2009;148(2):199-206.e2.

8. Salomao SR, Cinoto RW, Berezovsky A, Araujo-Filho A, Mitsuhiro MR, Mendieta L, et al. Prevalence and causes of vision impairment and blindness in older adults in Brazil: the Sao Paulo Eye Study. Ophthalmic Epidemiol. 2008;15(3):16775. 
9. Arieta CE, Oliveira DF, Lupinacci AP, Novaes P, Paccola M, Kara-José $\mathrm{N}$, et al. Cataract remains an important cause of blindness in Campinas, Brazil. Ophthalmic Epidemiol. 2009;16(1):58-63.

10. Brasil. Ministério da Saúde. Portarias 958/GM de 15 de Maio de 2008. Redefine a política nacional de procedimentos cirúrgicos eletivos de média complexidade. Diário Oficial da União, Brasília, DF. 16 mai. 2008. Seção 1: 44.

11. Brasil. Ministério da Saúde. Produção Ambulatorial do SUS Data SUS. [Internet]. Brasil; [citado 2013 set. 10]. Disponível em: http://tabnet.datasus.gov.br/cgi/tabcgi.exe?sia/cnv/qauf.def.

12. Silva LMP, Muccioli C, Belfort Jr R. Perfil socioeconômico e satisfação dos pacientes atendidos no mutirão de catarata do Instituto da Visão - UNIFESP. Arq Bras Oftalmol. 2004;67(5):737-44.

13. Kara-Junior N, Dellapi Jr R, Espindola RF. Dificuldades de acesso ao tratamento de pacientes com indicação de cirurgia de catarata nos Sistemas de Saúde Público e Privado. Arq Bras Oftalmol. 2011;74(5):323-5.

14. Caligaris LS, Medina NH, Lansingh VC, Waldman EA, YaacovPena F. Analyses of cataract surgery performed by the Unified Health System in Brazil, 2006-2007. Rev Panam Salud Publica. 2011;29(6):428-32.

15. Matai O, Schellini SA, Padovani CR. Condição ocular dos indivíduos facectomizados na região centro-oeste do estado de São Paulo:estudo populacional. Arq Bras Oftalmol. 2008;71(1):52-6.

16. Oliveira DF, Lira RP, Lupinacci AP, Paccola M, Arieta CE. Complicações de facectomias como causa de baixa visual em uma população com 50 ou mais anos de idade. Cad Saude Publica. 2008;24(10):2440-4. 
17. Soriano ES. Catarata e alterações do cristalino. In: Schor $P$, Chamon W , Belfort Jr R. Oftalmologia. São Paulo: Manole; 2004. p.269-275.(Série Guias de Medicina Ambulatorial e Hospitalar. UNIFESP).

18. Gallotti RM. Eventos adversos - o que são? Rev Assoc Med Bras. 2004;50(2):114.

19. Mendes W, Travassos C, Martins M, Marques PM. Adaptação dos instrumentos de avaliação de eventos aversos para uso em hospitais brasileiros. Rev Bras Epidemiol. 2008;11(1):55 - 66 .

20. Maltezou HC, Pappa O, Nikolopoulos G, Ftika L, Maragos A, Kaitsa $\mathrm{H}$, et al. Postcataract surgery endophthalmitis outbreak caused by multidrug-resistant Pseudomonas aeruginosa. Am J Infect Control. 2012;40(1):75-7.

21. Tan CS, Wong HK, Yang FP. Epidemiology of postoperative endophthalmitis in an Asian population: 11-year incidence and effect of intracameral antibiotic agents. J Cataract Refract Surg. 2012;38(3):425-30.

22. Luz RA, Padoveze MC, Cvintal T. Epidemiologic surveillance of postoperative endophthalmitis in a specialized ophthalmologic center in São Paulo, Brazil. Am J Infect Control. 2012;40(1):e13.

23. Gungel H, Eren MH, Pinarci EY, Altan C, Baylancicek DO, Kara $\mathrm{N}$, et al. An outbreak of Fusarium solani endophthalmitis after cataract surgery in an eye training and research hospital in Istanbul. Mycoses. 2011;54(6):e767-74.

24. Shorstein NH, Winthrop KL, Herrinton LJ. Decreased postoperative endophthalmitis rate after institution of intracameral antibiotics in a Northern California eye department. J Cataract Refract Surg. 2013;39(1):8-14. 
25. Garcia-Saenz MC, Arias-Puente A, Rodriguez-Caravaca G, Banuelos JB. Effectiveness of intracameral cefuroxime in preventing endophthalmitis after cataract surgery: Ten-year comparative study. J Cataract Refract Surg. 2010;36(2):203-7.

26. Guerra RL, Freitas B, Parcero CM, Maia Jr OO, Marback RL. An outbreak of forty five cases of Pseudomonas aeruginosa acute endophthalmitis after phacoemulsification. Arq Bras Oftalmol. 2012;75(5):344-7.

27. Mattos FB, Saraiva FP, Angotti-Neto H, Passos AF. Outbreak of Ochrobactrum anthropi endophthalmitis following cataract surgery. J Hosp Infect. 2013;83(4):337-40.

28. Brasil. SVS. Boletim eletrônico epidemiológico: Investigação sobre a ocorrência de endoftalmites pós-cirurgia de catarata Junho 2003. Ano 04 no03. [citado 2013 set. 10]. Disponível em: http://portal.saude.gov.br/portal/arquivos/pdf/Boletim_eletronico _03_ano04.pdf

29. Brasil. SVS. Boletim eletrônico epidemiológico: Surto de endoftalmite aguda após cirurgias oftalmológicas em Boa Vista - RR. Ano 07 no 05. [citado 2013 set. 10]. Disponível em: http://portal.saude.gov.br/portal/arquivos/pdf/boletim_eletronico _05_07.pdf.

30. Choi JS, Shyn KH. Development of toxic anterior segment syndrome immediately after uneventful phaco surgery. Korean J Ophthalmol. 22. Korea South2008. p. 220-7.

31. Unal M, Yucel I, Akar Y, Oner A, Altin M. Outbreak of toxic anterior segment syndrome associated with glutaraldehyde after cataract surgery. J Cataract Refract Surg. 2006;32(10):1696-701 .

32. Werner L, Sher JH, Taylor JR, Mamalis N, Nash WA, Csordas $\mathrm{JE}$, et al. Toxic anterior segment syndrome and possible association with ointment in the anterior chamber following cataract surgery. J Cataract Refract Surg. 2006;32(2):227-35. 
33. Delyfer MN, Rougier MB, Leoni S, Zhang Q, Dalbon F, Colin J, et al. Ocular toxicity after intracameral injection of very high doses of cefuroxime during cataract surgery. J Cataract Refract Surg. 2011;37(2):271-8.

34. Nizamani NB, Bhutto IA, Talpur KI. Cluster of Urrets-Zavalia syndrome: a sequel of toxic anterior segment syndrome. $\mathrm{Br} \mathrm{J}$ Ophthalmol. 2013;97(8):976-9.

35. Buzard K, Zhang JR, Thumann G, Stripecke R, Sunalp M. Two cases of toxic anterior segment syndrome from generic trypan blue. J Cataract Refract Surg. 36. United States: 2010 ASCRS and ESCRS. Published by Elsevier Inc; 2010. p. 2195-9.

36. Arslan OS, Unal M, Arici C, Gorgun E, Yenerel M, Cicik E. Descemet-stripping automated endothelial keratoplasty in eyes with toxic anterior segment syndrome after cataract surgery. $\mathrm{J}$ Cataract Refract Surg. 2010;36(6):965-9.

37. Ari S, Caca I, Sahin A, Cingu AK. Toxic anterior segment syndrome subsequent to pediatric cataract surgery. Cutan Ocul Toxicol. 2012;31(1):53-7.

38. Chaudhry NA, Lavaque AJ, Scott IU, Flynn Jr. HW, Liggett PE. A cluster of patients with acute-onset endophthalmitis following cataract surgery. Ophthalmic Surg Lasers Imaging. 2005;36(3):205-10.

39. Rishi E, Rishi P, Sengupta S, Jambulingam M, Madhavan HN, Gopal L, et al. Acute postoperative Bacillus cereus endophthalmitis mimicking toxic anterior segment syndrome. Ophthalmology. 2013;120(1):181-5.

40. Brian $\mathrm{G}$, Taylor $\mathrm{H}$. Cataract blindness-challenges for the 21st century. Bull World Health Organ. 2001;79(3):249-56.

41. Senne FM, Cardillo JA, Rocha EM, Kara-Jose N. Long-term visual outcomes in the Cataract-Free Zone Project in Brazil. Acta Ophthalmol Scand. 2002;80(3):262-6. 
42. Fernandes A. Epidemiologia das causas de deficiência visual e cegueira. In: Conselho Brasileiro de Oftalmologia (CBO). Olhares sobre o Brasil: Perspectivas da saúde ocular para o século XXI. 2ำed. São Paulo: Walprint; 2007. p 23-5.

43. Turci SR, Guilam MC, Camara MC. Epidemiologia e Saúde Coletiva: tendências da produção epidemiológica brasileira quanto ao volume, indexação e áreas de investigação - 2001 a 2006. Cien Saude Colet. 2010;15(4):1967-76.

44. Bastos LGC. Vigilância de doenças e agravos nãotransmissíveis na América Latina: o estado da arte. Mundo saude. 2005;29(1):82 - 7 .

45. Oliveira AC, Ciosak SI. Infecção de sítio cirúrgico no seguimento pós-alta: impacto na incidência e avaliação dos métodos utilizados. Rev Esc Enferm USP. 2004;38(4):379-85.

46. Cutler Peck CM, Brubaker J, Clouser S, Danford C, Edelhauser $\mathrm{HE}$, Mamalis N. Toxic anterior segment syndrome: common causes. J Cataract Refract Surg. 2010;36(7):1073-80.

47. Melo GB, Bispo PJ, Regatieri CV, Yu MC, Pignatari AC, Hofling-Lima AL. Incidência de endoftalmite após cirurgia de catarata (2002-2008) num hospital universitário brasileiro. Arq Bras Oftalmol. 2010;73(6):505-7.

48. Alves LFA, Kac MJ, Bisol T, Fernandes BF, Eskenazi DT. Síndrome tóxica do segmento anterior. Rev Bras Oftalmol. 2013;72(1):29-33.

49. Granzotto T. Anatomia do bulbo ocular. In: Putz C. Oftalmologia: ciências básicas. $2^{\circ}$ ed. Rio de Janeiro: Guanabara Koogan; 2011. p.257-484.

50. Rezende Filho F, Rezende F. Anatomia cirúrgica. In: Rezende F. Cirurgia da catarata. $2^{0}$ ed. Rio de Janeiro: Cultura Médica;2002. p.9-16. 
51. Meira DM, Oréfice F. Conceito e Classificação das uveítes. In: Uveíte: Clínca \& Cirúrgica. Rio de Janeiro: Cultura Médica; 2000. p.11- 27.

52. Rocha KM, Schor P. Cirurgia de Catarata. In: Bruno OM, Carvalho LV. Óptica e Fisiologia da Visão - Uma Abordagem Multidisciplinar. São Paulo: Roca; 2008. p. 188 - 92.

53. Neurauter R. Indicações e contra-indicações na cirurgia de catarata. In: Padilha MA. Catarata . 20 ed. Rio de Janeiro: Cultura Médica; 2008. p. 47 - 53.

54. Oliveira FB. Facectomia: técnicas intracapsular, extracapsular, facoemulsicação. In: Padilha MA. Catarata . 2oㅡ. Rio de Janeiro: Cultura Médica; 2008. p. 157 - 67.

55. Akaishi L. Complicações per e pós-operatórias. In: Rezende F. Cirurgia da catarata. $2^{\circ}$ ed. Rio de Janeiro: Cultura Médica; 2002. p.163-72.

56. Godoy G, Godoy CSO. Semiologia básica da córnea. In: CBO, Moreira CA, editor. Semiologia básica em oftalmologia. $2^{\circ}$ ed. Rio de Janeiro: Cultura Médica; 2011. p. 171-185.

57. Oréfice F, Santos DVV, Santana KG. Sinais e sintomas nas uveítes. In: Oréfice F, Santos DVV, Oréfice JL. Uveítes. 2ํe․ Rio de Janeiro: Guanabara Koogan; 2011. p. 13 - 27.

58. Kanski JJ. Oftalmologia Clínica: uma abordagem sistemática. $6^{\circ}$ ed. Rio de Janeiro: Elsevier; 2008. p.441 -455.

59. Munoz-Fernandez S, Martin-Mola E. Uveitis. Best Pract Res Clin Rheumatol. 2006;20(3):487-505.

60. Jabs DA, Nussenblatt RB, Rosenbaum JT. Standardization of uveitis nomenclature for reporting clinical data. Results of the First International Workshop. Am J Ophthalmol. 2005;140(3):509-16. 
61. Carneiro AJ, Passos D, Toledo RML, Pimenta DS. Cristalino e catarata. In: CBO. Arieta CEL, Padilha MA, editores. Semiologia básica em oftalmologia. 2o ed. Rio de Janeiro: Cultura Médica; 2011. p.147-70.

62. Krikonis TS, Panagiotoglou TD, Tsika C, Alegakis A, Pallikaris IG, Tsilimbaris MK. Endophthalmitis after cataract extraction: incidence, treatment, and outcome in Crete, Greece, during period 2000-2008. Semin Ophthalmol. 2009;24(6):234-8.

63. Korah S, Braganza A, Jacob P, Balaji V. An "epidemic" of post cataract surgery endophthalmitis by a new organism. Indian $\mathrm{J}$ Ophthalmol. 2007;55(6):464-6.

64. Akçakaya AA, Sargin F, Erbil HH, Yazici S, Yaylali SA, Mesçi C, et al. A cluster of acute-onset postoperative endophthalmitis over a 1-month period: investigation of an outbreak caused by uncommon species. Br J Ophthalmol. 2011;95(4):481-4.

65. Lloyd JC, Braga-Mele R. Incidence of postoperative endophthalmitis in a high-volume cataract surgicentre in Canada. Can J Ophthalmol. 2009;44(3):288-92.

66. Ramappa M, Majji AB, Murthy SI, Balne PK, Nalamada S, Garudadri $\mathrm{C}$, et al. An outbreak of acute post-cataract surgery Pseudomonas sp. endophthalmitis caused by contaminated hydrophilic intraocular lens solution. Ophthalmology. 2012;119(3):564-70.

67. Chen KJ, Lai CC, Sun MH, Chen TL, Yang KJ, Kuo YH, et al. Postcataract endophthalmitis caused by Enterococcus faecalis. Ocul Immunol Inflamm. 2009;17(5):364-9.

68. Carrim ZI, Richardson J, Wykes WN. Incidence and visual outcome of acute endophthalmitis after cataract surgery--the experience of an eye department in Scotland. $\mathrm{Br} \mathrm{J}$ Ophthalmol. 2009;93(6):721-5. 
69. Pijl BJ, Theelen T, Tilanus MA, Rentenaar R, Crama N. Acute endophthalmitis after cataract surgery: 250 consecutive cases treated at a tertiary referral center in the Netherlands. Am J Ophthalmol. 2010;149(3):482-7.e1-2.

70. Anderson OA, Lee V, Shafi S, Keegan D, Vafidis G. A model for the management of an atypical endophthalmitis outbreak. Eye (Lond). 2005;19(9):972-80.

71. Cakir M, Imamoglu S, Cekic O, Bozkurt E, Alagoz N, Oksuz L, et al. An outbreak of early-onset endophthalmitis caused by Fusarium species following cataract surgery. Curr Eye Res. 2009;34(11):988-95.

72. Al-Mezaine HS, Kangave D, Al-Assiri A, Al-Rajhi AA. Acuteonset nosocomial endophthalmitis after cataract surgery: incidence, clinical features, causative organisms, and visual outcomes. J Cataract Refract Surg. 2009;35(4):643-9.

73. Raen M, Sandvik GF, Drolsum L. Endophthalmitis following cataract surgery: the role of prophylactic postoperative chloramphenicol eye drops. Acta Ophthalmol. 2013;91(2):11822.

74. Cheng JH, Chang YH, Chen CL, Chen YH, Lu DW, Chen JT. Acute endophthalmitis after cataract surgery at a referral centre in Northern Taiwan: review of the causative organisms, antibiotic susceptibility, and clinical features. Eye (Lond). 2010;24(8):1359-65.

75. Cornut PL, Thuret G, Creuzot-Garcher C, Maurin M, Pechinot A, Bron A, et al. Relationship between baseline clinical data and microbiologic spectrum in 100 patients with acute postcataract endophthalmitis. Retina. 2012;32(3):549-57.

76. Ding $\mathrm{Y}$, Lin $\mathrm{M}$, Liu $\mathrm{H}$, Zhang $\mathrm{W}$, Wang L, Li Y. Outcomes of post-cataract surgery endophthalmitis referred to a tertiary center from local hospitals in the south of China. Infection. 2011;39(5):451-60. 
77. Keay L, Gower EW, Cassard SD, Tielsch JM, Schein OD. Postcataract surgery endophthalmitis in the United States: analysis of the complete 2003 to 2004 Medicare database of cataract surgeries. Ophthalmology. 2012;119(5):914-22.

78. Lin $\mathrm{M}$, Zhang $\mathrm{W}$, Liu $\mathrm{Y}$, Wang $\mathrm{L}$, Ding $\mathrm{Y}, \mathrm{Wu} \mathrm{X}$, et al. Nosocomial acute-onset postoperative endophthalmitis at a university teaching hospital in China. J Hosp Infect. 2011;79(4):323-7.

79. Wykoff CC, Parrott MB, Flynn HW, Jr., Shi W, Miller D, Alfonso EC. Nosocomial acute-onset postoperative endophthalmitis at a university teaching hospital (2002-2009). Am J Ophthalmol. 2010;150(3):392-8.e2.

80. Kodjikian L, Salvanet-Bouccara A, Grillon S, Forestier F, Seegmuller JL, Berdeaux G, et al. Postcataract acute endophthalmitis in France: national prospective survey. $J$ Cataract Refract Surg. 2009;35(1):89-97.

81. Jing Z, Yuli P, Qing G, Zhaohui L. Clinical analysis of cataract surgery complicated by endophthalmitis. Eye Science. 2012;27(3):147-51.

82. Friling $E$, Lundstrom M, Stenevi U, Montan P. Six-year incidence of endophthalmitis after cataract surgery: Swedish national study. J Cataract Refract Surg. 2013;39(1):15-21.

83. Jambulingam $M$, Parameswaran SK, Lysa $S$, Selvaraj $M$, Madhavan HN. A study on the incidence, microbiological analysis and investigations on the source of infection of postoperative infectious endophthalmitis in a tertiary care ophthalmic hospital: An 8-year study. Indian J Ophthalmol. 2010;58(4):297-302.

84. Rahimi M, Ghassemifar V, Nowroozzadeh MH. Outcome of endophthalmitis treatment in a tertiary referral center in southern Iran. Middle East Afr J Ophthalmol. 2012;19(1):10714. 
85. Mateos I, Valencia R, Torres MJ, Cantos A, Conde M, Aznar J. Nosocomial outbreak of Pseudomonas aeruginosa endophthalmitis. Infect Control Hosp Epidemiol. 2006;27(11):1249-51.

86. Pinna A, Usai D, Sechi LA, Zanetti S, Jesudasan NC, Thomas $\mathrm{PA}$, et al. An outbreak of post-cataract surgery endophthalmitis caused by Pseudomonas aeruginosa. Ophthalmology. 2009;116(12):2321-6 e1-4.

87. Romero-Aroca P, Mendez-Marin I, Salvat-Serra M, FernandezBallart J, Almena-Garcia M, Reyes-Torres J. Results at seven years after the use of intracamerular cefazolin as an endophthalmitis prophylaxis in cataract surgery. BMC Ophthalmol. 2012;24(12):2.

88. Myneni J, Desai SP, Jayamanne DG. Reduction in postoperative endophthalmitis with intracameral cefuroxime. J Hosp Infect. 2013;84(4):326-8.

89. Ravindran RD, Venkatesh R, Chang DF, Sengupta S, Gyatsho $\mathrm{J}$, Talwar B. Incidence of post-cataract endophthalmitis at Aravind Eye Hospital: outcomes of more than 42,000 consecutive cases using standardized sterilization and prophylaxis protocols. J Cataract Refract Surg. 2009;35(4):62936.

90. Freeman EE, Roy-Gagnon MH, Fortin E, Gauthier D, Popescu $\mathrm{M}$, Boisjoly $\mathrm{H}$. Rate of endophthalmitis after cataract surgery in quebec, Canada, 1996-2005. Arch Ophthalmol. 2010;128(2):230-4.

91. Horster S, Bader L, Seybold U, Eschler I, Riedel KG, Bogner JR. Stenotrophomonas maltophilia induced post-cataractsurgery endophthalmitis: Outbreak investigation and clinical courses of 26 patients. Infection. 2009;37(2):117-22.

92. Malhotra S, Mandal P, Patanker G, Agrawal D. Clinical profile and visual outcome in cluster endophthalmitis following cataract surgery in Central India. Indian J Ophthalmol. 2008;56(2):157-8. 
93. Bajimaya S, Kansakar I, Sharma BR, Byanju R. Outcome of cluster endophthalmitis in western plain region of Nepal. Kathmandu Univ Med J. 2010;8(29):102-8.

94. Sunenshine R, Schultz M, Lawrence MG, Shin S, Jensen B, Zubairi S, et al. An outbreak of postoperative gram-negative bacterial endophthalmitis associated with contaminated trypan blue ophthalmic solution. Clin Infect Dis. 2009;48(11):1580-3.

95. Apisarnthanarak A, Jirajariyavej S, Thongphubeth K, Yuekyen C, Warren DK, Fraser VJ. Outbreak of postoperative endophthalmitis in a Thai tertiary care center. Infect Control Hosp Epidemiol. 2008;29(6):564-6.

96. Chaudhry NA, Lavaque AJ, Scott IU, Flynn HW, Jr., Liggett PE. A cluster of patients with acute-onset endophthalmitis following cataract surgery. Ophthalmic Surg Lasers Imaging. 2005;36(3):205-10.

97. Janknecht $P$, Schneider CM, Ness $T$. Outbreak of Empedobacter brevis endophthalmitis after cataract extraction. Graefes Arch Clin Exp Ophthalmol. 2002;240(4):291-5.

98. Kenchappa P, Sangwan VS, Ahmed N, Rao KR, Pathengay A, Mathai $A$, et al. High-resolution genotyping of Pseudomonas aeruginosa strains linked to acute post cataract surgery endophthalmitis outbreaks in India. Ann Clin Microbiol Antimicrob. 2005;12(4):19.

99. Hugonnet S, Dosso A, Dharan S, Martin Y, Herrero ML, Regnier $\mathrm{C}$, et al. Outbreak of endophthalmitis after cataract surgery: the importance of the quality of the surgical wound. Infect Control Hosp Epidemiol. 2006;27(11):1246-8.

100. ESCRS. Prophylaxis of postoperative endophthalmitis following cataract surgery: results of the ESCRS multicenter study and identification of risk factors. J Cataract Refract Surg. 2007;33(6):978-88. 
101. Lundstrom M, Wejde G, Stenevi U, Thorburn W, Montan P. Endophthalmitis after cataract surgery: a nationwide prospective study evaluating incidence in relation to incision type and location. Ophthalmology. 2007;114(5):866-70.

102. Luz RA, Padoveze MC, Falabella P, Morais Lde C, Ghirelli W, Cvintal T. Risk factors for postoperative endophthalmitis caused by Pseudomonas aeruginosa: Possible role of environment. Am J Infect Control. 2013;41(12):1287-9.

103. Hellinger WC, Hasan SA, Bacalis LP, Thornblom DM, Beckmann SC, Blackmore C, et al. Outbreak of toxic anterior segment syndrome following cataract surgery associated with impurities in autoclave steam moisture. Infect Control Hosp Epidemiol. 2006;27(3):294-8.

104. Sengupta S, Chang DF, Gandhi R, Kenia H, Venkatesh R. Incidence and long-term outcomes of toxic anterior segment syndrome at Aravind Eye Hospital. J Cataract Refract Surg. 2011;37(9):1673-8.

105. Ozcelik ND, Eltutar K, Bilgin B. Toxic anterior segment syndrome after uncomplicated cataract surgery. Eur $\mathrm{J}$ Ophthalmol. 2010;20(1):106-14.

106. Monson MC, Mamalis N, Olson RJ. Toxic anterior segment inflammation following cataract surgery. J Cataract Refract Surg. 1992;18(2):184-9.

107. Moyle W, Yee RD, Burns JK, Biggins T. Two consecutive clusters of toxic anterior segment syndrome. Optom Vis Sci. 2013;90(1):e11-23.

108. Avisar R, Weinberger D. Corneal endothelial morphologic features in toxic anterior segment syndrome. Cornea. 2010;29(3):251-3. 
109. Jehan FS, Mamalis N, Spencer TS, Fry LL, Kerstine RS, Olson RJ. Postoperative sterile endophthalmitis (TASS) associated with the memorylens. J Cataract Refract Surg. 26. United States2000. p. 1773-7.

110. Kremer I, Levinger E, Levinger S. Toxic anterior segment syndrome following iris-supported phakic IOL implantation with viscoelastic Multivisc BD. Eur J Ophthalmol. 20. Italy2010. p. 451-3.

111. Van Philips LA. Toxic anterior segment syndrome after foldable artiflex iris-fixated phakic intraocular lens implantation. J Ophthalmol [Internet]. 2011 PMC3136180]; 2011:[982410 p.].

112. Huang $Y$, Dai $Y$, Wu $X$, Lan J, Xie L. Toxic anterior segment syndrome after pediatric cataract surgery. J AAPOS. 2010;14(5):444-6.

113. Pineda R, Jain V, Gupta $P$, Jakobiec FA. Descemet's stripping endothelial keratoplasty: an effective treatment for toxic anterior segment syndrome with histopathologic findings. Cornea. 2010;29(6):694-7.

114. Moshirfar M, Whitehead G, Beutler BC, Mamalis N. Toxic anterior segment syndrome after Verisyse iris-supported phakic intraocular lens implantation. J Cataract Refract Surg. 2006;32(7):1233-7.

115. Jun EJ, Chung SK. Toxic anterior segment syndrome after cataract surgery. J Cataract Refract Surg. 36. United States: 2010 ASCRS and ESCRS. Published by Elsevier Inc; 2010. p. 344-6.

116. Kutty PK, Forster TS, Wood-Koob C, Thayer N, Nelson RB, Berke SJ, et al. Multistate outbreak of toxic anterior segment syndrome, 2005. J Cataract Refract Surg. 2008;34(4):585-90.

117. Kelley M, Srinivasan A, Pelletier A. Toxic Anterior Segment Syndrome After Cataract Surgery - Maine, 2006. MMWR. 2007;56(25):629-30. 
118. Bodnar Z, Clouser S, Mamalis N. Toxic anterior segment syndrome: Update on the most common causes. J Cataract Refract Surg. 2012.

119. Rose V. Keeping Our Eyes on TASS: Our Experience in the Ambulatory Care Setting. Am J Infect Control. 2012;40(5):e149e50.

120. Clouser S. Toxic anterior segment syndrome: how one surgery center recognized and solved its problem. Insight. 2004;29(1):47.

121. Kim SY, Park YH, Kim HS, Lee YC. Bilateral toxic anterior segment syndrome after cataract surgery. Can $\mathrm{J}$ Ophthalmol. 2007;42(3):490-1 .

122. Leder HA, Goodkin M, Buchen SY, Calogero D, Hilmantel G, Hitchins VM, et al. An investigation of enzymatic detergents as a potential cause of toxic anterior segment syndrome. Ophthalmology. 2012;119(7):e30-5.

123. Parikh C, Sippy BD, Martin DF, Edelhauser HF. Effects of enzymatic sterilization detergents on the corneal endothelium. Arch Ophthalmol. 2002;120(2):165-72.

124. Mamalis N. ASCRS TASS task force: An ongoing journey. J Cataract Refract Surg. 2012;38(11):1883-4.

125. Calogero D, Buchen SY, Tarver ME, Hilmantel G, Lucas AD, Eydelman MB. Evaluation of intraocular reactivity to metallic and ethylene oxide contaminants of medical devices in a rabbit model. Ophthalmology. 2012;119(7):e36-42.

126. Buchen SY, Calogero D, Hilmantel G, Eydelman MB. Rabbit ocular reactivity to bacterial endotoxin contained in aqueous solution and ophthalmic viscosurgical devices. Ophthalmology. 2012;119(7):e4-e10. 
127. Sakimoto A, Sawa M, Oshida $T$, Sugaya $S$, Hirono $T$, Ishimori A. Minimum endotoxin concentration causing inflammation in the anterior segment of rabbit eyes. Jpn J Ophthalmol. 2009;53(4):425-32.

128. Mathys $\mathrm{KC}$, Cohen $\mathrm{KL}$, Bagnell $\mathrm{CR}$. Identification of unknown intraocular material after cataract surgery: evaluation of a potential cause of toxic anterior segment syndrome. J Cataract Refract Surg. 2008;34(3):465-9.

129. Chen KH, Lin SY, Li MJ, Cheng WT. Retained antibiotic ophthalmic ointment on an intraocular lens 34 months after. Am J Ophthalmol. 2005;139(4):743-5.

130. Wong JG, Bank A. Surgical removal of intraocular antibiotic ointment after routine cataract phacoemulsification. J Cataract Refract Surg. 2006;32(5):890-2.

131. Humayun M, Gottlieb CC, Rafuse PE. Intraocular ophthalmic ointment following clear corneal phacoemulsification: Clinical implications. J Cataract Refract Surg. 2006;32(12):2135-8.

132. Brasil. Lei no 8080 , de 19 de Setembro de 1990. Dispõe sobre as condições para a promoção, proteção e recuperação da saúde, a organização e o funcionamento dos serviços correspondentes e dá outras providências. [Internet]. Brasília; 1990 [citado 2013 set. 20]. Diponível em: http://www.planalto.gov.br/ccivil_03/leis//8080.htm.

133. Oliveira AC, Ciosak SI. Infecção de sítio cirúrgico em hospital universitário: vigilância pós-alta e fatores de risco. Rev Esc Enferm USP. 2007;41(2):258-63.

134. Takahashi RF, Oliveira MAC. Atuação da equipe de enfermagem na vigilância epidemiológica. In: Brasil. Instituto para o Desenvolvimento da Saúde. Universidade de São Paulo. Ministério da Saúde. Manual de Enfermagem. Brasília: Ministério da Saúde; 2001. p.220-24 (Série A. Normas e Manuais Técnicos, 135). 
135. Brasil. Ministério da Saúde, Secretaria de Vigilância em Saúde, Departamento de Vigilância Epidemiológica. Guia de vigilância epidemiológica. 7ํe ed. Brasília: Ministério da Saúde; 2009. 816 p. (Série A. Normas e Manuais Técnicos).

136. Waldman EA. Vigilância em Saúde Pública. São Paulo: Fundação Peirópolis; 1998. p.91-112. (Série Saúde \& Cidadania, 7).

137. Batista TF, Rodrigues MCS. Vigilância de infecção de sítio cirúrgico pós-alta hospitalar em hospital de ensino do Distrito Federal, Brasil: estudo descritivo retrospectivo no período 2005-2010. Epidemiol serv saúde. 2012;21(2):253 - 64.

138. Oliveira AC, Ciosak SI, D'Lorenzo C. Vigilância pós-alta e o seu impacto na incidência da infecção do sítio cirúrgico. Rev Esc Enferm USP. 2007;41(4):653-9.

139. Secretaria de Estado da Saúde de São Paulo. Divisão de Infecção Hospitalar do Centro de Vigilância Epidemiológica "Prof. Alexandre Vranjac". Coordenadoria de Controle de Doenças. Sistema de Vigilância Epidemiológica das Infecções Hospitalares do Estado de São Paulo - Análise dos dados de 2005. Rev Saude Publica. 2007;41(4):674-83.

140. Oliveira AC, Soares JL, Garcia CA, Scatena PD, D'osvaldo L, Ciosak SI. Seguimento pós-alta do paciente cirúrgico: uma análise da importância da subnotificação da incidência da infecção do sítio cirúrgico. Rev min enferm. 2003;7(1):48 - 51.

141. Padoveze MC, Falcão ACMG, Vanzeli AC, Fortaleza CMCB. Projeto Piloto: Implantação de Sistema de Vigilância Epidemiológica das Infecções Hospitalares - Direção Regional de Saúde de São José dos Campos (DIR XXI).BEPA. Ano 2; nº 22: 12 - 20. 
142. Brasil. Agência Nacional de Vigilância Sanitária(ANVISA). Sítio Cirúrgico. Critérios nacionais de infecções relacionadas à assistência à saúde [Internet]. 2009 mar. p. 1-19. [citado 2013 set. 25] Disponível em: http://www.anvisa.gov.br/servicosaude/manuais/criterios_nacio nais_ISC.pdf.

143. Lee TB, Baker OG, Lee JT, Scheckler WE, Steele L, Laxton CE. Recommended practices for surveillance. Association for Professionals in Infection Control and Epidemiology, Inc. Surveillance Initiative working Group. Am J Infect Control. 1998;26(3):277-88.

144. Nichiata LY, Takahashi RF, Fracolli LA, Gryschek AL. Relato de uma experiência de ensino de enfermagem em saúde coletiva: a informática no ensino de vigilância epidemiológica. Rev Esc Enferm USP. 2003;37(3):36-43.

145. Freixas N, Salles M, Garcia L. Cambios en el control de la infección nosocomial: nuevos retos y competencias de la enfermera de control de infección. Enferm Infecc Microbiol Clin. 2009;27(5):285-9.

146. Padoveze MC. De Florence Nightingale até os dias de hoje: o papel da enfermagem na prevenção das infecções relacionadas à Assistência à Saúde. Prática Hospitalar (Impresso). 2012; 14: 66-68.

147. Carraro TE. Os postulados de Nightingale e Semmelweis: poder/vital e prevenção/contágio como estratégias para a evitabilidade das infecções. Rev Lat Am Enfermagem. 2004;12(4):650-7.

148. Parahoo k. Nursing Research: principles, process and issues. $2^{\text {nd }}$ ed. New York: Palgrave Macmillan; 2006. $481 \mathrm{p}$.

149. Gill CJ, Gill GC. Nightingale in Scutari: her legacy reexamined. Clin Infect Dis. 2005;40(12):1799-805. 
150. World Health Organization (WHO). Active ageing: a policy framework. [Internet].2002 apr. 1-59. [citado 2012 nov. 25] Disponível em: http://whqlibdoc.who.int/hq/2002/who_nmh_nph_02.8.pdf.

151. Temporini E, Kara-José N. A perda da visão - estratégias de prevenção. Arq Bras Oftalmol. 2002;67(4):597-601.

152. Costa MF, Ciosak SI. Atenção integral na saúde do idoso no Programa Saúde da Família: visão dos profissionais de saúde. Rev Esc Enferm USP. 2010;44(2):437-44.

153. Horta AL, Ferreira DC, Zhao LM. Envelhecimento, estratégias de enfrentamento do idoso e repercussões na família. Rev Bras Enferm. 2010;63(4):523-8.

154. Marback R, Temporini E, Kara Junior N. Emotional factors prior to cataract surgery. Clinics. 2007;62(4):433-8.

155. Kara-Junior N, Temporini ER, Kara-Jose N. Cataract surgery: expectations of patients assisted during a community project in Sao Paulo, state of Sao Paulo, Brazil. Rev Hosp Clin Fac Med Sao Paulo. 2001;56(6):163-8.

156. Rodrigues SL, Watanabe HA, Derntl AM. A saúde de idosos que cuidam de idosos. Rev Esc Enferm USP. 2006;40(4):493500 .

157. Lamoureux EL, Fenwick E, Pesudovs K, Tan D. The impact of cataract surgery on quality of life. Curr Opin Ophthalmol. 2011;22(1):19-27.

158. Ribeiro JEC, Freitas MM, Araújo GS, Rocha THR. Associação entre aspectos depressivos e déficit visual causado por catarata em pacientes idosos. Arq Bras Oftalmol. 2004;67(5):795-9. 
159. Eydelman MB, Tarver ME, Calogero D, Buchen SY, Alexander KY. The Food and Drug Administration's Proactive toxic anterior segment syndrome Program. Ophthalmology. 2012;119(7):1297-302.

160. Doshi RR, Arevalo JF, Flynn HW, Jr., Cunningham ET, Jr. Evaluating exaggerated, prolonged, or delayed postoperative intraocular inflammation. Am J Ophthalmol. 2010;150(3):295304 e1.

161. Mamalis N, Edelhauser HF, Dawson DG, Chew J, LeBoyer RM, Werner L. Toxic anterior segment syndrome. J Cataract Refract Surg. 2006;32(2):324-33.

162. Conner RL. Toxic anterior segment syndrome; US Food and Drug Administration product and device clearance. AORN J. 2006;84(5):841-7.

163. Johnston J. Toxic anterior segment syndrome - more than sterility meets the eye. AORN J. 2006;84(6):967-84. 
APÊNDICE A - Impresso para anotação médica da consulta pósoperatória

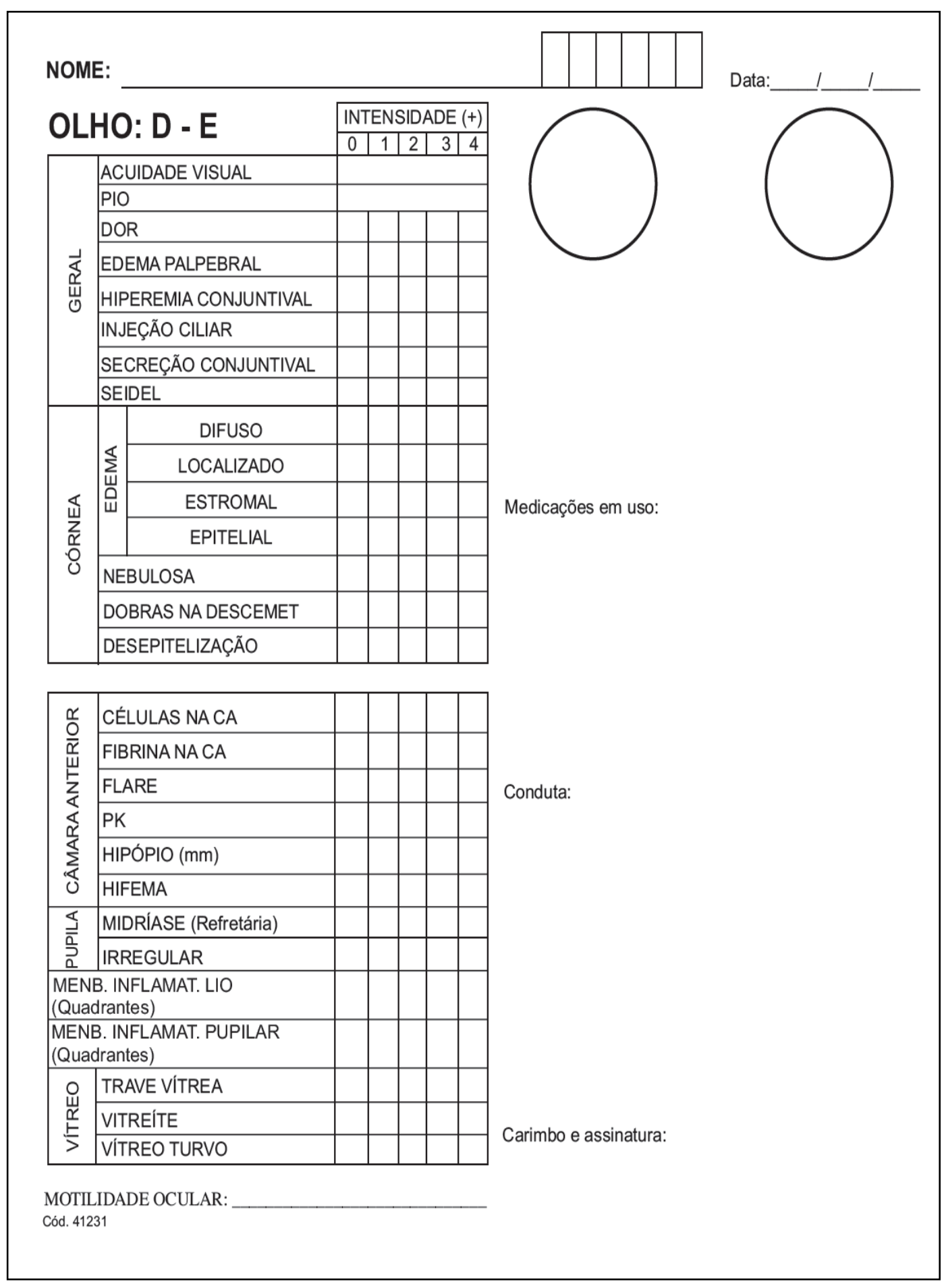


APÊNDICE B - Tabela de conversão da acuidade visual em percentual de acuidade visual central

\begin{tabular}{|c|c|}
\hline Equivalente de Snellen & $\begin{array}{c}\text { Percentual de eficiência } \\
\text { da visão central }\end{array}$ \\
\hline $20 / 20$ & 100 \\
\hline $20 / 25$ & 95 \\
\hline $20 / 30$ & 91 \\
\hline $20 / 40$ & 85 \\
\hline $20 / 50$ & 75 \\
\hline $20 / 60$ & 67 \\
\hline $20 / 70$ & 63 \\
\hline $20 / 80$ & 60 \\
\hline $20 / 100$ & 50 \\
\hline $20 / 200$ & 20 \\
\hline $20 / 400$ & 10 \\
\hline CD & 0 \\
\hline MM & 0 \\
\hline PL & 0 \\
\hline NPL & 0 \\
\hline
\end{tabular}

Adaptado de: Holladay JT. Visual acuity measurements. J Cataract Refract Surg 2004; 30: 287-90. 
APÊNDICE C - Formulário de vigilância epidemiológica para TASS e endoftalmite após cirurgias de catarata

\section{FORMULÁRIO DE VIGILANCIA EPIDEMIOLOGICA PARA "TASS E ENDOFTALMITE"}

NOME: PRONTUÁRIO:

CIRURGIA PRIMÁRIA:

DATA DA CIRURGIA: $\mathrm{N}^{\circ}$ DE RETORNOS:

APRESENTAÇÃO CLÍNICA

\begin{tabular}{|l|l} 
& DOR \\
EDEMA DE CÓRNEA & HIPEREMIA CONJUNTIVAL
\end{tabular}

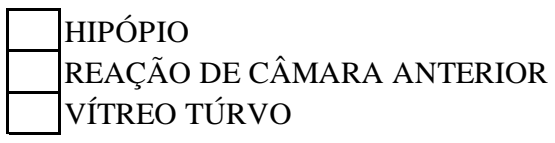

REINTERVENÇÕES APÓS A CIRURGIA DE CATARTA

LAVAGEM DE CÂMARA ANTERIOR

VITRECTOMIA ANTERIOR

VITRECTOMIA POSTERIOR

INJEÇÃO DE ANTIBIÓTICO INTRA-VÍTREO OUTRA:

CULTURA DE HUMOR VÍTREO

CULTURA DE HUMOR AQUOSO

RESULTADO POSITIVO DE UMA DAS AMOSTRAS

RESULTADO NEGATIVO DE UMA DAS AMOSTRAS
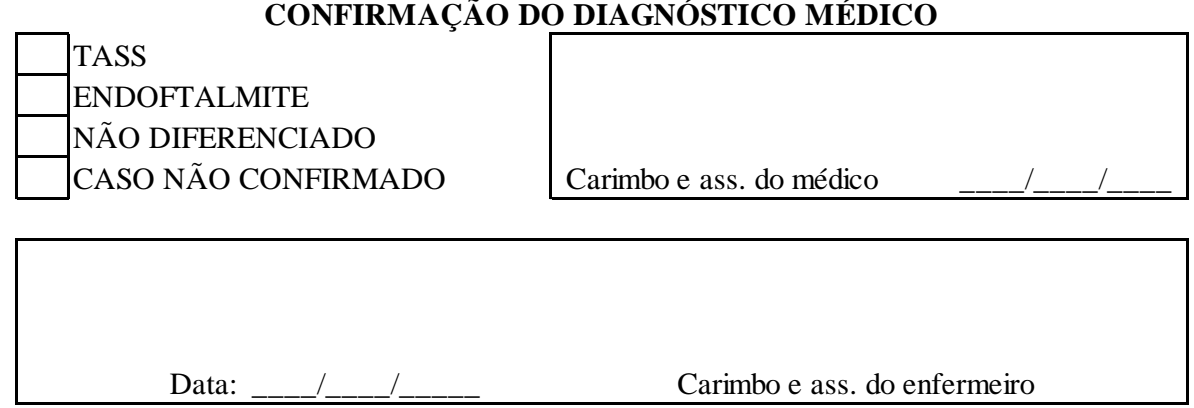

Instruções:

$1=$ Macar apenas em caso de resposta positiva

$2=$ A confirmação do diagnóstico pelo médico só deverá ser feita após três meses da data da suspeita do EA. 
APÊNDICE D - Exemplo de um formulário criado no programa Epiinfo para vigilância de eventos adversos após cirurgia de catarata

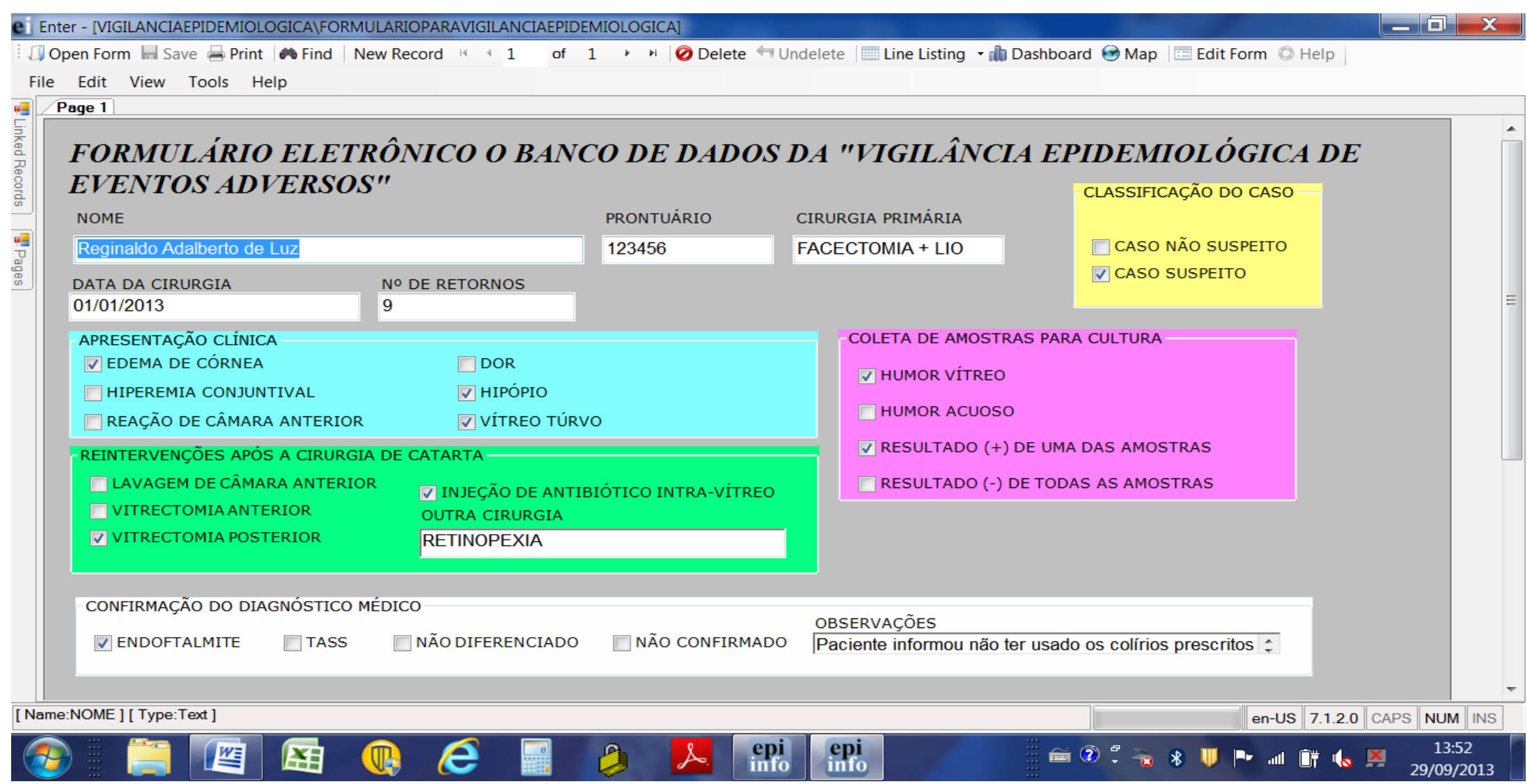




\section{ANEXO 1 - Autorização da instituição co-participante}

São Paulo, 01 de fevereiro de 2013

À Diretoria do Centro de Oftalmologia Tadeu Cvintal

Ref.: Autorização para Pesquisa

Solicito a autorização desta instituição para a realização da pesquisa intitulada "Endoftalmite após cirurgia para extração da catarata: tratamento e evolução clínica"

Informo que se trata de um estudo retrospectivo com o propósito de avaliar dados de prontuários da instituição. Não será realizada nenhuma intervenção em seres humanos, aplicação de testes, questionários ou entrevistas. Assim, fica dispensada a apresentação do Termo de Consentimento Livre e Esclarecido.

Outrossim, informo que será preservada a confidencialidade dos sujeitos em todo e qualquer meio de divulgação da produção científica decorrente do presente estudo.

Atenciosamente,

Pesquisador/responsável:

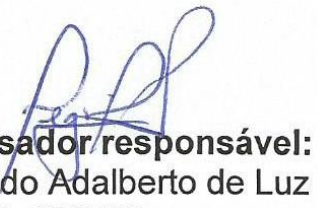

COREN: 168505

Autorizado por :

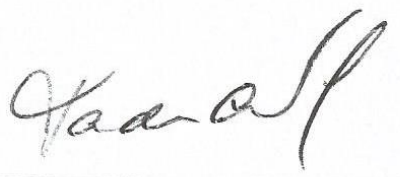

Diretor Clínico do Centro de Oftalmologia Tadeu Cvintal

Dr. Tadeu Cvintal

0R. THOEU CVINTAL

GRII10801 
ANEXO 2 - Parecer consubstanciado do CEP

\section{ESCOLA DE ENFERMAGEM DA UNIVERSIDADE DE SÃO PAULO - EEUSP}

\section{PARECER CONSUBSTANCIADO DO CEP}

\section{DADOS DO PROJETO DE PESQUISA}

Título da Pesquisa: Eventos adversos após cirurgia para extração da catarata: incidência e caracterização.

Pesquisador: Reginaldo Adalberto de Luz

Área Temática:

Versão: 1

CAAE: 12529513.0 .0000 .5392

Instituição Proponente: Escola de Enfermagem da Universidade de São Paulo - EEUSP

Patrocinador Principal: Financiamento Próprio

\section{DADOS DO PARECER}

Número do Parecer: 222.560

Data da Relatoria: 18/03/2013

Apresentação do Projeto:

Cirurgias para extração da catarata têm sido cada vez mais realizadas no Brasil e eventos adversos no pósoperatório podem comprometer significativamente a visão do paciente. Dentre as complicações mais importantes estão a Endoftalmite e a Síndrome Tóxica do Segmento Anterior. O pesquisador se propõe a realizar um estudo de coorte prospectivo para analisar esses eventos adversos e identificar fatores de riscos associados.A pesquisa será realizada no Centro de Oftalmologia Tadeu Cvintal (COTC) que realiza as cirurgias em um centro cirúrgico no Hospital Silvio Romero (hospital-dia). O atendimento pré e pósoperatório ocorre exclusivamente nas dependências do COTC. A fonte de dados será o prontuário do paciente que permanece no CTOC (o prontuário vai ao hospita-dia no dia da cirurgia e retorna ao CTOC).Os dados serão coletados no $7^{\circ}$ e $30^{\circ}$ dia após a cirurgia. A amostra será composta por pacientes submetidos à cirurgia para extração da catarata em um período suficiente para a coleta de no mínimo 1.000 pacientes. 0 pesquisador apresenta no projeto o instrumento de coleta de dados contendo variáveis biosociodemográficas, do procedimento cirúrgico, evolução pós-oepratória e uma lista de itens com possíveis fatores de risco relacionados aos eventos adversos em estudo.

Objetivo da Pesquisa:

Objetivo Geral

- Caracterizar os eventos adversos selecionados (Endoftalmite e TASS) após cirurgias de catarata.

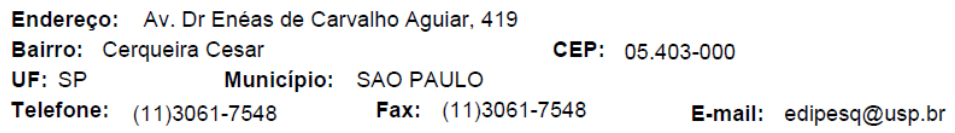


ANEXO 3 - Gráfico do IBGE demonstrando a tendência do envelhecimento da população brasileira

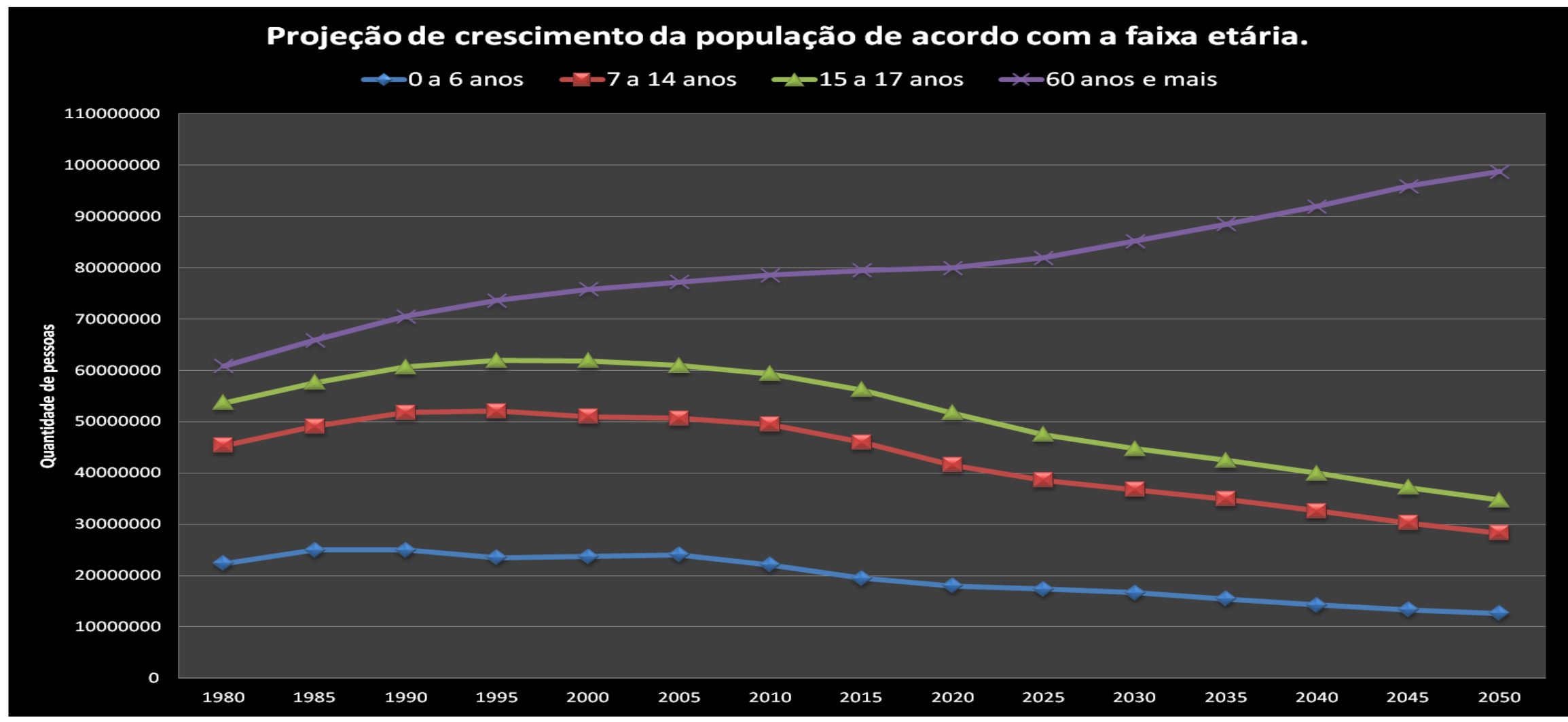

Fonte: IBGE, Projeção da População do Brasil por Sexo e Idade para o Período 1980-2050 - Revisão 2008

Disponível em: http://seriesestatisticas.ibge.gov.br/series.aspx?vcodigo=POP305\&sv=35\&t=revisao-2008-projecao-da-populacao-grupos-especiais-deidade 